CARLOS GUILHERME LINKEVICIUS GURY

\title{
COMPENSAÇÃO DE ATRITO EM VÁLVULAS DE CONTROLE
}

\author{
Dissertação apresentada à Escola \\ Politécnica da Universidade de São \\ Paulo para obtenção do título de \\ Mestre em Engenharia
}

SÃO PAULO

2008 
CARLOS GUILHERME LINKEVICIUS GURY

\section{COMPENSAÇÃO DE ATRITO EM VÁLVULAS DE CONTROLE}

Dissertação apresentada à Escola

Politécnica da Universidade de

São Paulo para obtenção do título de Mestre em Engenharia

Área de Concentração:

Engenharia de Sistemas

Orientador:

Prof. Dr. Claudio Garcia

SÃO PAULO 
FICHA CATALOGRÁFICA

Gury, Carlos Guilherme Linkevicius

Compensação de atrito em válvulas de controle / C.G.L. Gury. -- São Paulo, 2008.

$105 \mathrm{p}$.

Dissertação (Mestrado) - Escola Politécnica da Universidade de São Paulo. Departamento de Engenharia de Telecomunicações e Controle.

1. Atrito 2. Válvulas de controle pneumático 3. Sistemas de controle 4. Controle de Processos (variabilidade) I. Universidade de São Paulo. Escola Politécnica. Departamento de Engenharia de Telecomunicações e Controle II. t. 


\section{AGRADECIMENTOS}

Ao Professor, amigo e orientador Claudio Garcia, que sempre esteve ao meu lado para apoiar a elaboração deste trabalho.

Aos professores da banca examinadora, cujas contribuições foram de muita valia para este trabalho.

Aos meus pais e minha irmã, que assim como o resto de minha família, estiveram sempre presentes, me apoiando durante toda minha vida.

À minha noiva Gabriela, que me acompanha desde o final do meu curso de graduação na Universidade e que passou por muitos momentos importantes deste trabalho comigo.

Aos meus colegas de pesquisa e aos amigos presentes no meu cotidiano nestes três últimos anos, que tanto contribuíram para esta pesquisa.

Às empresas em que trabalhei durante o decorrer do meu Mestrado, que me possibilitaram cursar as disciplinas e me ausentar da empresa em momentos cruciais.

E a todos os amigos que fiz no decorrer de minha vida. Saibam que vocês foram, são e serão sempre importantes nas conquistas mais importantes da minha vida. 


\section{RESUMO}

O atrito é uma não-linearidade que geralmente produz o mau desempenho de um sistema mecânico com partes móveis. Neste trabalho, o elemento mecânico estudado é a válvula de controle de processos, que é o elemento final de controle mais empregado nas indústrias de processo. A presença de atrito na válvula eleva a variabilidade da malha de controle, gerando impacto em toda a cadeia produtiva da planta, devido, principalmente, ao aumento do consumo de energia e à rejeição de produto final fora de especificação. Desta forma, os estudos visando a redução de variabilidade passaram a ter uma importância econômica muito grande, pois causam impacto direto na lucratividade do negócio. Muitos estudos foram realizados visando diagnosticar, medir e compensar o atrito. Neste trabalho, se implementam técnicas propostas na literatura para compensação de atrito em válvulas de controle. Para avaliar seu desempenho, são apresentadas as conclusões obtidas nos experimentos e são propostas possíveis implementações futuras, seguindo esta linha de pesquisa. 


\begin{abstract}
Friction is a nonlinearity that generally produces bad performance of a mechanical system with moving parts. In this work, the studied mechanical element is the process control valve, which is the most used final control element in process industries. The presence of friction in control valves increases control loop variability, generating impact in all plant productive chain, due to the increase of energy consumption and rejection of end product that is out of specification. In such a way, we can see that the studies aiming variability reduction had started to have a great economic importance, due to its direct impact in business profitability. Many studies have been done aiming friction diagnosis, measurement and compensation. In this work, techniques that have been proposed on the literature for friction compensation in control valves are implemented. The conclusions obtained in the experiments are presented to evaluate the performance of the compensators and possible future implementations are proposed, following this research line.
\end{abstract}




\section{LISTA DE FIGURAS}

Figura 1: Representação gráfica das não-linearidades ....................................................................9

Figura 2: Representação gráfica de não-linearidades, incluindo agora o slip-jump.............................. 11

Figura 3: Modelo da malha de vazão, sem a presença de compensador ............................................. 16

Figura 4: Diagrama do ambiente Hardware in the Loop....................................................................... 18

Figura 5: Foto do Hardware in the Loop utilizado nos ensaios............................................................. 18

Figura 6: Representação da estratégia de controle através do uso do IOL .........................................20

Figura 7: Diagrama de blocos do compensador Knocker ....................................................................2 24

Figura 8: Sinal típico de saída do Knocker ....................................................................................25

Figura 9: Esquema integrado de detecção, estimação e compensação de atrito estático, conforme

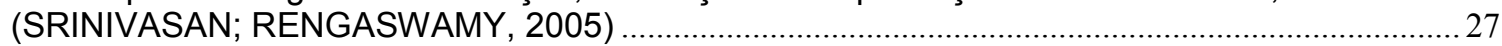

Figura 10: Diagrama de blocos do compensador 2move ....................................................................28

Figura 11: Malha Fechada de Vazão, incluindo os compensadores de atrito......................................33

Figura 12: Resposta ao degrau, sem compensadores, ambiente $100 \%$ simulado ............................... 37

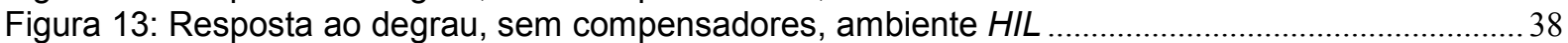

Figura 14: Compensador IOL x sem compensador, atrito low, 100\% simulado, degrau.......................40

Figura 15: Compensador IOL x sem compensador, atrito low, HIL, degrau ......................................... 41

Figura 16: Compensador IOL x sem compensador, atrito high, 100\% simulado, degrau .................... 42

Figura 17: Compensador IOL x sem compensador, atrito high, HIL, degrau ..................................... 43

Figura 18: Compensador Knocker $\mathrm{x}$ sem compensador, atrito low, $100 \%$ simulado, degrau ...............45

Figura 19: Compensador Knocker x sem compensador, atrito low, HIL, degrau ...................................46

Figura 20: Compensador Knocker x sem compensador, atrito high, 100\% simulado, degrau .............. 47

Figura 21: Compensador Knocker x sem compensador, atrito high, HIL, degrau ...............................48

Figura 22: Compensador 2 move $\mathrm{x}$ sem compensador, atrito low, 100\% simulado, degrau .....................50

Figura 23: Compensador 2move x sem compensador, atrito low, $\mathrm{HIL}$, degrau ......................................5 51

Figura 24: Compensador 2move x sem compensador, atrito high, 100\% simulado, degrau................52

Figura 25: Compensador 2move x sem compensador, atrito high, HIL, degrau .................................53

Figura 26: Gráfico de ISE, ensaio em degrau, atrito low, ambiente $100 \%$ simulado .................................55

Figura 27: Gráfico de ISE, ensaio em degrau, atrito low, ambiente HIL ..............................................55

Figura 28: Gráfico de ISE, ensaio em degrau, atrito high, ambiente $100 \%$ simulado...........................56

Figura 29: Gráfico de ISE, ensaio em degrau, atrito high, ambiente HIL.............................................56

Figura 30: Resposta à perturbação, sem compensadores, ambiente 100\% simulado...........................59

Figura 31: Resposta à perturbação, sem compensadores, ambiente HIL .............................................60

Figura 32: Compensador IOL x sem compensador, atrito low, 100\% simulado, perturbação................ 61

Figura 33: Compensador IOL x sem compensador, atrito low, HIL, perturbação.....................................62

Figura 34: Compensador IOL x sem compensador, atrito high, 100\% simulado, perturbação ..............63

Figura 35: Compensador IOL x sem compensador, atrito high, HIL, perturbação ...................................63

Figura 36: Compensador Knocker x sem compensador, atrito low, 100\% simulado, perturbação........ 64

Figura 37: Compensador Knocker x sem compensador, atrito low, HIL, perturbação ........................... 65

Figura 38: Compensador Knocker x sem compensador, atrito high, 100\% simulado, perturbação ......66 66

Figura 39: Compensador Knocker x sem compensador, atrito high, HIL, perturbação .......................... 67

Figura 40: Compensador 2move x sem compensador, atrito low, 100\% simulado, perturbação .......... 68

Figura 41: Compensador 2move x sem compensador, atrito low, HIL, perturbação .............................. 69

Figura 42: Compensador 2move x sem compensador, atrito high, 100\% simulado, perturbação......... 70

Figura 43: Compensador 2move x sem compensador, atrito high, HIL, perturbação............................. 71

Figura 44: Gráfico de ISE, ensaio de perturbação, atrito low, ambiente 100\% simulado ......................73

Figura 45: Gráfico de ISE, ensaio de perturbação, atrito low, ambiente HIL .................................... 73

Figura 46: Gráfico de ISE, ensaio de perturbação, atrito high, ambiente 100\% simulado .....................74

Figura 47: Gráfico de ISE, ensaio de perturbação, atrito high, ambiente HIL ........................................ 74

Figura 48: Resposta à má-sintonia, sem compensadores, ambiente $100 \%$ simulado ...........................76

Figura 49: Resposta à má-sintonia, sem compensadores, ambiente HIL .............................................77

Figura 50: Compensador IOL x sem compensador, atrito low, 100\% simulado, má-sintonia ................79

Figura 51: Compensador IOL x sem compensador, atrito low, HIL, má-sintonia ....................................8 80

Figura 52: Compensador IOL x sem compensador, atrito high, 100\% simulado, má-sintonia...............81

Figura 53: Compensador IOL x sem compensador, atrito high, HIL, má-sintonia................................. 81

Figura 54: Compensador Knocker x sem compensador, atrito low, 100\% simulado, má-sintonia ........ 82 
Figura 55: Compensador Knocker $x$ sem compensador, atrito low, HIL, má-sintonia ............................. 83

Figura 56: Compensador Knocker $x$ sem compensador, atrito high, 100\% simulado, má-sintonia....... 84

Figura 57: Compensador Knocker $x$ sem compensador, atrito high, HIL, má-sintonia............................ 85

Figura 58: Compensador 2 move $\mathrm{x}$ sem compensador, atrito low, 100\% simulado, má-sintonia............ 86

Figura 59: Compensador 2 move $x$ sem compensador, atrito low, HIL, má-sintonia ................................ 87

Figura 60: Compensador 2 move x sem compensador, atrito high, $100 \%$ simulado, má-sintonia .......... 88

Figura 61: Compensador 2move x sem compensador, atrito high, HIL, má-sintonia ............................. 89

Figura 62: Gráfico de ISE, ensaio de má-sintonia, atrito low, ambiente 100\% simulado .......................91

Figura 63: Gráfico de ISE, ensaio de má-sintonia, atrito low, ambiente HIL ........................................91

Figura 64: Gráfico de ISE, ensaio de má-sintonia, atrito high, ambiente 100\% simulado.......................92

Figura 65: Gráfico de ISE, ensaio de má-sintonia, atrito high, ambiente HIL .......................................92

Figura 66: Sem compensador, 100\% simulado, posição da haste da válvula ........................................94

Figura 67: Compensador IOL, 100\% simulado, posição da haste da válvula ............................................95

Figura 68: Compensador Knocker, 100\% simulado, posição da haste da válvula...................................95

Figura 69: Compensador 2move, 100\% simulado, posição da haste da válvula .....................................96

Figura 70: Sem compensador, HIL, posição da haste da válvula ............................................................97

Figura 71: Compensador IOL, HIL, posição da haste da válvula ............................................................... 98

Figura 72: Compensador Knocker, HIL, posição da haste da válvula ........................................................99

Figura 73: Compensador 2move, HIL, posição da haste da válvula ......................................................... 100 


\section{LISTA DE TABELAS}

Tabela 1: Parâmetros dos dois níveis de atrito na válvula ................................................................... 32

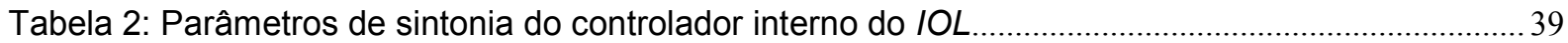

Tabela 3: Parâmetros de sintonia do compensador Knocker ...............................................................4 44

Tabela 4: Instante dos movimentos do controlador 2move ................................................................. 49

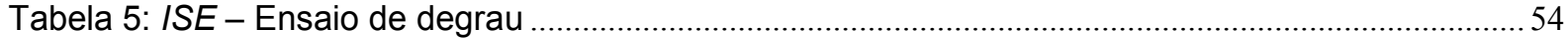

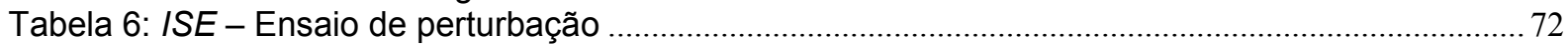

Tabela 7: Sintonia do Controlador PI da malha para ensaios do item 4.3......................................... 76

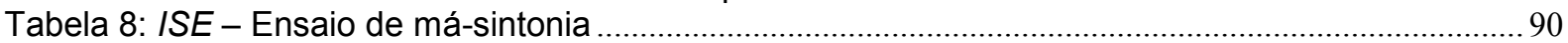

Tabela 9: Características dos compensadores - atrito high, ambiente HIL ................................... 101 


\section{LISTA DE ABREVIATURAS E SIGLAS}

IOL

HIL

V/P

$I M C$

PLC

DCS

ISE

$\mathrm{PI}$
Input-output linearization

Hardware in the loop

Conversor tensão-pressão

Internal model control

Programmable logic controller

Distributed control system ou digital control system

Integrated square error

Controlador proporcional-integral 


\section{LISTA DE SÍMBOLOS}

$\Delta P$

$F_{C}$

$F_{S}$

$F_{V}$

$V_{s}$

$D V$

$u_{c}$

$y$

$u_{k}$

G

Amplitude do pulso do compensador Knocker

Período do pulso do compensador Knocker

Intervalo entre os pulsos do compensador Knocker

Nível de atrito estimado

Massa das partes móveis da válvula

Posição da haste da válvula

Velocidade da haste da válvula

Força aplicada pelo atuador da válvula

Força da mola

Força de atrito

Força relacionada à perda de carga do fluido

Força adicional necessária para acomodar o obturador na sede da válvula

Área do diafragma do atuador pneumático

Pressão de ar

Constante elástica da mola

Área desbalanceada do obturador

Perda de carga

Coeficiente de atrito de Coulomb

Coeficiente de atrito estático

Coeficiente de atrito viscoso

Velocidade de Stribeck

Intervalo de velocidade nula no modelo de Karnopp

Saída do controlador PI da malha de vazão

Saída da planta de vazão

Saída dos compensadores externos

Filtro da ação de controle do compensador $I O L$

Inclinação da função tanh utilizada no compensador $I O L$

Sinal de saída do controlador interno $G$ para o bloco $I O L$

Sinal de referência

Sinal de erro (= referência - valor real)

Ganho do controlador $G$

Ganho do controlador $G$

Ganho do controlador PI da malha de vazão

Tempo integral do controlador PI

Período de amostragem do sistema

Instante de início do pulso anterior do compensador Knocker

Faixa de escolha do período de amostragem do Knocker

Valor em estado estacionário da saída do controlador

Valor em estado estacionário da posição da haste da válvula

Valor em estado estacionário da saída do processo

Amplitude da oscilação causada pelo atrito estático

Freqüência da oscilação causada pelo atrito estático

Número inteiro que multiplica o primeiro movimento do compensador 2 move 


\section{SUMÁRIO}

CAPÍTULO 1. INTRODUÇÃO .....................................................................................1

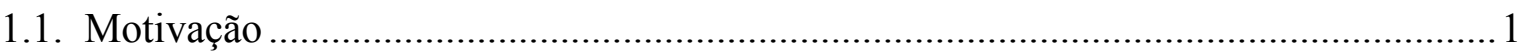

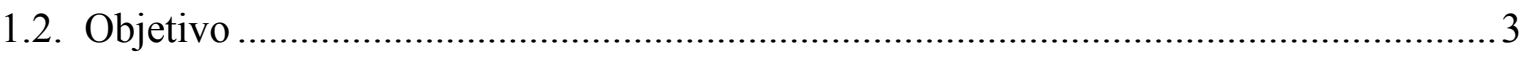

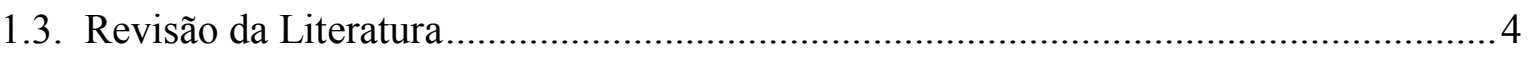

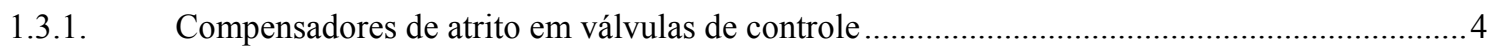

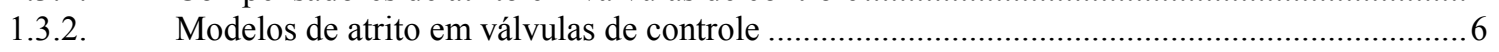

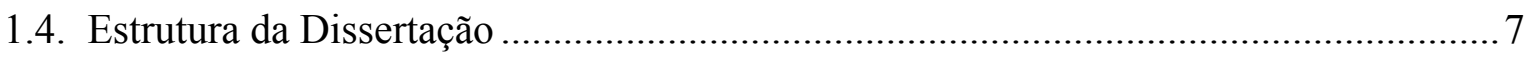

CAPÍTULO 2. DESCRIÇÃO DO PROBLEMA ...................................................................8

2.1. Descrição das não-linearidades na válvula de controle ............................................... 8

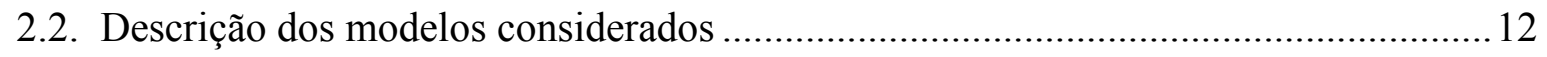

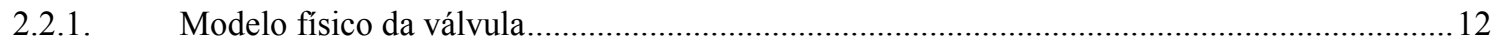

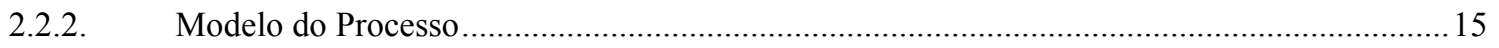

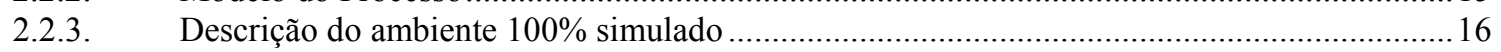

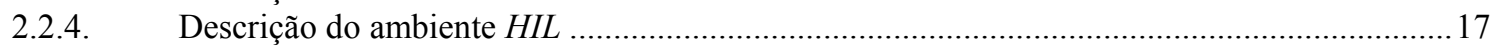

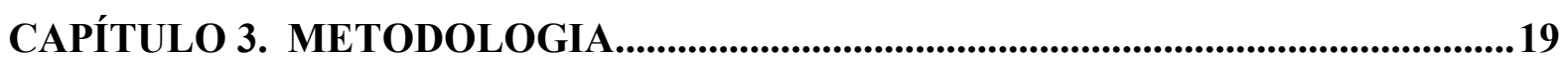

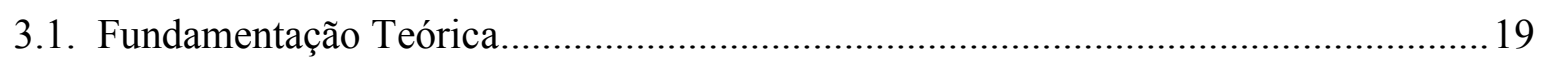

3.1.1. Modelo de compensador 1: IOL $\quad$...................................................................................... 19

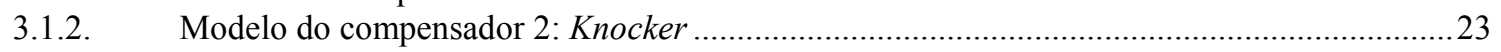

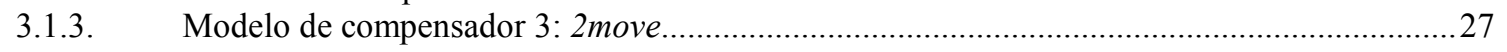

3.2. Procedimentos de avaliação dos compensadores ....................................................... 31

3.2.1. Degrau no sinal de Referência do controlador PI da planta de vazão ..........................................31

3.2.2. Comportamento dos compensadores na presença de perturbações ............................................... 31

3.2.3. Comportamento dos compensadores quando o controlador PI da malha de vazão

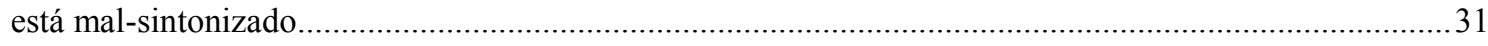

3.2.4. Parâmetros do modelo da válvula com atrito .......................................................................... 31

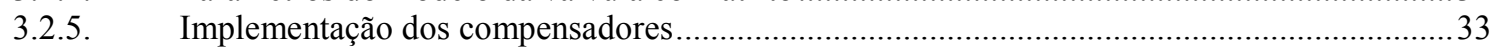

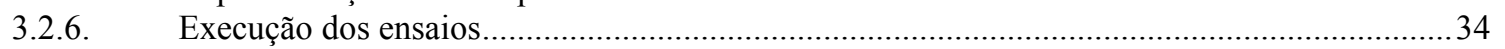

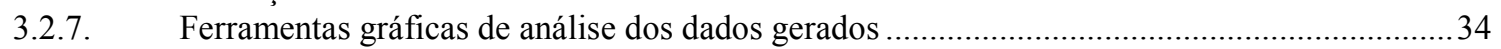

3.2.8. Ferramentas matemáticas de análise de desempenho .....................................................................

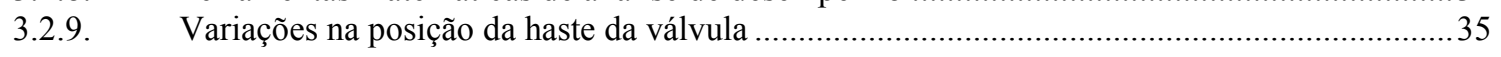

CAPÍTULO 4. RESULTADOS DOS ENSAIOS ............................................................36

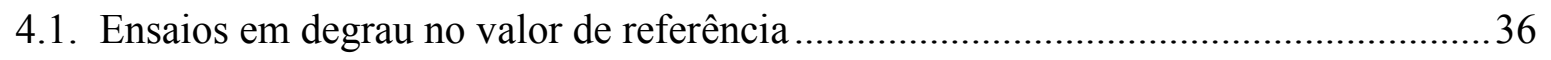

4.1.1. Ensaios em degrau sem o uso dos compensadores de atrito ............................................36

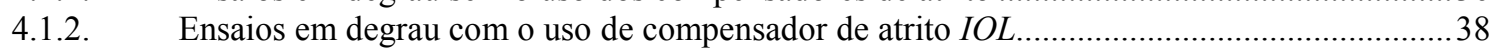

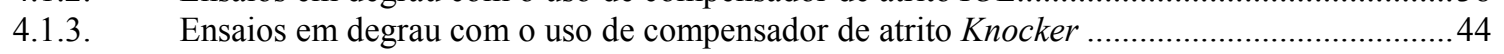

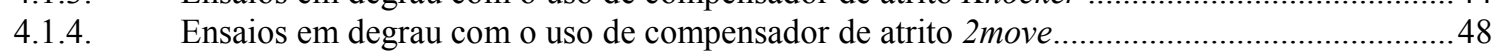

4.1.5. Análise comparativa do ISE entre os compensadores para o ensaio de degrau .....................54 


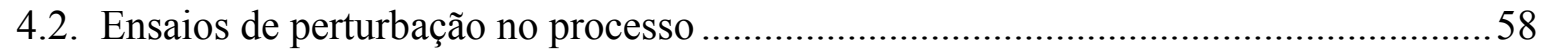

4.2.1. Ensaios de perturbação sem o uso dos compensadores de atrito ...............................................58

4.2.2. Resposta à perturbação com o uso de compensador de atrito $I O L$............................................60

4.2.3. Resposta à perturbação com o uso de compensador de atrito Knocker ......................................64

4.2.4. Resposta à perturbação com o uso de compensador de atrito 2move ………………………......67

4.2.5. Análise comparativa do ISE entre os compensadores para o ensaio de perturbação .................71

4.3. Ensaios de má-sintonia no controlador PI da malha de vazão ..................................75

4.3.1. Ensaios de má-sintonia do controlador sem o uso dos compensadores de atrito ...................75

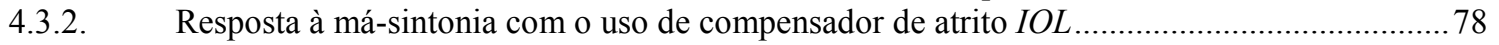

4.3.3. Resposta à má-sintonia com o uso de compensador de atrito Knocker..................................82

4.3.4. Resposta à má-sintonia com o uso de compensador de atrito 2 move .....................................85

4.3.5. Análise comparativa do ISE entre os compensadores para o ensaio de má-sintonia ...............89

4.4. Breve análise das oscilações geradas na haste da válvula com o uso dos compensadores

CAPÍTULO 5. CONCLUSÕES E SUGESTÕES PARA TRABALHOS FUTUROS..101

5.1. Conclusões. 101

5.2. Sugestões para trabalhos futuros 103

REFERÊNCIAS 


\section{CAPÍTULO 1. INTRODUÇÃO}

\subsection{Motivação}

As válvulas de controle são atualmente o elemento final da malha de controle mais empregado nas indústrias de processo. Uma planta típica, dependendo do seu porte, pode conter até mesmo milhares de válvulas de controle. O fato da válvula de controle ser um equipamento mecânico e, conseqüentemente, possuir partes móveis, proporciona o aparecimento de componentes não lineares de atrito. De acordo com os trabalhos de (HÄGGLUND, 2002; SRINIVASAN et al., 2005), 90\% das válvulas da indústria de processo possuem atuadores pneumáticos. Portanto, este tipo de equipamento é o objeto de estudo deste trabalho.

Segundo (SRINIVASAN; RENGASWAMY, 2005), de 20 a 30\% das malhas oscilam devido à presença de atrito ou histerese nas válvulas de controle. Levandose em conta o mesmo trabalho, estudos realizados na última década apontam que apenas um terço dos controladores industriais apresenta desempenho considerado aceitável. Estes números são bastante próximos dos números apresentados por (HÄGGLUND, 2002), que em seu trabalho informou que por volta de $30 \%$ das malhas de controle auditadas em uma indústria de papel canadense apresentaram problemas de variabilidade relacionados a não-linearidades nas válvulas de controle.

Ainda no campo de problemas em válvulas, de acordo com (KAYIHAN; DOYLE III, 2000), mais de $80 \%$ das válvulas auditadas pela empresa EnTech Control Engineering não passaram pelos padrões de desempenho dinâmico. Novamente, grande parte dos casos estava relacionada à presença de não-linearidades na válvula, como o atrito por exemplo. Entretanto, outro fator que também foi detectado nestas auditorias é que, muitas vezes, as válvulas de controle estavam maldimensionadas, o que também produz impacto direto em seu desempenho e, conseqüentemente, no desempenho da malha de controle.

Os estudos mencionados anteriormente apresentam números significativos, que revelam o potencial de melhora possível no campo de compensação de atrito. 
Apesar de não ser o foco deste trabalho, a detecção do atrito na malha de controle é muito importante para o processo de compensação. Existem algumas técnicas de detecção já estudadas, sendo estas técnicas divididas basicamente em técnicas intrusivas, ou seja, técnicas que possuam interação on-line com o processo, e técnicas não-intrusivas, ou seja, técnicas que se baseiam, por exemplo, nos dados históricos do processo para avaliar a válvula, sem a necessidade de interação online com o processo. Neste trabalho, adotou-se a seguinte premissa: a válvula de controle possui atrito, ou seja, o atrito já foi detectado. Alguém poderia alegar que uma possível solução seria simplesmente retirar a válvula do processo, realizar sua manutenção e retorná-la ao processo. De fato, quando possível, esta é uma solução bastante razoável. Entretanto, nem todos os processos industriais permitem uma parada não-programada para manutenção, devido à sua criticidade.

Segundo (SRINIVASAN; RENGASWAMY, 2005), as paradas programadas de uma planta acontecem tipicamente no período entre seis meses e três anos de operação, sendo que neste período em que uma válvula com problema tem que permanecer operando de maneira sub-ótima, o consumo de energia e a qualidade do produto final são afetados diretamente. No mesmo trabalho, os autores informam que o custo médio de manutenção de uma válvula gira entre US\$400,00 a US\$ $2.000,00$. Mesmo não sendo o foco deste trabalho, aqui fica claro a importância da detecção de quais válvulas possuem problemas: durante a parada programada, apenas as válvulas realmente críticas e problemáticas sofreriam manutenção, reduzindo drasticamente os custos com manutenção desnecessária de válvulas que não apresentam problema.

Ainda pensando no ponto de vista econômico, em (CHOUDHURY; THORNHILL; SHAH, 2005), os autores apontam que até mesmo uma melhora de $1 \%$ na eficiência do consumo de energia ou na manutenção dos controladores pode representar milhões de dólares de economia para a indústria de processos como um todo. Cada vez mais o impacto econômico passa a ter destaque nesta linha de pesquisa, pois a redução de variabilidade deixa de ser apenas uma questão de melhoria operacional e passa a ter grande efeito no aumento da lucratividade das empresas. 


\subsection{Objetivo}

Neste trabalho, três técnicas de compensação de atrito propostas na literatura são avaliadas. A primeira técnica, proposta por (KAYIHAN; DOYLE III, 2000), é baseada em linearização entrada/saída e usada em controle não-linear, sendo chamada de $I O L$ neste trabalho. A segunda técnica foi proposta inicialmente por (HÄGGLUND, 2002) e depois melhor interpretada e aprimorada por (SRINIVASAN; RENGASWAMY, 2005), sendo chamada de Knocker. Por fim, a terceira foi proposta por (SRINIVASAN; RENGASWAMY, 2007) e é chamada de 2 move.

Uma vez implementados os compensadores, seus desempenhos são avaliados em diversos ensaios. Os ensaios são divididos em dois grupos: ensaios $100 \%$ simulados e ensaios no ambiente HIL (Hardware in the Loop). No ambiente $100 \%$ simulado, todo o teste é baseado em modelos, inclusive a válvula de controle, enquanto que no HIL, a válvula de controle é real e, através de interfaces de saída/aquisição de dados, o ambiente simulado interage com a válvula de controle real.

O desenvolvimento dos compensadores e sua implementação é ambientada no software Matlab/Simulink $\circledast$, da Mathworks. 


\subsection{Revisão da Literatura}

\subsubsection{Compensadores de atrito em válvulas de controle}

O estudo da compensação de atrito em sistemas mecânicos é relativamente recente. Os primeiros trabalhos nesta área de pesquisa ocorreram em meados dos anos 90. Os trabalhos de (DE CARLI; CONG, 1995), (FEEMSTER et al., 1999) e (CANUDAS; LISCHINSKY, 1997) já propunham o estudo de técnicas de compensação de atrito em sistemas mecânicos. Entretanto, em todos os trabalhos mencionados anteriormente, o sistema mecânico em questão era um servomecanismo DC e não válvulas de controle pneumáticas.

Está claro que o intuito deste trabalho é a compensação de atrito em válvulas de controle pneumáticas, conforme descrito anteriormente. Apesar das características de atrito e de outras não linearidades, como histerese e backlash, serem as mesmas nos servomecanismos e nas válvulas de controle pneumáticas, as técnicas de compensação projetadas inicialmente para servomecanismos não se mostraram eficientes para a compensação do atrito em válvulas de controle. Isto acontece porque a dinâmica da válvula de controle é bem diferente da dinâmica do servomecanismo, fazendo com que as técnicas válidas para estes últimos não fossem eficientes na compensação de atrito em válvulas de controle pneumáticas, principalmente porque as técnicas propostas para compensação de atrito em servomecanismos se baseiam em sinais de alta-freqüência, e este tipo de sinal não apresenta efeito prático nas válvulas de controle, devido à dinâmica bem mais lenta. Por este motivo, alguns pesquisadores iniciaram a busca por métodos eficientes de compensação de atrito para válvulas de controle pneumáticas.

O uso de linearização de entrada-saída (input-output linearization ou $I O L$ ) foi proposto por (KAYIHAN; DOYLE III, 2000) para a compensação do atrito em válvulas de controle pneumáticas. Através da implementação desta técnica, foi projetado um controlador por modelo interno. Este compensador se baseia em uma estrutura de espaço de estados e exige realimentação completa de estados para funcionar corretamente. A técnica de obtenção da linearização entrada-saída não é detalhada em (KAYIHAN; DOYLE III, 2000). Por este motivo, os trabalhos de 
(ISIDORI, 1989) e (SILVA, 2003) foram utilizados para obter maiores detalhes da implementação desta técnica, a qual necessita do modelo de atrito da válvula de controle e seus parâmetros.

Pensando em evitar o problema de dependência dos parâmetros da válvula de controle, (HÄGGLUND, 2002) propôs uma técnica de compensação de atrito estático em válvulas de controle pneumáticas, chamada Knocker. A idéia básica do Knocker é adicionar ao sinal de saída do controlador um trem de pulsos, que pode ser definido por três parâmetros: a amplitude do sinal a, o período do sinal $\tau$ e o intervalo entre os pulsos $h_{k}$. A energia de cada pulso é dada pelo produto a $\tau$, e deve ser suficiente para superar o atrito que mantém a válvula parada, ou seja, o atrito estático. O nível de energia dos pulsos é muito importante, pois além de ser necessária uma quantidade mínima de energia para superar o atrito estático, o excesso de energia pode levar a válvula para condições de saturação, além é claro de causar desperdício de energia. Como o posicionador da válvula de controle possui dinâmica integradora, os pulsos podem ter energia limitada, pois a cada novo pulso a energia vai sendo acumulada até ocorrer o escorregamento da válvula. Os pulsos que sucedem imediatamente o escorregamento da válvula não são desperdiçados, já que a válvula atinge uma nova posição travada logo após movimentar-se. Esta técnica é interessante porque não exige o conhecimento dos parâmetros da válvula de controle, o que possibilita seu uso em válvulas reais com facilidade.

A versatilidade desta técnica de compensação de atrito estático em válvulas de controle pneumáticas despertou o interesse de (SRINIVASAN; RENGASWAMY, 2005). O fato de a técnica do Knocker não exigir conhecimento dos parâmetros da válvula é muito interessante do ponto de vista prático, pois torna sua implementação muito mais fácil em malhas de controle reais. De forma complementar ao trabalho proposto por (HÄGGLUND, 2002), os autores (SRINIVASAN; RENGASWAMY, 2005) estudaram de forma mais detalhada o efeito da sintonia dos três parâmetros do Knocker no desempenho do compensador. Além disso, estabeleceram que esta sintonia está diretamente ligada à detecção da presença e quantificação do atrito estático na válvula de controle. Finalmente, (SRINIVASAN; RENGASWAMY, 2005) propuseram uma metodologia de detecção, quantificação, sintonia de compensador 
e compensação de atrito estático em válvulas de controle pneumáticas, usando o Knocker devidamente sintonizado como compensador de atrito.

Entretanto, segundo a literatura consultada, ambas as técnicas citadas anteriormente ( $I O L$ e Knocker) possuem uma característica comum que pode prejudicar sua implementação prática. Tanto no $I O L$ quanto no Knocker, a redução da variabilidade do processo é alcançada em troca do aumento da variabilidade da posição da haste da válvula de controle. $O$ aumento da freqüência e da velocidade de movimentação da haste pode danificar as válvulas de controle, além de reduzir drasticamente sua vida útil.

Pensando nisto, (SRINIVASAN; RENGASWAMY, 2007) propuseram um compensador que reduz o efeito de transferência de variabilidade do processo para a haste da válvula, denominado 2 move. Assim como no compensador Knocker, o compensador 2 move não exige conhecimento do modelo de processo, tampouco da válvula. Este compensador propõe, através de pelo menos dois movimentos, tirar a válvula da posição travada, levá-la para a condição de estado estacionário aderente ao valor de referência e mantê-la nesta posição indefinidamente, até que outro valor de referência seja estabelecido. Este modelo, entretanto, exige conhecimento do nível estimado de atrito estático, chamado de $d$ pelos autores. Mesmo sendo necessário o valor do parâmetro $d$, testes realizados demonstraram que este compensador tem bom desempenho mesmo com elevados níveis de incerteza deste parâmetro. O compensador 2move mostrou resultados bastante satisfatórios e robustos nos testes realizados pelos autores. Entretanto, pela característica de projeto do compensador, após a haste da válvula atingir sua posição de estado estacionário, o tempo mínimo exigido pelo processo para atingir seu valor de referência é pelo menos igual ao tempo de acomodação do processo.

\subsubsection{Modelos de atrito em válvulas de controle}

Existem diversos modelos de atrito que podem ser implementados no ambiente em que os compensadores de serão testados. Em seus trabalhos (GARCIA, 2006; GARCIA, 2008) estudou oito modelos de atrito, sendo dois modelos estáticos (Clássico e Karnopp), dois modelos dinâmicos (Sete Parâmetros e Lugre) e quatro modelos orientados a dados de processo (Stenman, Choudhury, Kano e He). A 
escolha do modelo é fundamental para este trabalho, pois o modelo escolhido deve ser capaz de reproduzir, de forma satisfatória, o fenômeno do slip-jump na válvula de controle. O slip-jump representa o comportamento da válvula na presença de atrito estático, e o atrito estático é uma não-linearidade que atrapalha consideravelmente o desempenho da válvula de controle. Dos modelos propostos e estudados em (GARCIA, 2006; GARCIA, 2008), optou-se pelo modelo de Karnopp, pois este modelo se mostrou eficiente na detecção do comportamento do atrito em torno da velocidade nula, além de ser facilmente implementável no ambiente de simulação.

Além da escolha do modelo de atrito, é muito importante saber diferenciar os diversos tipos de não-linearidades da válvula de controle de processos, para evitar diagnósticos equivocados. Pensando nisso, os autores (CHOUDHURY; THORNHILL; SHAH, 2005) e (GARCIA, 2006) descrevem em seus trabalhos quais as principais características de cada uma das principais não-linearidades de uma válvula de controle de processo pneumática. Com relação ao conceito de atrito estático, os autores (CHOUDHURY; THORNHILL; SHAH, 2005) propõem uma definição formal para esta não-linearidade, utilizando como base a nomenclatura da American National Standard Institution (ANSI) para backlash, histerese e banda morta, buscando, desta forma, padronizar a nomenclatura das não-linearidades.

\subsection{Estrutura da Dissertação}

Esta dissertação está estruturada da seguinte maneira: o Capítulo 2 é composto pela descrição do problema, pela apresentação do modelo do processo e da válvula de controle com atrito bem como da formulação matemática dos compensadores de atrito. No Capítulo 3, encontra-se a implementação das técnicas de compensação do atrito e as considerações que foram adotadas. No Capítulo 4 são apresentados os resultados obtidos nas simulações realizadas e nos ensaios feitos no ambiente HIL, comparando-os com os resultados obtidos para um sistema que não utilize nenhum compensador de atrito. No Capítulo 5 , as conclusões deste trabalho são apresentadas e os próximos passos a serem seguidos nesta linha de pesquisa são sugeridos. 


\section{CAPÍTULO 2. DESCRIÇÃO DO PROBLEMA}

O problema aqui tratado corresponde à compensação do atrito em válvulas de controle, visando reduzir a variabilidade do processo. Na primeira seção deste capítulo são apresentadas e brevemente descritas as características das principais não-linearidades que afetam o comportamento dinâmico de válvulas de controle, dentre elas o atrito. Na seção seguinte, são descritos os modelos da válvula com atrito e do processo.

\subsection{Descrição das não-linearidades na válvula de controle}

Antes de qualquer coisa, é importante discutir um pouco sobre as principais nãolinearidades encontradas em uma válvula de controle. Para isso, o trabalho de (CHOUDHURY; THORNHILL; SHAH, 2005), no qual são descritas as principais nãolinearidades em uma válvula de controle, fundamentadas na American National Standard Institution (ANSI), será utilizado como base.

A primeira não-linearidade a ser descrita é o backlash, traduzido livremente como "jogo" ou "folga". O backlash é um movimento relativo que ocorre entre as partes móveis de um sistema mecânico, gerado pela folga entre estas partes, tipicamente quando o sentido do movimento sofre mudança.

Outra não-linearidade bastante comum é a histerese. A histerese é a propriedade de um elemento que é evidenciada pela dependência do valor da saída, para uma dada excursão da entrada, no histórico de excursões anteriores e na direção do cruzamento atual. De forma simplificada, em um elemento com histerese, a resposta ou "percurso" percorrido pelo sistema para uma dada entrada é diferente quando esta entrada é crescente ou decrescente, o que pode ser evidenciado na Figura 1.

A deadband, traduzida como "banda morta", é a faixa através da qual um sinal de entrada pode variar, ao mudar de direção, sem iniciar uma mudança observável no sinal de saída. A seguir, na Figura 1, é possível notar também que a banda morta possui relações distintas e separadas de entrada-saída para sinais crescentes e 
decrescentes. Outra característica da banda morta é que ela produz atraso de fase (phase lag) entre entrada e saída.

A deadzone, traduzida como "zona morta", é uma faixa pré-determinada da entrada na qual a saída permanece inalterada, independente da mudança de direção do sinal de entrada. A seguir, na Figura 1, pode-se notar que existe somente uma relação de entrada-saída, independentemente se os sinais forem crescentes ou decrescentes. Ao contrário da banda morta, a zona morta não produz atraso de fase (phase lag) entre entrada e saída.

A seguir, na Figura 1, três das quatro não-linearidades descritas até agora são representadas (exceto backlash).
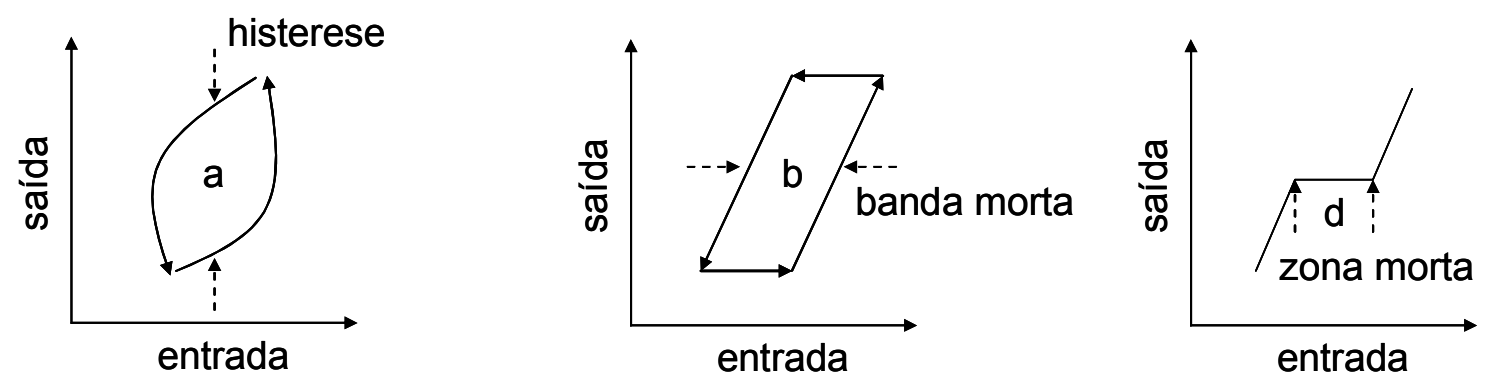

Figura 1: Representação gráfica das não-linearidades

Conforme mencionado anteriormente, o principal intuito deste trabalho é a compensação de componentes de atrito em geral, dentre os quais se encontra o atrito estático. Entretanto, não existe nenhuma definição consensual para atrito estático entre diversos autores que publicaram trabalhos sobre o tema. A seguir, algumas definições retiradas do trabalho de (CHOUDHURY; THORNHILL; SHAH, 2005) são citadas:

Segundo a Entech, atrito estático pode ser definido da seguinte maneira:

Atrito estático gera a tendência de travar-escorregar. Este fenômeno causa resolução limitada na movimentação resultante da válvula de controle. $A$ terminlogia da ISA ainda não foi ajustada para encontrar definição adequada. Travar-escorregar é a tendência da válvula de controle emperrar enquanto está em repouso, e repentinamente escorregar depois que uma força seja aplicada. (CHOUDHURY; THORNHILL; SHAH, 2005, p.643) 
Ainda em seu trabalho, (CHOUDHURY; THORNHILL; SHAH, 2005) citam uma definição dada por Ruel:

Atrito estático (em inglês, sticition), é a combinação das palavras stick (parado) e friction (atrito), criado para enfatizar a diferença entre atrito estático e atrito dinâmico. $\mathrm{O}$ atrito estático ocorre quando o atrito estático (inicial) excede $\mathrm{o}$ atrito dinâmico (durante o movimento) dentro da válvula. $\mathrm{O}$ atrito estático descreve o comportamento emperrado da haste da válvula quando pequenas mudanças são tentadas. $O$ atrito de um objeto em movimento é menor do que o atrito de um objeto parado. $\mathrm{O}$ atrito estático pode impedir que a haste da válvula se mova no caso de pequenas mundanças na entrada de controle, e então a haste se move quando existir força suficiente para vencer o atrito estático. O resultado do atrito estático é que a força necessária para levar a haste da válvula a se mover é maior do que a força necessária para levar a haste para a posição desejada. $\mathrm{Na}$ presença de atrito estático, o movimento é saltado. (CHOUDHURY; THORNHILL; SHAH, 2005, p.643).

Tendo em mãos algumas definições, os autores (CHOUDHURY; THORNHILL; SHAH, 2005) propuseram uma definição formal baseada nas características em comum que os demais pesquisadores haviam apontado para atrito estático, além de incorporar as nomenclaturas e características descritivas empregadas nas definições da ANSI para histerese, deadband, deadzone e backlash.

A definição proposta por (CHOUDHURY; THORNHILL; SHAH, 2005) para atrito estático e que será adotada daqui por diante neste trabalho, é a seguinte:

Atrito estático é uma propriedade de um elemento de tal forma que sua movimentação suave, em resposta a uma entrada variável, seja precedida por um salto abrupto repentino, chamado slip-jump. O slip-jump é expresso como uma porcentagem da amplitude de saída e sua origem em um sistema mecânico é o próprio atrito estático, o qual excede o atrito dinâmico que aparece durante a movimentação suave da válvula. (CHOUDHURY; THORNHILL; SHAH, 2005, p.644).

A partir das definições dadas anteriormente para atrito estático, fica evidente que uma característica marcante desta não-linearidade é a ocorrência do slip-jump. De 
acordo com (GARCIA, 2006), o slip-jump corresponde ao escorregamento momentâneo sofrido pela haste da válvula quando a força de atrito estático é superada pela força externa aplicada e, por alguns instantes, esta força enfrenta uma resistência muito menor, gerando uma grande aceleração e, conseqüentemente, gerando um pico na velocidade da haste e causando, desta forma, uma rápida movimentação da mesma.

A seguir, na Figura 2, diversas não-linearidades da válvula de controle são ilustradas juntamente, incluindo agora o slip-jump.

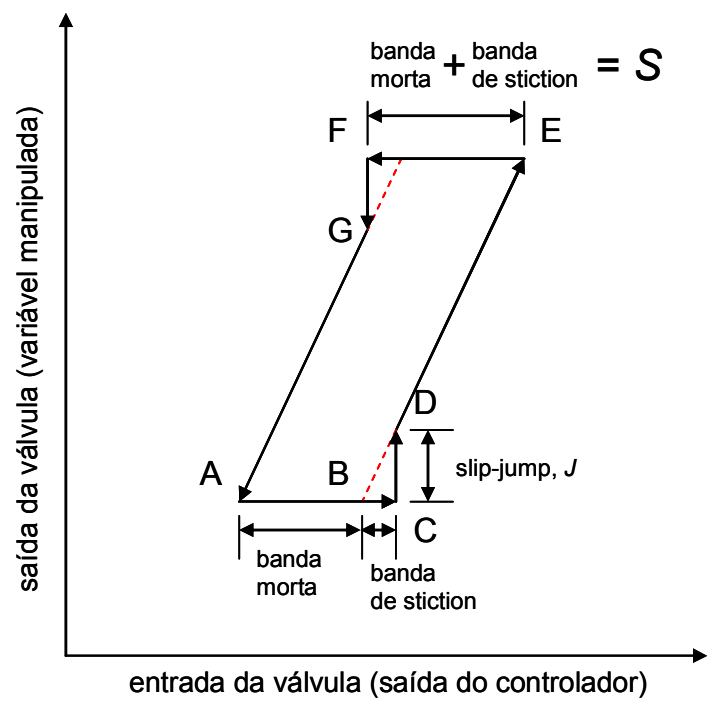

Figura 2: Representação gráfica de não-linearidades, incluindo agora o slip-jump

Agora que o atrito estático já foi definido, o próximo passo é discorrer brevemente sobre possíveis causadores de atrito em uma malha de controle. De acordo com o trabalho de (KAYIHAN; DOYLE III, 2000), as forças de atrito presentes na válvula de controle, entre elas o atrito estático, estão relacionadas principalmente ao engaxetamento da válvula. O engaxetamento, que é formado por anéis de materiais compostos, funciona como um selo dinâmico entre o atuador e o material que flui através da válvula. Existem diversas variações destes compostos de engaxetamento, assim como diferentes arranjos. As configurações de engaxetamento dependem dos requisitos de temperatura e diferença de pressão no corpo da válvula. Tipicamente, o material utilizado no engaxetamento é feito de carbono, compostos de grafite ou Teflon. O desgaste do engaxetamento ou sua fixação muito exagerada podem elevar demasiadamente os níveis de atrito, contribuindo inclusive para o aparecimento do atrito estático. 
Uma vez definido o que é atrito estático e qual sua principal origem em uma válvula de controle, o próximo passo é discorrer sobre os modelos (válvula, atrito e processo) que serão utilizados neste trabalho, além da estrutura do HIL.

\subsection{Descrição dos modelos considerados}

As descrições são iniciadas pelo modelo da válvula com atrito, passando depois para o modelo do processo e, finalmente, para o conceito HIL.

\subsubsection{Modelo físico da válvula}

A válvula de controle de processos pneumática foi modelada a partir da expressão da somatória das forças do sistema mecânico, de acordo com a segunda lei de Newton. Esta abordagem foi proposta por vários dos autores utilizados como fonte de pesquisa neste trabalho. Em seus respectivos trabalhos, os autores (KAYIHAN; DOYLE III, 2000; CHOUDHURY et al., 2005; SRINIVASAN et al., 2005; GARCIA, 2006; GARCIA, 2008) partem da expressão do somatório de forças para modelar a válvula de controle e suas respectivas forças de atrito.

A equação do balanço de forças para uma válvula de controle é a seguinte:

$$
m \frac{d^{2} x_{1}}{d t^{2}}=\sum \text { Forças }=F_{a}-F_{r}-F_{f}-F_{\text {fluido }}-F_{\text {sede }}
$$

onde:

$m$ é a massa das partes móveis da válvula (tipicamente a haste e o obturador);

$x_{1}$ é a posição da haste da válvula;

$F_{a}=A u$ é a força aplicada pelo atuador da válvula, sendo $A$ a área do diafragma e $u$ a pressão de ar;

$F_{r}=-k x_{1}$ é a força da mola, onde $k$ é a constante da mola;

$F_{\text {fluido }}=-\alpha \Delta P$ é a força relacionada à perda de carga do fluido, onde $\alpha$ é a área desbalanceada do obturador e $\triangle P$ a perda de carga;

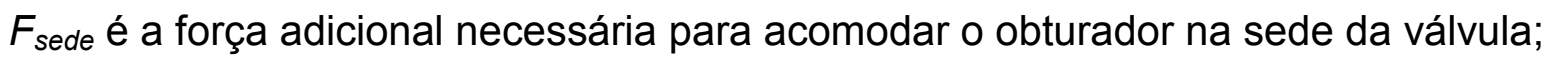

$F_{f}$ é a força de atrito, que é detalhada a seguir. 
Assim como foi feito em (KAYIHAN; DOYLE III, 2000), assumiu-se que $F_{\text {fluido }} \mathrm{e}$ $F_{\text {sede }}$ são nulos, uma vez que ambas as forças apresentam contribuição desprezível no modelo da válvula se comparadas com as demais componentes no balanço de forças. Sendo assim, a Equação (1) pode ser reescrita, desprezando $F_{\text {fluido }}$ e $F_{\text {sede }}$. Desta forma, chega-se na Equação (2):

$$
m \frac{d^{2} x_{1}}{d t^{2}}=\sum \text { Forças }=F_{a}-F_{r}-F_{f}
$$

O próximo passo é trabalhar na escolha do modelo de atrito que será adotado para esta dissertação.

Em seus trabalhos, (GARCIA, 2006; GARCIA, 2008), o autor estudou diversos modelos de atrito propostos anteriormente para uma válvula de controle. Os modelos de atrito podem ser divididos em três grupos: os modelos estáticos de atrito, os modelos dinâmicos de atrito e os modelos de atrito orientados a dados de processo.

Nos modelos estáticos de atrito, como o próprio nome já diz, os parâmetros do modelo não dependem do tempo, ao contrário do que acontece nos modelos dinâmicos, nos quais alguns dos parâmetros variam com o transcorrer do tempo.

Os modelos estáticos de atrito levam em conta três componentes principais: o atrito estático, o atrito viscoso e o atrito de Coulomb. Desta forma, a força de atrito pode ser descrita da seguinte forma:

$F_{f}\left(x_{2}\right)=\left[F_{C}+\left(F_{S}-F_{C}\right) \mathrm{e}^{-\left(x_{2} / v_{S}\right)^{2}}\right] \operatorname{sgn}\left(x_{2}\right)+F_{V} x_{2}$

onde:

$F_{C}=$ coeficiente de atrito de Coulomb;

$F_{S}=$ coeficiente de atrito estático;

$F_{V}=$ coeficiente de atrito viscoso;

$v_{S}=$ velocidade de Stribeck;

$x_{2}=$ velocidade da haste.

Feita esta breve introdução sobre modelos de atrito e tomando como base a Equação (3), o próximo passo é a descrição do modelo de atrito a ser utilizado nas 
simulações deste trabalho. Em (GARCIA, 2006; GARCIA, 2008) foram estudados dois modelos de atrito estático: Clássico e Karnopp.

O modelo adotado neste trabalho é o modelo estático de atrito de Karnopp. Não é utilizado o modelo estático clássico de atrito porque ele apresenta um comportamento indesejado em torno da velocidade nula de movimentação da haste da válvula de controle, pois em simulações a velocidade nunca alcança exatamente a velocidade nula, fazendo com que a velocidade oscile em torno deste valor. A seguir, na Equação (4), é representado o modelo estático clássico, tornando mais fácil a compreensão do comportamento da velocidade da haste da válvula de controle quando este modelo é adotado.

$$
F_{f}= \begin{cases}{\left[F_{C}+\left(F_{S}-F_{C}\right) \mathrm{e}^{-\left(x_{2} / v_{S}\right)^{2}}\right] \operatorname{sgn}\left(x_{2}\right)+F_{V} x_{2}} & \text { se } x_{2} \neq 0 \\ \left(F_{a}-F_{r}\right) & \text { se } x_{2}=0 \text { e }\left|F_{a}-F_{r}\right| \leq F_{S} \\ F_{S} \operatorname{sgn}\left(F_{a}-F_{r}\right) & \text { se } x_{2}=0 \text { e }\left|F_{a}-F_{r}\right|>F_{S}\end{cases}
$$

A expressão da primeira linha da Equação (4) indica a situação em que a haste da válvula de controle está em movimento, e possui um termo independente da velocidade, $F_{C}$ (conhecido como atrito de Coulomb) e um termo relativo ao atrito viscoso, $F_{V} x_{2}$ (dependente linearmente da velocidade).

Já na segunda linha da Equação (4), a expressão que representa a válvula de controle emperrada é apresentada. Neste caso, a velocidade da haste da válvula de controle emperrada é nula e não muda, e, portanto a aceleração da haste também é nula. Sendo assim, o lado direito da equação de balanço de forças através da segunda lei de Newton, dada pela Equação (2), é zero. Desta forma, $F_{f}=F_{a}-F_{r}$.

Por fim, a terceira linha da Equação (4) representa a situação no instante da iminência de movimentação da válvula de controle. Neste instante, a soma das forças é $\left(F_{\mathrm{a}}-F_{r}\right)-F_{S} s g n\left(F_{\mathrm{a}}-F_{r}\right)$. Esta soma é diferente de zero se $\left|F_{\mathrm{a}}-F_{r}\right|>F_{S}$. Então, a aceleração deixa de ser nula e a válvula começa a se mover. 
Para lidar com o comportamento oscilatório próximo da velocidade nula, (GARCIA, 2006; GARCIA, 2008) propõe então o modelo estático de atrito de Karnopp. Através deste modelo, o problema de chaveamento entre equações da segunda e da terceira linha da Equação (4) que acontece no modelo estático de atrito clássico é evitado, já que é definida uma banda na qual a velocidade seja nula.

O modelo estático de atrito de Karnopp propõe o estabelecimento de um intervalo em torno de $x_{2}=0$, criando desta forma uma zona morta para $\left|x_{2}\right|<D V$. Se $\left|x_{2}\right|<D V$, a força de atrito será uma versão saturada da força externa $F_{e}$ ou, caso contrário, uma função estática da velocidade, conforme a Equação (2). Por este motivo, o valor no qual a velocidade da haste da válvula de controle seja forçada para zero (DV), deve ser um valor suficientemente baixo para evitar um salto considerável na força de atrito estático.

Até o momento, o modelo da válvula de controle de processos e o modelo estático de atrito de Karnopp foram descritos. O próximo passo é a descrição sucinta do processo que é utilizado para o estudo do comportamento do atrito em válvulas de controle de processo.

\subsubsection{Modelo do Processo}

Processos diferentes apresentam dinâmicas diferentes, e, por esse motivo, é normal esperar-se que os resultados obtidos para uma mesma válvula de controle, aplicada em processos diferentes, também sejam diferentes. Entretanto, como o trabalho é realizado tanto em ambiente simulado quanto em ambiente HIL, a escolha do modelo do processo é fundamental para tornar a simulação viável, num tempo razoável. Por este motivo, será adotado um único modelo de processo para a execução das simulações.

Desta forma, o modelo do processo foi escolhido pensando-se principalmente na duração das simulações, pois como o passo de integração adotado $\left(10^{-5} \mathrm{~s}\right)$ foi muito pequeno, plantas com dinâmicas muito lentas exigiriam simulações muito longas para permitir a visualização dos fenômenos de atrito e o funcionamento dos compensadores. Desta forma, a escolha recaiu sobre o modelo de um circuito fechado de vazão, já que dentre diversos modelos disponíveis, foi este que tinha a 
menor constante de tempo dominante, o que reduz de forma significativa a duração das simulações. Este modelo é descrito sucintamente a seguir.

A Figura 3 ilustra o diagrama de blocos do sistema a ser estudado.

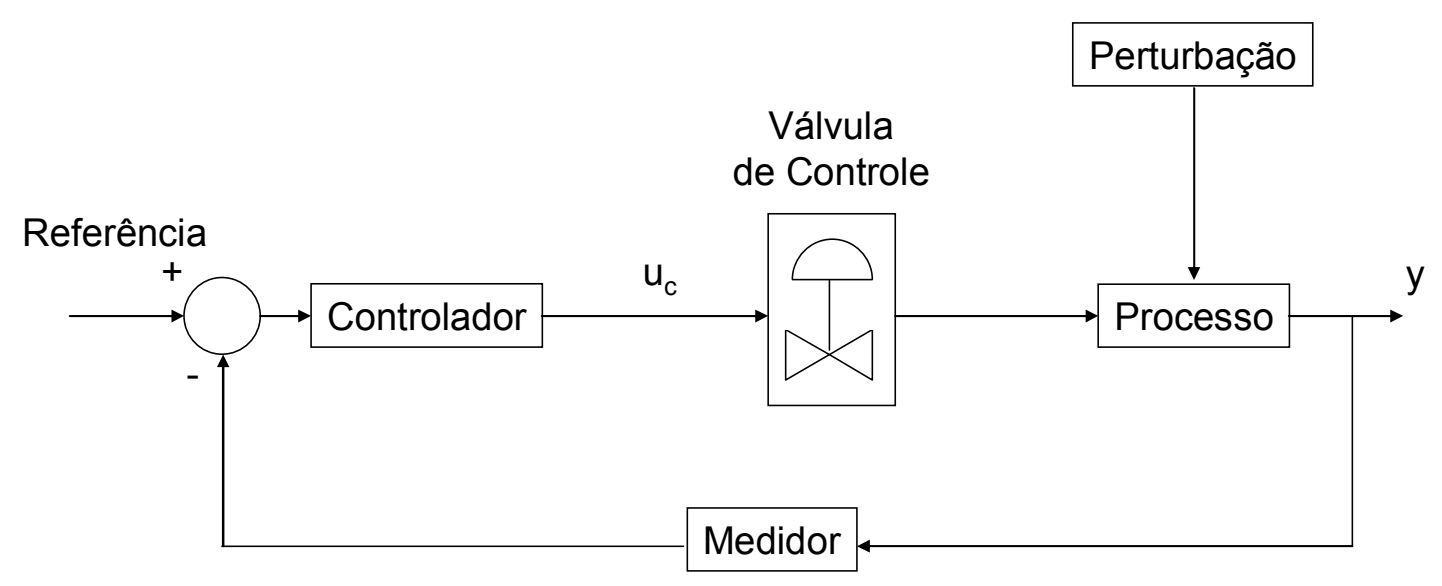

Figura 3: Modelo da malha de vazão, sem a presença de compensador

A Figura 3 ilustra o diagrama de blocos do modelo da malha de vazão que é utilizada neste trabalho. O diagrama de blocos da Figura 3 representa um circuito de vazão com tubulação de 2", pelo qual circula água através do acionamento de uma bomba. A vazão é controlada por meio de um controlador PI, conectado a uma válvula de controle. A leitura da vazão é feita através de um medidor.

\subsubsection{Descrição do ambiente $100 \%$ simulado}

Inicialmente, pretendia-se realizar este trabalho somente no ambiente $100 \%$ simulado. Neste caso, todos os ensaios seriam realizados a partir de um computador, através do software Matlab/Simulink®.

Esta abordagem é muito interessante do ponto de vista prático, pois permite que todos os ensaios sejam realizados em qualquer computador que tenha o software de simulação instalado.

Por outro lado, os ensaios $100 \%$ simulados nem sempre têm condições de representar o que acontece numa planta real, por mais perfeita que seja a modelagem do sistema, principalmente no que diz respeito ao modelo da planta e ao modelo da válvula de controle com atrito. 
Felizmente, foi possível preparar uma estrutura de simulação num ambiente híbrido, chamado HIL. Desta forma, os ensaios são realizados tanto no ambiente $100 \%$ simulado quanto no ambiente HIL.

\subsubsection{Descrição do ambiente $H I L$}

O ambiente HIL (Hardware in the Loop) pode ser considerado um ambiente de simulação híbrido, no qual parte do sistema é real e parte do sistema é simulado. No caso deste trabalho, é utilizado um conjunto de válvula de controle de processo + atuador reais.

A válvula e o atuador utilizados neste trabalho são do fabricante Fisher. Para possibilitar a aquisição dos sinais de posição e pressão, algumas modificações foram feitas. A primeira modificação foi a instalação de um sensor de pressão no atuador da válvula. Também foi feita uma alteração no circuito elétrico do posicionador da válvula, possibilitando desta forma adquirir os sinais de posição da haste da válvula. A última modificação foi a instalação de um conversor V/P (tensão pressão), que é responsável pela conversão do sinal elétrico enviado pela placa de aquisição de dados em um sinal de pressão, capaz de acionar o atuador da válvula.

Uma vez feitas as alterações no hardware do conjunto válvula + atuador, também foi necessário utilizar uma interface de aquisição de dados no computador. Esta interface de aquisição recebe os sinais da posição da haste e da pressão no atuador, além também é claro de enviar os sinais para o conversor V/P. Desta forma, esta interface de aquisição possibilita a interação entre o ambiente simulado (controlador PI, processo e medidor de vazão) com o ambiente real (válvula + atuador com acessórios).

A abordagem proposta pelo HIL vem sendo cada vez mais utilizada em pesquisas, pois permite avaliar o comportamento de um equipamento real através de uma ferramenta de simulação. No caso deste trabalho, a idéia é avaliar o comportamento de compensadores de atrito em válvulas de controle. Nada melhor do que uma válvula real de controle para avaliar se o compensador funciona ou não na prática. A válvula real utilizada nos ensaios foi uma válvula tipo globo de 2 polegadas, modelo FSNT-217, enquanto o atuador foi do tipo pneumático (com diafragma) e retorno por mola, modelo FS657, ambos fabricados pela Fischer. 
Sendo assim, além dos ensaios $100 \%$ simulados, este trabalho possui parte dos ensaios realizados no ambiente HIL. As Figuras 4 e 5 a seguir apresentam um diagrama e uma foto da solução HIL utilizada durantes os ensaios.

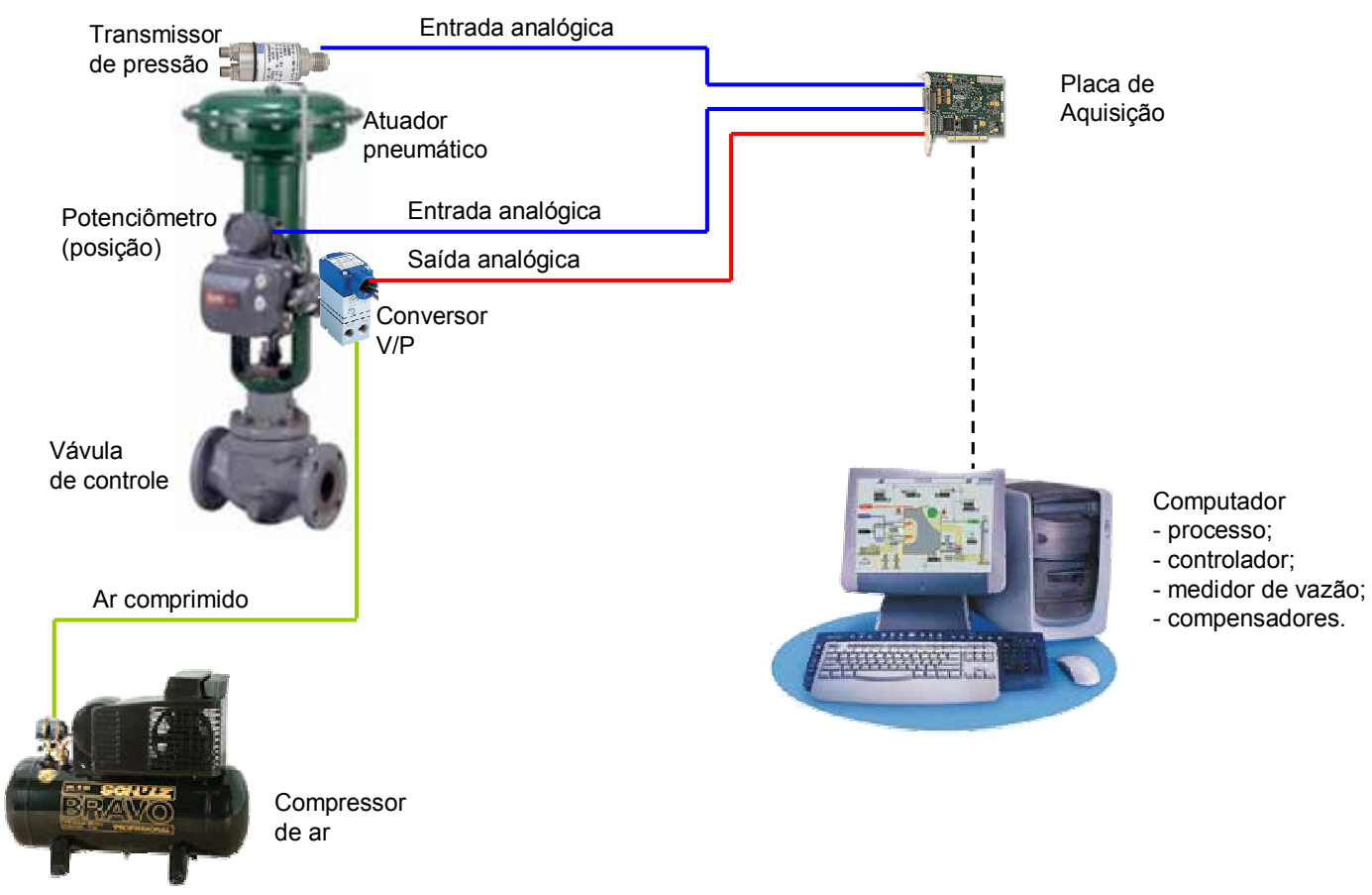

Figura 4: Diagrama do ambiente Hardware in the Loop

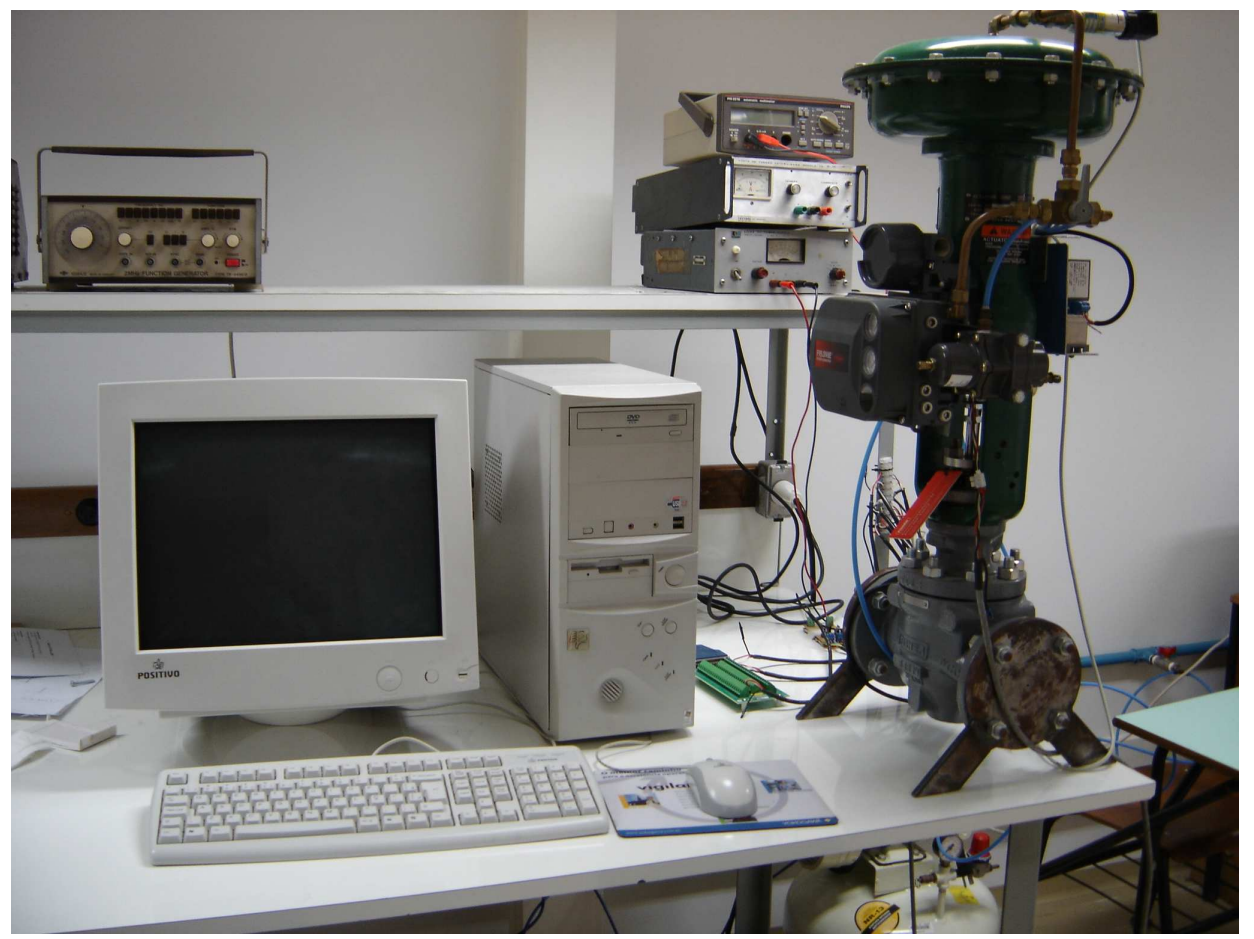

Figura 5: Foto do Hardware in the Loop utilizado nos ensaios 


\section{CAPÍTULO 3. METODOLOGIA}

No capítulo anterior, o problema estudado nesta dissertação foi descrito. De forma bastante sucinta, este problema pode ser resumido como a implementação de técnicas de compensação de atrito em válvulas de controle, visando aumentar o desempenho operacional da planta.

Neste capítulo, seão descritas três técnicas de compensação de atrito em válvulas de controle, técnicas estas que são implementadas no próximo capítulo, para verificar sua praticidade e eficiência no aumento do desempenho operacional de plantas industriais.

Além disso, é estabelecido o procedimento utilizado para a implementação dos compensadores, além dos critérios de desempenho utilizados para avaliar o seu funcionamento.

\subsection{Fundamentação Teórica}

\subsubsection{Modelo de compensador 1: $I O L$}

O primeiro modelo de compensador de atrito utiliza o método de Input-Output Linearization. Este compensador é chamado de $I O L$ neste trabalho. O IOL foi proposto pelos autores (KAYIHAN; DOYLE III, 2000). Em seu trabalho, os autores propõem a utilização de métodos geométricos diferenciais para incorporar os efeitos das não-linearidades do atrito no algoritmo de controle da válvula. Desta forma, sistemas não lineares podem ser transformados em sistemas lineares, através da realimentação completa de estados. Maiores detalhes sobre esta técnica podem ser encontrados em (SILVA, 2003), (ISIDORI, 1989) e (KRAVARIS; CHUNG, 1987).

Os autores partiram do princípio da linearização entrada-saída para obter um mapa de transformação. A relação entre a entrada do mapa (sinal do controlador) e a saída do sistema pode ser projetada para se comportar como um sistema linear, e desta forma representada por sua função de transferência (os pólos correspondentes devem estar no semi-plano esquerdo, para garantir a estabilidade). Desta forma, segundo (KAYIHAN; DOYLE III, 2000), a lei de controle do IOL pode 
ser representada por um modelo linear, além de disponibilizar teoricamente um rastreamento livre de erro de regime permanente.

No $I O L$, a compensação de atrito envolve a incorporação da descontinuidade do atrito diretamente na lei de controle quando a velocidade seja zero, fazendo com que a ação de controle também seja descontínua quando a velocidade seja nula. De acordo com os autores, este tipo de compensação de atrito é similar ao controle por modo deslizante, no qual o controlador tenta se aproximar e rastrear a descontinuidade, mantendo sua estrutura no algoritmo de controle. Entretanto, a menos que o sistema real seja modelado exatamente em torno da região da descontinuidade, de forma que não existam incertezas nos parâmetros, o controle por modo deslizante causa oscilações na ação de controle assim como o próprio IOL.

Os autores propuseram uma estratégia que incorpora o $I O L$ ao controle por modelo interno (IMC), buscando melhorar o desempenho do rastreamento apresentado atualmente pelos controladores lineares presentes nos posicionadores inteligentes disponíveis no mercado. Eles sugerem que o efeito oscilatório na ação de controle possa ser eliminado através da aproximação da descontinuidade por uma função mais suave, fazendo assim com que a ação de controle atinja a descontinuidade de forma suave, ao invés de ficar oscilando em torno dela. A estratégia de controle proposta pelos autores é mostrada na Figura 6.

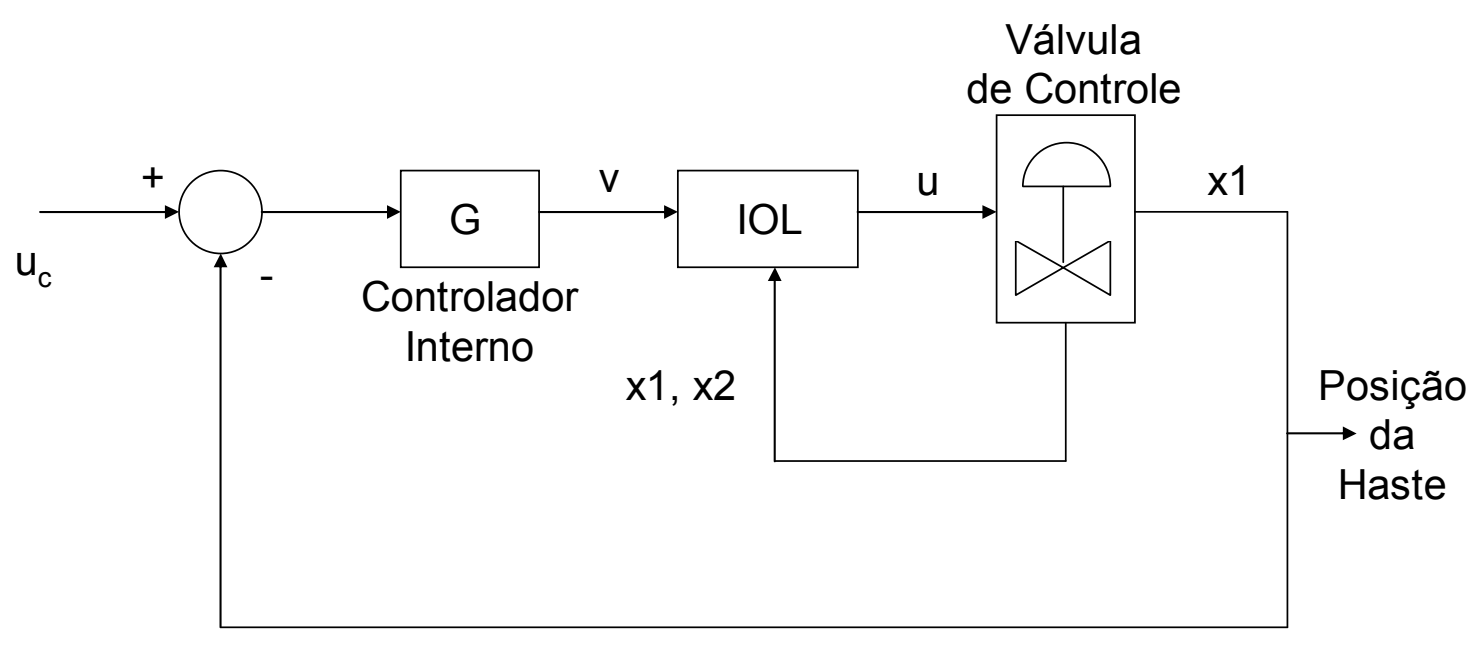

Figura 6: Representação da estratégia de controle através do uso do IOL 
onde:

$u_{c}$ : saída do controlador;

G: filtro da ação de controle;

IOL: lei de controle que incorpora todas as dinâmicas não-lineares da válvula, com informação completa de estados, para compensar os efeitos de atrito;

u: saída do IOL, que irá atuar diretamente na válvula de controle.

O modelo adotado para a válvula de controle foi descrito anteriormente nesta dissertação, e pode ser encontrado na Equação (1). Entretanto, como o trabalho de (KAYIHAN; DOYLE III, 2000) está orientado para espaço de estados, a Equação (1) deve ser transformada em um conjunto de expressões no espaço de estados, conforme indicado a seguir:

$$
\begin{aligned}
& \dot{x}_{1}^{*}=x_{2} \\
& m \dot{*} \dot{x}_{2}=A u-k x_{1}-\left[F_{C}+\left(F_{S}-F_{C}\right) \exp ^{-\left(x_{2} / v_{S}\right)^{2}}\right] \operatorname{sgn}\left(x_{2}\right)-F_{V} x_{2} \\
& y=x_{1}
\end{aligned}
$$

onde:

y: saída do espaço de estados.

Até o momento, o modelo da válvula no espaço de estados foi descrito. $O$ próximo passo é descrever a lei de controle $I O L$ propriamente dita.

Para evitar os efeitos oscilatórios na ação de controle devido ao chaveamento entre diferentes expressões de atrito em torno do zero, é sugerido por (KAYIHAN; DOYLE III, 2000) a utilização de uma aproximação contínua das leis de controle de chaveamento. Através deste método, a descontinuidade do controlador é suavizada para uma fina camada-limite na vizinhança da superfície de chaveamento. A função tanh foi escolhida para uso como uma função contínua e suave, ao invés da função sgn. À medida que a inclinação $(\sigma)$ da função tanh $(x)$ aumenta, a resposta converge para a resposta de sgn (x). Esta aproximação é utilizada na Equação (7) para a criação da lei de controle IOL.

Finalmente, (KAYIHAN; DOYLE III, 2000) projetaram a lei de controle IOL. Segundo os autores, buscando-se evitar comportamentos oscilatórios, o sistema 
linear foi projetado como dois sistemas de primeira ordem idênticos em série. $O$ comportamento desejado de resposta agressiva, conforme proposto pelos fabricantes de válvula, é um tempo de resposta de aproximadamente 1 segundo. Os pólos do sistema foram gerados com valor de $\tau=0,1$. Sem dinâmica de zeros e com a imposição dos pólos feita apropriadamente, o sistema é localmente estável ao redor de $x_{0}$. $O$ ponto $x_{0}$ pode ser definido como qualquer velocidade e posição ao longo do curso da válvula. A lei de controle IOL é representada a seguir, na Equação (6):

$u=\frac{v-x_{1}-2 x_{2}}{A \tau^{2}}-\frac{f_{2}(x)}{A}$

onde:

$$
f_{2}(x)=-k x_{1}-\left[F_{C}+\left(F_{S}-F_{C}\right) \exp ^{-\left(x_{2} / v_{S}\right)^{2}}\right] \tanh \left(x_{2}\right)-F_{V} x_{2}
$$

Uma vez detalhado todo o desenvolvimento do compensador $I O L$, a idéia inicial era implementar exatamente o compensador proposto por (KAYIHAN; DOYLE III, 2000). Porém, durante a leitura deste trabalho e após diversas tentativas de implementação do compensador, detectaram-se alguns erros de digitação e falta de clareza no procedimento de implementação, o que gerou dúvidas. Por este motivo, buscou-se na própria literatura proposta em (KAYIHAN; DOYLE III, 2000) e em outras fontes, qual a metodologia utilizada para a obtenção do compensador proposto. Através do estudo de (ISIDORI, 1989) e (SILVA, 2003), foi possível obterse um novo modelo de compensador, utilizando-se o princípio $I O L$.

Com a linearização entrada-saída $I O L$ e a inclusão de um controlador interno, busca-se estabilizar a posição da haste da válvula, mesmo na presença de atrito. As equações (8) e (9) descrevem o bloco $\mathrm{IOL}$ calculado novamente:

$u=\frac{1}{A / m}\left(-f_{2 n e w}(x)+v\right)$

onde:

$f_{2 n e w}(x)=\frac{-k x_{1}-\left[\left(F_{C}+\left(F_{S}-F_{C}\right) \exp ^{-\left(x_{2} / v_{S}\right)^{2}}\right) \tanh \left(\sigma x_{2}\right)-F_{V} x_{2}\right]}{m}$ 
Na Equação (8), existe o sinal $v$, que faz parte do controlador IOL. Tendo como base o trabalho de (SILVA, 2003), o sinal v pode ser calculado através da Equação (10), a seguir:

$$
v=u_{c}^{* *}-K_{0} e-K_{1} e^{*}
$$

onde:

$v=$ sinal de saída do controlador interno G para o IOL;

$u_{c}=$ sinal de referência, originado no controlador do processo;

$e=$ sinal de erro (=referência - valor real);

$k_{0}, k_{1}=$ ganhos do controlador $\mathrm{G}$.

A realimentação completa de estados é necessária para a lei de controle $I O L$. Portanto, a medição contínua dos estados é requerida. Sendo assim, no caso de ensaios $100 \%$ simulados, é utilizado o modelo estático de atrito de Karnopp, já que este modelo disponibiliza tanto $x_{1}$ quanto $x_{2}$. Para os ensaios com o HIL, é utilizado um derivador do sinal $x_{1}$ para obter $x_{2}$.

Uma característica final que deve ser destacada é a dependência desta abordagem com relação aos conhecimentos dos parâmetros físicos da válvula, como por exemplo, a massa da haste da válvula e a constante elástica da mola, além, é claro, dos coeficientes de atrito.

\subsubsection{Modelo do compensador 2: Knocker}

O segundo modelo de compensador implementado nesta dissertação foi proposto inicialmente por (HÄGGLUND, 2002). Em seu trabalho, o autor propõe a técnica do Knocker para compensar o atrito em válvulas de controle. Nesta técnica, o compensador de atrito adiciona pulsos às mudanças do sinal de controle, onde cada pulso tem uma quantidade de energia que compensa exatamente $\mathrm{o}$ atrito estático. A definição exata da quantidade de energia é muito importante, pois uma quantidade de energia baixa manteria a válvula emperrada, enquanto que uma quantidade de energia mais alta provocaria um deslizamento maior do que o desejado. 
A idéia básica do Knocker é adicionar pulsos curtos, de amplitude e duração iguais, na direção da taxa de mudança do sinal de controle, ao próprio sinal de controle, de forma a superar o atrito estático. A presença de um integrador no controlador do processo faz com que o nível de base para os pulsos mude gradualmente enquanto o erro de controle for diferente de zero. Por este motivo, a pressão no atuador irá aumentar gradualmente, até que a válvula deslize. Segundo (HÄGGLUND, 2002), podem ocorrer muitos pulsos indesejados do Knocker logo após o deslizamanto da haste, pois o sinal de medição poderá não reagir ao deslizamento imediatamente, e, portanto, o mesmo poderá acontecer com o sinal de controle. Entretanto, estes pulsos indesejados não causarão problemas, pois a válvula estará emperrada em uma nova posição, na qual os pulsos não serão suficientes para superar o nível de atrito estático. Por este motivo, é importante utilizar uma pequena quantidade de energia em cada pulso.

A seguir, na Figura (7), o princípio de funcionamento do Knocker em uma malha de controle fechada é ilustrado.

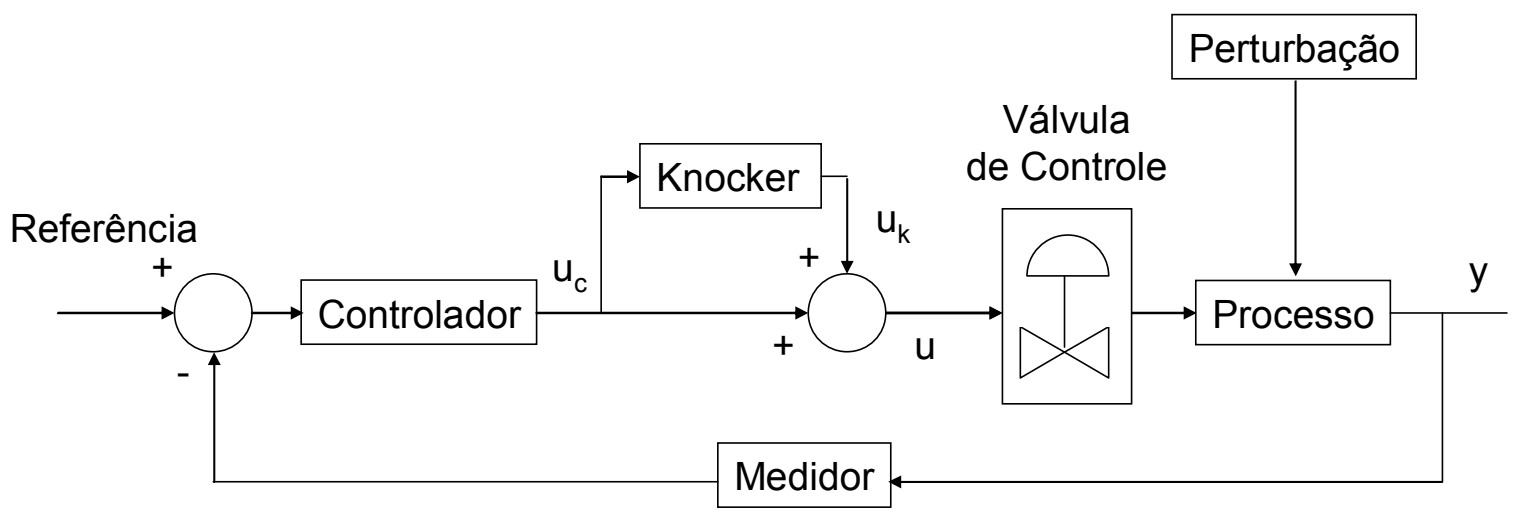

Figura 7: Diagrama de blocos do compensador Knocker

O diagrama de blocos da Figura (7) é muito semelhante ao diagrama de blocos da Figura (3). A única diferença é a inclusão do bloco de compensador. O sinal de controle $u(t)$ que entra na válvula de controle é composto por dois termos. A seguir, na Equação (11), a expressão do sinal de controle $u(t)$ é apresentada.

$u(t)=u_{c}(t)+u_{k}(t)$

onde:

$u_{c}(t)$ : saída do controlador;

$u_{k}(t)$ : saída do Knocker. 
Tipicamente, $u_{c}(t)$ é a saída de um controlador PID padrão, com parâmetros de ganho $K$, tempo integral $T_{i}$ e tempo derivativo $T_{d}$, cujo período de amostragem é $h$ segundos.

A saída $u_{k}(t)$ do Knocker é formada por uma seqüência de pulsos, que pode ser caracterizada através de três parâmetros: o intervalo entre cada pulso $h_{k}$, a amplitude do pulso a e a largura do pulso $\tau$. A seguir, na Figura 8, uma amostra de um sinal típico de saída do Knocker $\left(u_{k}(t)\right)$ é ilustrada.

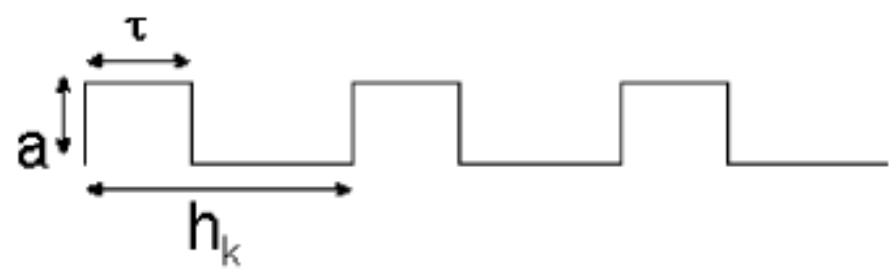

Figura 8: Sinal típico de saída do Knocker

Durante cada intervalo de pulso, $u_{k}(t)$ é dado pelas expressões descritas a seguir, na Equação (12).

$u_{k}(t)=\left\{\begin{array}{lr}a \operatorname{sgn}\left(u_{c}(t)-u_{c}\left(t_{p}\right)\right) & \text { se } t \leq t_{p}+h_{k}+\tau \\ 0 & \text { se } t>t_{p}+h_{k}+\tau\end{array}\right.$

onde:

$t_{p}=$ instante de início do pulso anterior.

Os parâmetros do Knocker devem ser escolhidos adequadamente, pois conforme mencionado anteriormente, os pulsos devem ser suficientemente grandes, de forma que a válvula receba energia suficiente para deslizar e, ao mesmo tempo, pequenos o suficiente para não causar nenhum deslizamento adicional.

A escolha de $\tau$ também é importante, pois não se deve alimentar o posicionador com muita energia no momento em que a válvula escorregar. Por este motivo, é desejável utilizar um valor relativamente pequeno de $\tau$. Segundo (HÄGGLUND, 2002), testes de campo apontaram para a escolha de $\tau$ entre $h$ ou $2 h$, onde $h$ é o tempo de amostragem do controlador do processo.

O último parâmetro do Knocker é o $h_{k}$. O período de amostragem $h_{k}$ deve ser maior do que $h$ por motivos óbvios. Além disso, $h_{k}$ também deve ser maior do que a largura do pulso $\tau$. Desta forma, é desejável manter $h_{k}$ pequeno com relação à 
constante de tempo da malha fechada, de forma que o nível de base para os pulsos não mude tanto entre dois pulsos sucessivos. Segundo (HÄGGLUND, 2002), é razoável escolher o período de amostragem $h_{k}$ do Knocker através de uma relação com a largura de pulso $\tau$. Uma escolha simples sugerida pelo autor é $h_{k}=n \tau$, onde $n$ está na faixa de $2<n<5$.

Com relação à escolha dos parâmetros, (HÄGGLUND, 2002) menciona que não existe motivo aparente para ter um a ajustável, ou seja, a pode ser fixo. Entretanto, os autores (SRINIVASAN; RENGASWAMY, 2005) afirmam que escolher um a adequado para cada válvula em particular é extremamente importante para o bom funcionamento da técnica do Knocker.

Outro fato importante levantado pelos autores (SRINIVASAN; RENGASWAMY, 2005) é que a amplitude a deve ser escolhida com base na estimativa da severidade do atrito estático $(d)$, obtida a partir dos dados de operação. Em seu trabalho, os autores (SRINIVASAN; RENGASWAMY, 2005) realizaram diversos testes, tanto no ambiente de simulação quanto em experimentos reais, e em ambos os casos comprovaram como a escolha dos três parâmetros do Knocker influenciam a eficiência do compensador.

Mesmo não sendo o principal escopo deste trabalho, é importante destacar a abordagem muito interessante proposta por (SRINIVASAN; RENGASWAMY, 2005), na qual é feita a integração da técnica de compensação do Knocker com uma técnica de detecção e estimação do atrito estático, de forma a ajustar os parâmetros do Knocker de forma otimizada. A seguir, na Figura 9, tem-se uma representação gráfica da abordagem proposta por (SRINIVASAN; RENGASWAMY, 2005). 


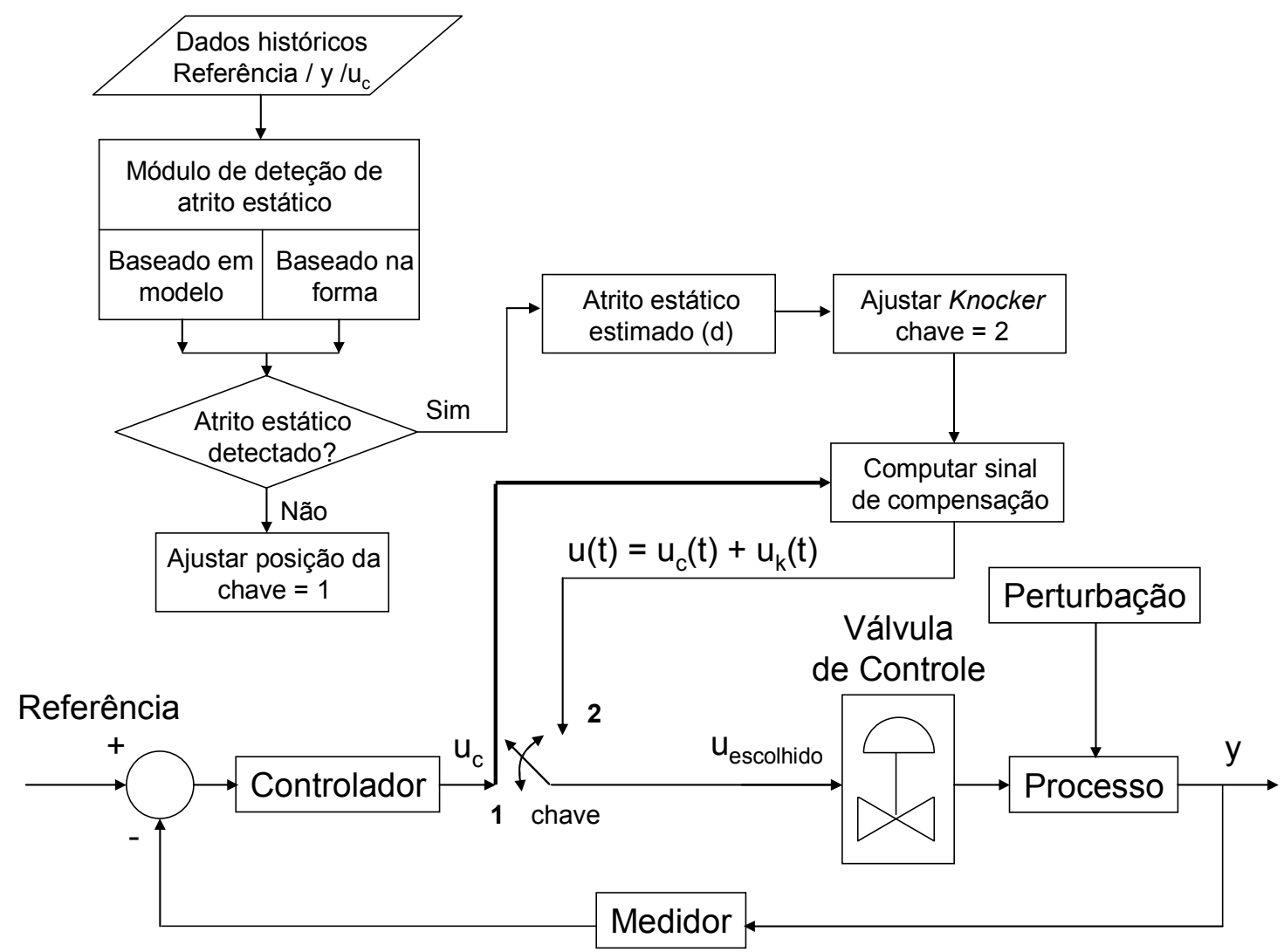

Figura 9: Esquema integrado de detecção, estimação e compensação de atrito estático, conforme (SRINIVASAN; RENGASWAMY, 2005)

A análise da Figura 9 indica a importância de estimar um valor para o atrito estático. No caso desta dissertação, o valor do atrito estático já é conhecido.

A técnica proposta na Figura 9 é uma técnica bastante elaborada e não é implementada neste trabalho. Entretanto, trata-se de uma melhoria futura que é sugerida ao final deste trabalho.

Uma característica final que deve ser destacada é que, nessa abordagem, não existe dependência com relação ao conhecimento dos parâmetros físicos da válvula, possibilitando o uso desta técnica em qualquer válvula, independentemente do conhecimento de seus parâmetros.

\subsubsection{Modelo de compensador 3: 2 move}

O compensador 2move foi proposto por (SRINIVASAN; RENGASWAMY, 2007). O intuito deste compensador é diminuir as supostas oscilações transmitidas para a haste da válvula nos compensadores anteriores (IOL e Knocker), uma vez que este 
tipo de oscilação pode danificar a válvula, reduzindo desta forma drasticamente sua vida útil. O compensador 2 move tem a mesma função dos compensadores descritos anteriormente: reduzir a variabilidade da saída do processo com o mínimo de energia adicionado ao sinal de controle.

A seguir, na Figura 10, o diagrama de blocos que representa o sistema em malha fechada, já considerando o compensador, é ilustrado.

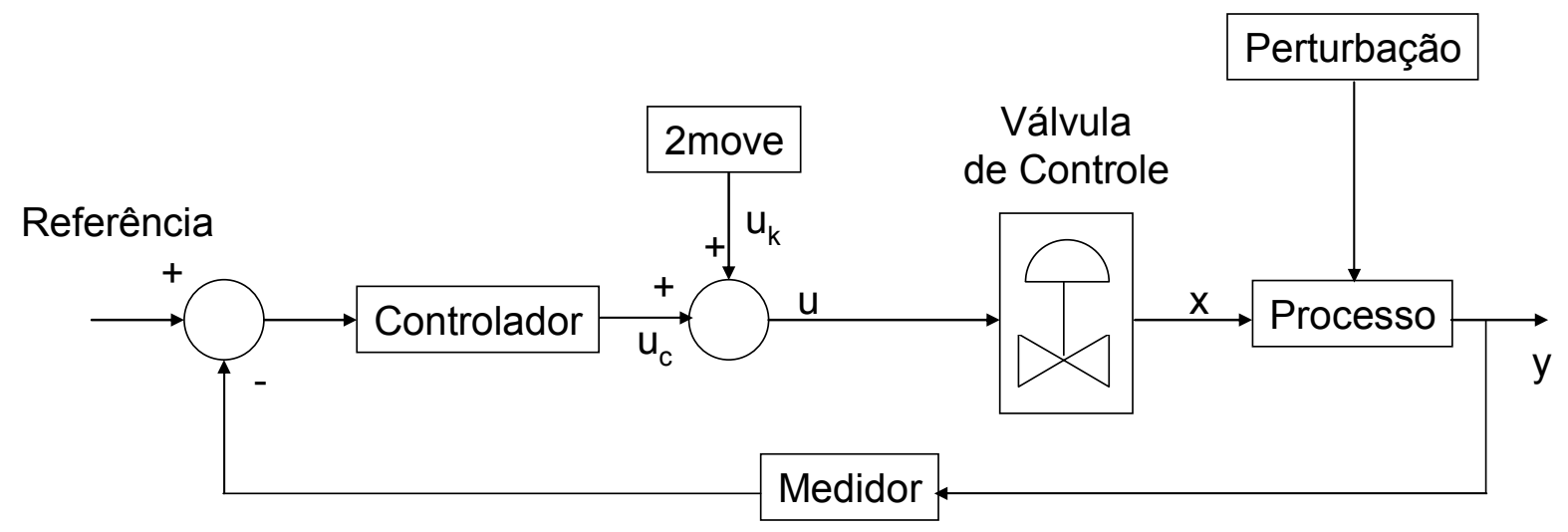

Figura 10: Diagrama de blocos do compensador 2 move

A formulação do compensador 2 move possui ainda algumas variáveis adicionais: $u_{s s}, x_{s s}$ e $y_{s s}$ representam os valores em estado estacionário da saída do controlador, posição da haste e da saída do processo na ausência de não-linearidades. O desenvolvimento do compensador também leva em conta os parâmetros $A_{1}$ (amplitude) e $\omega$ (freqüência) da oscilação induzida pelo atrito estático na saída do controlador. Finalmente, o desenvolvimento do compensador considera que são conhecidos, medidos ou facilmente obtidos os seguintes parâmetros: saída do processo $(y)$, saída do controlador $\left(u_{c}(t)\right)$ e o valor de referência da malha (Referência).

Para elaborar conceitualmente este compensador, (SRINIVASAN; RENGASWAMY, 2007) fizeram um estudo detalhado do fenômeno do slip-jump e chegaram a três observações importantes.

A primeira é que o atrito estático em uma válvula operando em malha fechada não permite que a haste da válvula atinja sua posição de estado estacionário, podendo inclusive causar ciclos-limite em torno da região de operação do estado estacionário. 
A segunda observação é que a haste desliza e fica travada repetidamente entre duas posições.

Finalmente, a terceira observação é que, na ausência de atrito estático, após o término dos transientes, tanto a haste da válvula quanto a saída do processo atingem seus valores de estado estacionário.

A partir das três observações acima, os autores concluíram que, através da adição de um sinal de compensação na saída do controlador, a haste é forçada a atingir e permanecer na sua posição de estado estacionário e, conseqüentemente, a saída do processo atingirá seu valor estacionário, ou seja, será igual ao valor de referência do controlador. Para alcançar este objetivo, são necessárias duas tarefas.

A primeira tarefa é fazer com que o sinal de compensação adicionado force a haste para sua posição de estado estacionário, após uma quantidade desejada de movimentos. A segunda tarefa, complementar à primeira, é garantir que o sinal de compensação não permita que a haste se mova desta posição de estado estacionário.

Segundo (SRINIVASAN; RENGASWAMY, 2007), em um sistema em malha fechada que possui ciclo-limite gerado por não-linearidades, os seguintes aspectos devem ser assumidos no desenvolvimento do compensador 2 move:

(1) A planta $G_{p}$ é estável;

(2) Na ausência de não-linearidades, o controlador estabiliza a planta e a saída do controlador, e a haste e a saída do processo atingem seus valores estacionários;

(3) Não existem erros no modelo da planta;

(4) A medição do atrito estático é exata;

(5) A posição atual da haste é um valor de estado estacionário;

(6) O processo não é afetado por ruídos de medição ou qualquer outro distúrbio medido ou não medido.

Desta forma, (SRINIVASAN; RENGASWAMY, 2007) propõem um sinal de compensação que, para qualquer instante $t$, mantém a haste da válvula em uma posição estacionária, ao mesmo tempo em que a saída do processo alcança seu 
valor de referência. Este sinal de compensação é descrito a seguir, através da Equação (13), na qual $d$ representa o valor de atrito estático estimado:

$\left|u_{c}(t)+u_{k}(t)\right|<d$

Além disso, o sinal de compensação $u_{k}$ será sempre limitado por um valor conforme especificado na Equação (14):

$\left|u_{k}(t)\right|<d+A_{1}$

Finalmente, após algumas considerações adicionais sobre como atingir o estado estacionário da haste, (SRINIVASAN; RENGASWAMY, 2007) propõem o modelo 2 move para compensação de atrito estático. Este modelo é descrito a seguir, através das três expressões da Equação (15):

$$
\begin{aligned}
& u_{k}(t)=\left|u_{c}(t)\right|+d \\
& u(t)=u_{c}(t)+\operatorname{sgn}\left(\frac{d u_{c}(t)}{d t}\right) u_{k}(t) \\
& u_{k}(t+1)=-u_{c}(t+1)
\end{aligned}
$$

A partir das três expressões da Equação (15), (SRINIVASAN; RENGASWAMY, 2007) fizeram algumas observações importantes.

A primeira delas foi feita através da análise das expressões 1 e 3 da Equação (15), e aponta que o segundo movimento não depende do primeiro movimento. É importante destacar que, na indústria, a faixa do controlador é geralmente normalizada entre $0-100 \%$. Conseqüentemente, o primeiro movimento de compensação ocorre de tal forma que este movimento esteja de fato na faixa de 0$100 \%$ e não force a válvula para a posição totalmente aberta ou totalmente fechada.

A segunda observação é que o sinal de compensação do primeiro movimento pode ser qualquer valor que mova a haste da posição emperrada. Por este motivo, um conjunto de possíveis primeiros sinais de compensação pode ser $u_{k}(t)=\left|u_{c}(t)\right|+\alpha_{1} d$, onde $\alpha_{1}$ é um valor real maior que 1. Desta forma, existem diversas maneiras de projetar o primeiro movimento do compensador. A única restrição é que os movimentos não podem causar saturação da válvula. 
A terceira observação é que a movimentação da válvula para seu estado estacionário pode ser feita em mais que dois movimentos.

\subsection{Procedimentos de avaliação dos compensadores}

A estrutura de simulação proposta neste trabalho possibilita a variação de diversos parâmetros dos modelos envolvidos. A seguir, são descritos os ensaios realizados para avaliar o desempenho dos compensadores.

\subsubsection{Degrau no sinal de Referência do controlador PI da planta de vazão}

No Capítulo 2 deste trabalho, foi apresentado, na Figura 3, o modelo da planta de vazão, em malha fechada, sem compensador. A idéia deste ensaio é impor um degrau no sinal de referência da malha fechada para uma situação sem compensador e depois comparar o desempenho da malha quando os compensadores são acionados.

\subsubsection{Comportamento dos compensadores na presença de perturbações}

Citando novamente a Figura 3 do Capítulo 2, pode-se perceber um bloco de perturbação no diagrama de blocos. A idéia deste ensaio é simular a presença de perturbações no processo, para avaliar se os compensadores de atrito possuem bom desempenho sob esta condição.

\subsubsection{Comportamento dos compensadores quando o controlador PI da malha de vazão está mal-sintonizado}

Um último ensaio é o de sintonia do controlador PI da malha de vazão. Suponha que o próprio controlador esteja gerando oscilações na malha de vazão, e não o atrito. A idéia deste ensaio é verificar se, no caso de uma malha mal-sintonizada, os compensadores de atrito podem ajudar a diminuir as oscilações.

\subsubsection{Parâmetros do modelo da válvula com atrito}

Os diferentes compensadores são ensaiados em um modelo de válvula que pode assumir diferentes características de atrito, e também com a válvula real do 
ambiente HIL. Este trabalho se baseia em dois níveis de atrito, que são chamados de low (válvula com as gaxetas completamente soltas) e high (válvula com as gaxetas extremamente apertadas). Os parâmetros estimados dos coeficientes de atrito $F_{S}, F_{C}$ e $F_{V}$, para o nível de atrito low, foram obtidos em (ROMANO; GARCIA, 2008), assim como os parâmetros $m$ (massa da mola) e $k$ (constante elástica da mola). Já os parâmetros estimados dos coeficientes de atrito $F_{S}, F_{C}$ e $F_{V}$, para o nível de atrito high, foram obtidos em (UEHARA et al., 2008). Estes parâmetros são utilizados quando os ensaios são $100 \%$ simulados e também, é claro, no caso do ambiente HIL, com o compensador IOL, que recebe os parâmetros levantados, uma vez que o compensador $I O L$ possui dependência com relação aos parâmetros da válvula.

A seguir, na Tabela 1, estão listados os parâmetros para os dois níveis de atrito da válvula que será simulada neste trabalho.

Tabela 1: Parâmetros dos dois níveis de atrito na válvula

\begin{tabular}{|c|c|c|}
\hline Parâmetro & Low & High \\
\hline$A$ : área do diafragma $\left(\mathrm{m}^{2}\right)$ & 0,0445 & 0,0445 \\
\hline m: massa das partes móveis $(\mathrm{kg})$ & 1,60 & 1,60 \\
\hline$k$ : constante da mola $(\mathrm{N} / \mathrm{m})$ & $2,15^{*} 10^{5}$ & $2,15^{*} 10^{5}$ \\
\hline$F_{C}$ : coeficiente de atrito de Coulomb (N) & 152,70 & 537 \\
\hline$F_{s:}$ coeficiente de stiction $(\mathrm{N})$ & 152,70 & 609,5 \\
\hline$F_{v}$ : coeficiente de atrito viscoso $(\mathrm{Ns} / \mathrm{m})$ & 4865 & $2,10^{*} 10^{4}$ \\
\hline$v_{s}:$ velocidade de Stribeck $(\mathrm{m} / \mathrm{s})$ & $2,54^{*} 10^{-4}$ & $2,54^{*} 10^{-4}$ \\
\hline
\end{tabular}

Para cada um dos níveis de atrito listados anteriormente, são realizados os ensaios de degrau no valor de referência, comportamento dos compensadores na presença de perturbações na malha e ensaios para avaliar o comportamento dos compensadores quando o controlador PI da malha de vazão estiver mal-sintonizado. 


\subsubsection{Implementação dos compensadores}

Seguindo adiante com o procedimento proposto, já se definiu até o presente momento os tipos de ensaio (degrau, perturbação e má-sintonia do controlador) e qual os níveis de atrito ensaiados. Além disso, já estava previamente definido o modelo da planta (vazão) e do controlador de processo ( $\mathrm{PI})$. O próximo passo é a implementação do modelo dos compensadores no ambiente Matlab/Simulink ${ }^{\circledR}$.

Uma vez implementados os compensadores em linguagem de programação do Matlab/Simulink ${ }^{\circledR}$, cada um deles é incluído no modelo de malha fechada de vazão representado na Figura 3. A estrutura do modelo da malha fechada de vazão ensaiada, incluindo agora os modelos dos compensadores, é ilustrada na Figura 11.

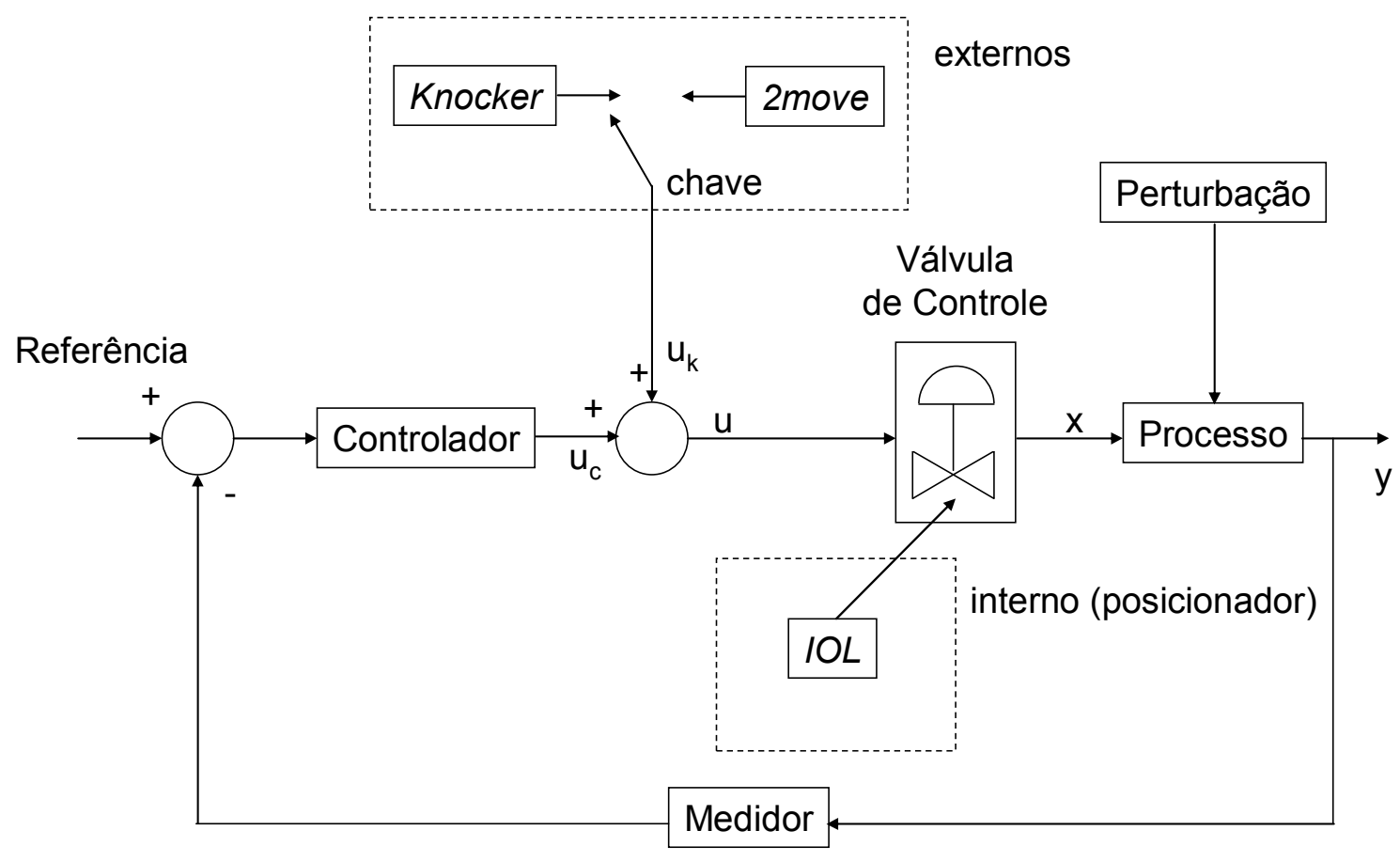

Figura 11: Malha Fechada de Vazão, incluindo os compensadores de atrito

A análise da Figura 11 aponta para alguns aspectos que ainda não haviam sido comentados neste trabalho. Tanto o compensador Knocker quanto o compensador 2move são considerados compensadores do tipo externo, ou seja, são compensadores que adicionam um sinal à saída do controlador da planta, para tentar compensar os efeitos do atrito. Os compensadores externos podem, portanto ser implementados no ambiente controle de uma planta real, ou seja, no software de programação do $P L C$ ou do DCS da planta, o que é muito interessante do ponto de vista de plantas reais. 
Por outro lado, o IOL é um compensador do tipo interno, ou seja, deve ser implementado internamente, no posicionador da válvula de controle. Os resultados obtidos com este compensador por (KAIYAHAN, DOYLE III, 2000) foram muito bons, mas o fato dele ser do tipo interno o torna uma opção um pouco difícil de ser implementada nas plantas reais, já que exigiria que os fabricantes de posicionadores modificassem o software interno destes equipamentos, de forma a possibilitar a sua implementação.

\subsubsection{Execução dos ensaios}

Neste ponto, já é possível executar os ensaios da malha fechada de vazão com compensação de atrito. O único cuidado a ser tomado nesta etapa é a escolha do passo de integração do algoritmo computacional do Simulink ${ }^{\circledR}$, pois um passo muito grande pode causar perdas de informações importantes do ensaio, principalmente o efeito do slip-jump gerado pelo atrito estático, enquanto que um passo muito pequeno pode gerar ensaios demasiadamente demorados.

\subsubsection{Ferramentas gráficas de análise dos dados gerados}

Ao final dos ensaios, diversos dados estão disponíveis para análise. Os dados são inicialmente analisados graficamente. O principal gráfico analisado é aquele que representa a saída da planta de vazão com relação ao sinal de referência.

\subsubsection{Ferramentas matemáticas de análise de desempenho}

A análise gráfica dos dados obtidos indica visualmente qual a melhora de desempenho obtida a partir do acionamento dos compensadores. Entretanto, para quantificar esta melhoria, utiliza-se uma ferramenta matemática para avaliar a melhoria de desempenho da malha após a inclusão do compensador. A ferramenta utilizada neste trabalho é a Integral do Erro Quadrático (ISE). A idéia é comparar o valor encontrado de ISE para o controlador PI da malha de vazão sem compensação com os valores obtidos de ISE para cada um dos três compensadores implementados, obtendo-se então uma relação de melhoria de controle atingida a partir do acionamento do compensador. 


\subsubsection{Variações na posição da haste da válvula}

Este trabalho está baseado tanto em um ambiente 100\% simulado, quanto em um ambiente híbrido, o HIL. Pode-se encarar o HIL como algo bem mais próximo de um processo real, já que a válvula é real. Pensando nisso, também é analisada qual a quantidade de movimentação introduzida por cada um dos compensadores de atrito na haste da válvula, para verificar até que ponto as técnicas podem ser aplicadas em processos industriais reais. Para isso, são mostrados gráficos que indicam a posição da haste da válvula com relação ao tempo. 


\section{CAPÍTULO 4. RESULTADOS DOS ENSAIOS}

No capítulo anterior, os três compensadores de atrito foram descritos detalhadamente. Também foram descritos os tipos de ensaios realizados com os compensadores.

Neste capítulo, os compensadores descritos anteriormente são implementados no ambiente Matlab/Simulink ${ }^{\circledR}$. Os diversos ensaios propostos anteriormente são realizados e os resultados obtidos são apresentados.

\subsection{Ensaios em degrau no valor de referência}

O primeiro ensaio realizado é o ensaio em degrau no valor de referência. Este ensaio, assim como os demais, é realizado tanto no ambiente $100 \%$ simulado quanto no ambiente HIL. Em cada ensaio realizado, são apresentados e analisados os resultados gráficos da saída da planta de vazão com relação ao sinal de referência.

\subsubsection{Ensaios em degrau sem o uso dos compensadores de atrito}

Os ensaios realizados no ambiente $100 \%$ simulado têm as seguintes características em comum:

- Duração de simulação = 200 segundos;

- Passo de integração $=10^{-5}$ segundos;

- Decimação dos pontos = 100;

- Instante do degrau = 50 segundos;

- Amplitude do degrau $=5 \%$ do valor de referência.

Com relação ao controlador PI da malha de vazão, a sintonia utilizada durante as simulações e considerada a sintonia que estabiliza a malha é a seguinte:

- Ganho do controlador $\left(K_{c}\right)=1,115$;

- Tempo integral do controlador $\left(T_{i}\right)=1,93 \mathrm{~s} / \mathrm{rep}$

Uma vez definidas as características acima, o primeiro ensaio realizado é o ensaio em degrau no ambiente $100 \%$ simulado, sem compensador de atrito, na 
válvula com níveis de atrito low e high. A Figura 12 mostra o resultado do ensaio em degrau para os dois níveis de atrito, com relação ao valor de referência:

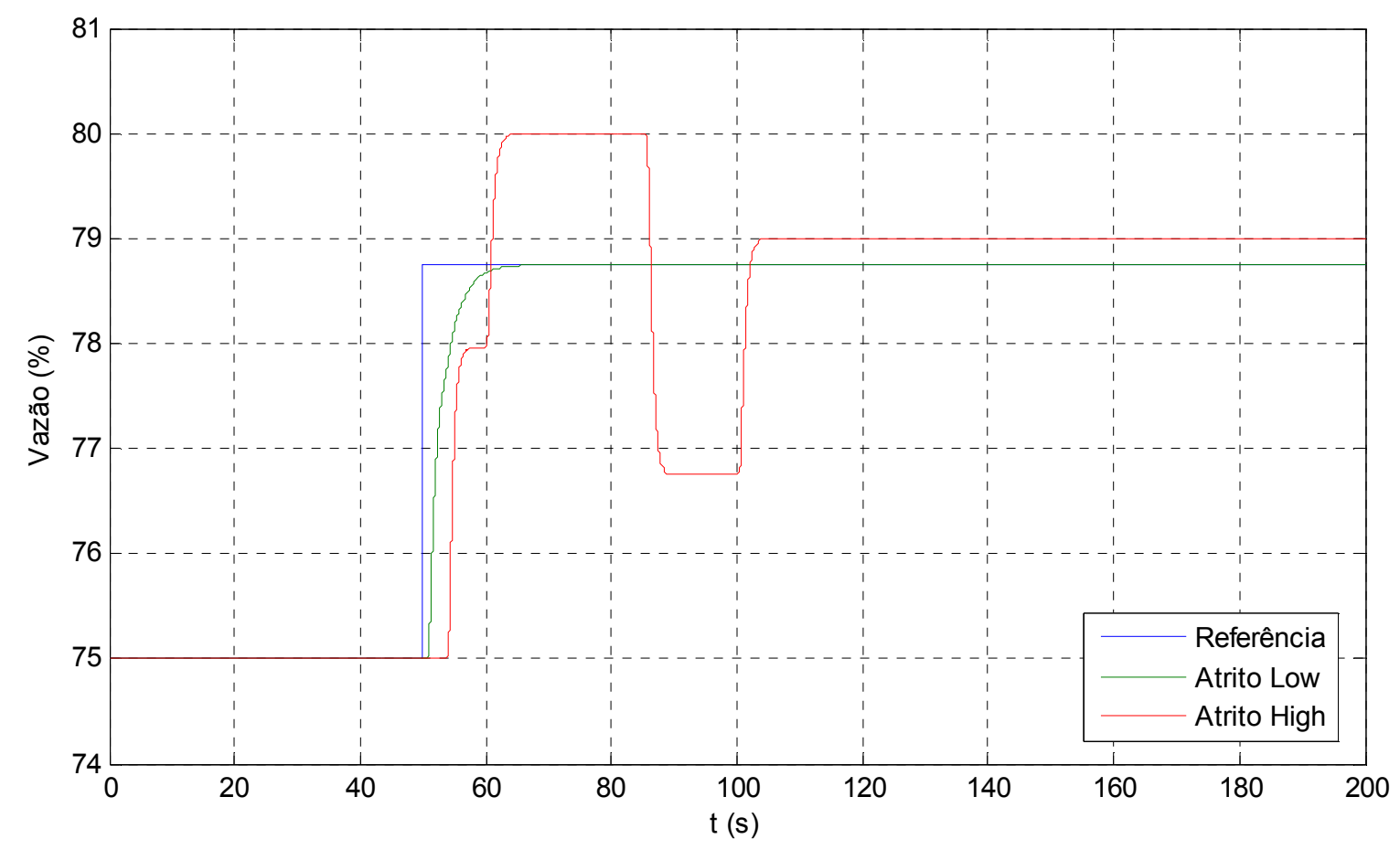

Figura 12: Resposta ao degrau, sem compensadores, ambiente $100 \%$ simulado

A análise do gráfico da Figura 12 indica que, no ambiente $100 \%$ simulado, o próprio compensador PI da malha de vazão é capaz de levar a vazão da malha ao valor de referência solicitado apenas para o nível de atrito low, o que não ocorre para o nível de atrito high. Outra característica que fica clara na Figura 12 é que, para os dois níveis de atrito, a resposta do sistema apresenta uma demora na resposta, sendo esta demora muito maior para o nível de atrito high.

Uma comparação interessante a ser feita é o comportamento da resposta ao degrau, sem compensadores, no ambiente HIL. O resultado desta simulação é mostrado a seguir, na Figura 13: 


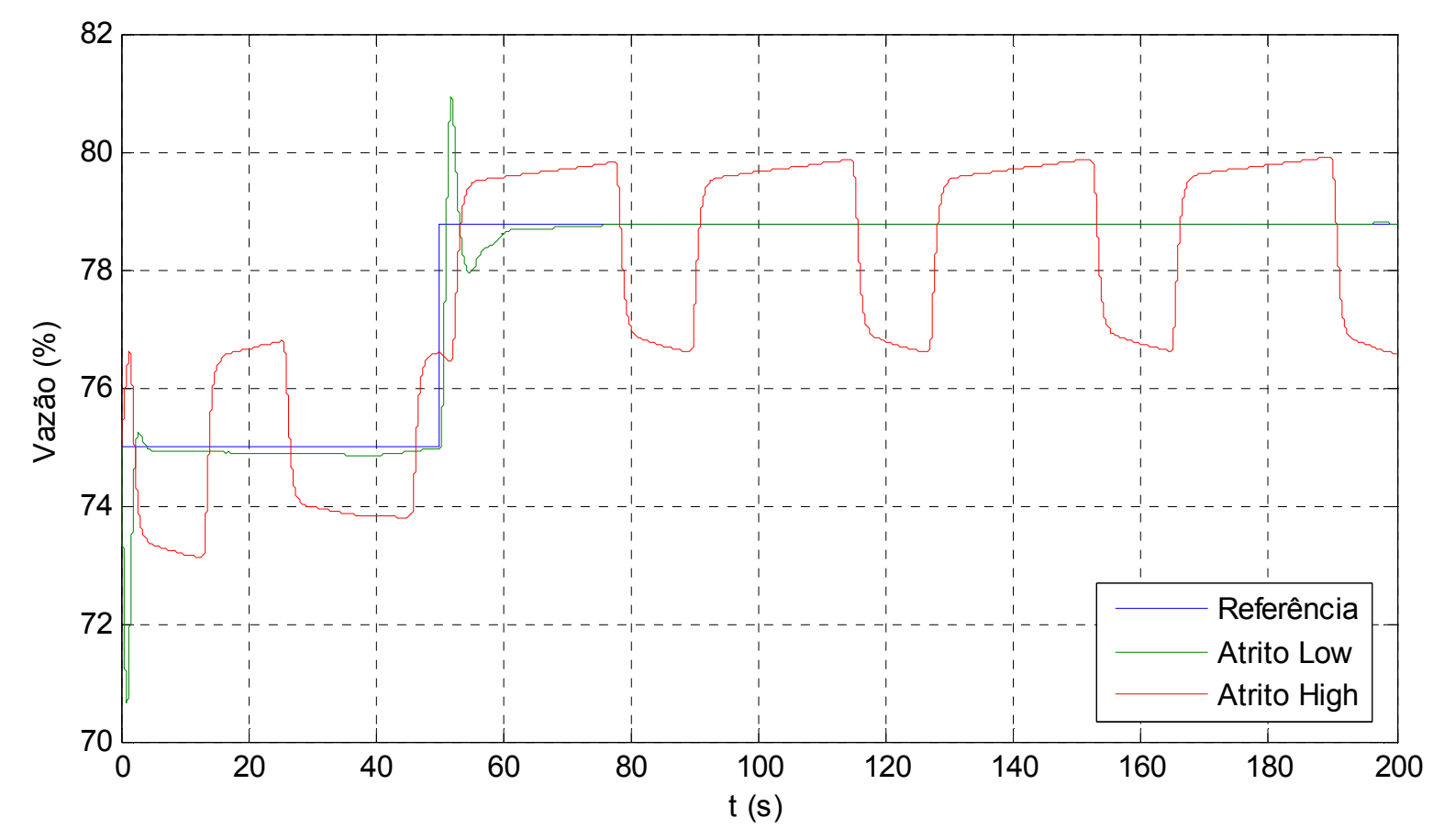

Figura 13: Resposta ao degrau, sem compensadores, ambiente HIL

O resultado obtido no ambiente HIL, para a malha sem compensador de atrito, mostra que, principalmente para o nível de atrito high, o sistema oscila, muito provavelmente devido à presença de atrito estático, fazendo com que o controlador PI de vazão não seja capaz de estabilizar a malha. Por outro lado, no caso do nível de atrito low, é possível notar que o controlador PI de vazão consegue estabilizar a malha. Desta forma, pode-se dizer que os resultados encontrados no ambiente $100 \%$ simulado ficaram próximos dos resultados do ambiente HIL. Com relação à demora na resposta, no nível de atrito low, no ambiente simulado esta demora foi maior do que no ambiente HIL. Com relação à demora na resposta do nível de atrito high, pode-se dizer o mesmo: ela foi maior no ambiente simulado no que no ambiente HIL.

As diferenças de resultados obtidos entre o ambiente simulado e o ambiente HIL, ainda que pequenas, mostram como é importante a utilização de equipamentos reais nos ensaios.

\subsubsection{Ensaios em degrau com o uso de compensador de atrito $I O L$}

Os ensaios realizados no item anterior mostraram que, no caso de atrito high, sem compensador de atrito, no ambiente HIL, a malha apresenta comportamento 
oscilatório. Nos próximos itens, é feita a análise do comportamento da malha para cada um dos três compensadores estudados neste trabalho, começando pelo IOL.

Antes de qualquer coisa, os parâmetros $k 0$ e $k 1$ do controlador interno do $I O L$ precisam ser definidos. A escolha destes parâmetros foi feita através de tentativa e erro, uma vez que no trabalho de (SILVA, 2003) não é mencionada nenhum técnica para realizar esta sintonia. Devido aos erros de modelagem, adotaram-se sintonias diferentes para o ambiente $100 \%$ simulado e para o ambiente $H I L$, de forma que as respostas obtidas com os ensaios nos dois ambientes fossem próximas. Por outro lado, a sintonia foi a mesma caso se considere o nível de atrito por ensaio. A seguir, na Tabela 2, são apresentados os valores de $k 0$ e $k 1$ para cada um dos ambientes de simulação:

Tabela 2: Parâmetros de sintonia do controlador interno do $I O L$

\begin{tabular}{|l|c|c|}
\hline Ambiente de simulação & $\boldsymbol{k} \mathbf{0}$ & $\boldsymbol{k} \mathbf{1}$ \\
\hline Ambiente $100 \%$ simulado & $2 * 10^{5}$ & $10^{5}$ \\
\hline Ambiente HIL & $2,5^{*} 10^{5}$ & $10^{4}$ \\
\hline
\end{tabular}

Uma vez definidos os parâmetros $k 0$ e $k 1$ do compensador $I O L$, o próximo passo é a análise gráfica dos resultados obtidos através da utilização do compensador.

A seguir, na Figura 14, é ilustrada a resposta a degrau do sistema, em ambiente $100 \%$ simulado, quando o compensador $I O L$ é utilizado, comparada com a resposta do sistema sem a presença de compensador, para o nível de atrito low, no ambiente $100 \%$ simulado. 


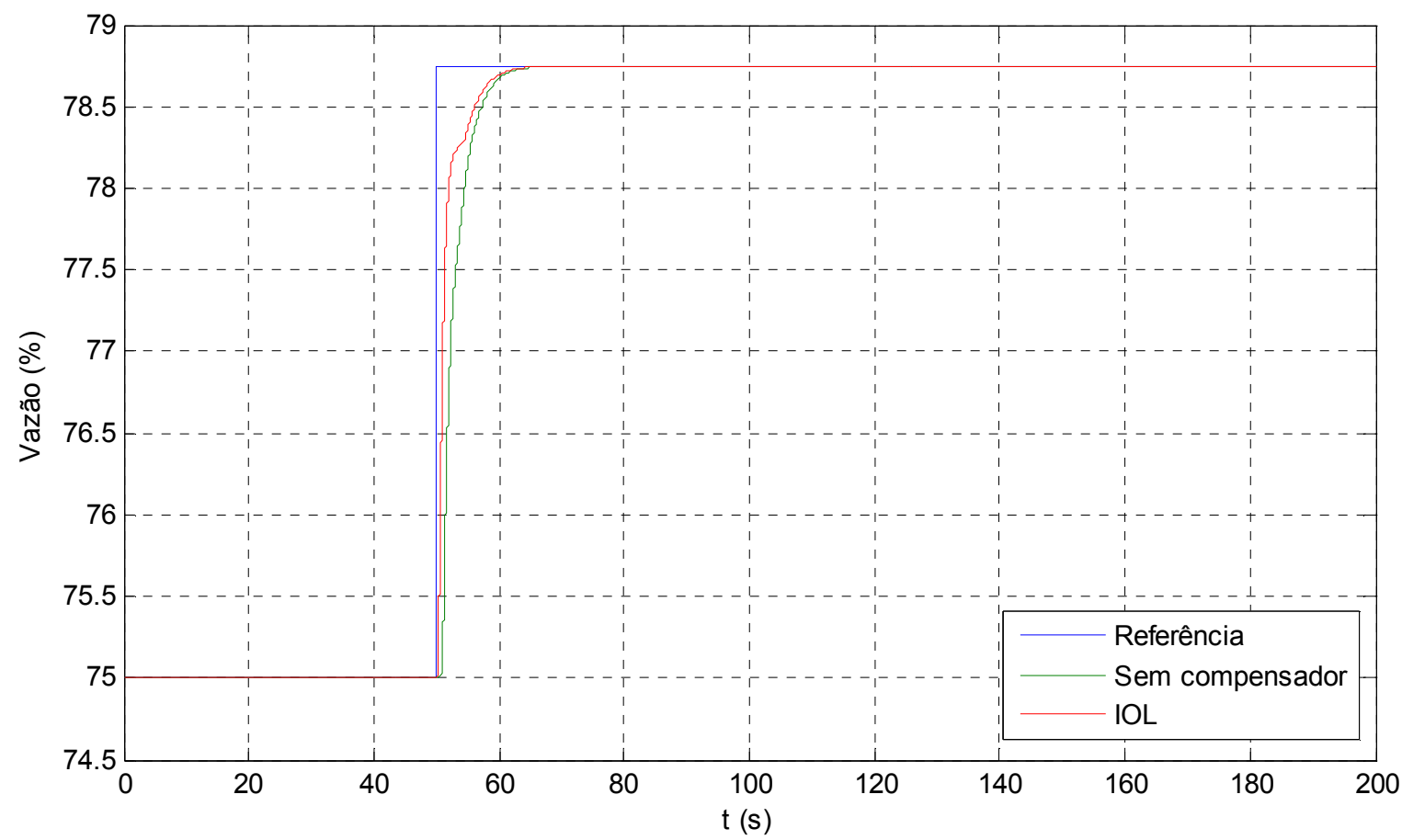

Figura 14: Compensador $I O L$ x sem compensador, atrito low, $100 \%$ simulado, degrau

A análise da Figura 14 indica que, para o nível de atrito low, não existe uma melhora muito significativa quando o compensador $I O L$ é utilizado. A única melhora existente, e que é praticamente imperceptível no gráfico, é a diminuição da demora da resposta. Para este nível de atrito, tanto o ensaio sem compensador quanto o ensaio com o IOL não apresentaram sobressinal na resposta.

A seguir, na Figura 15, apresentam-se os resultados obtidos no HIL, para nível de atrito low: 


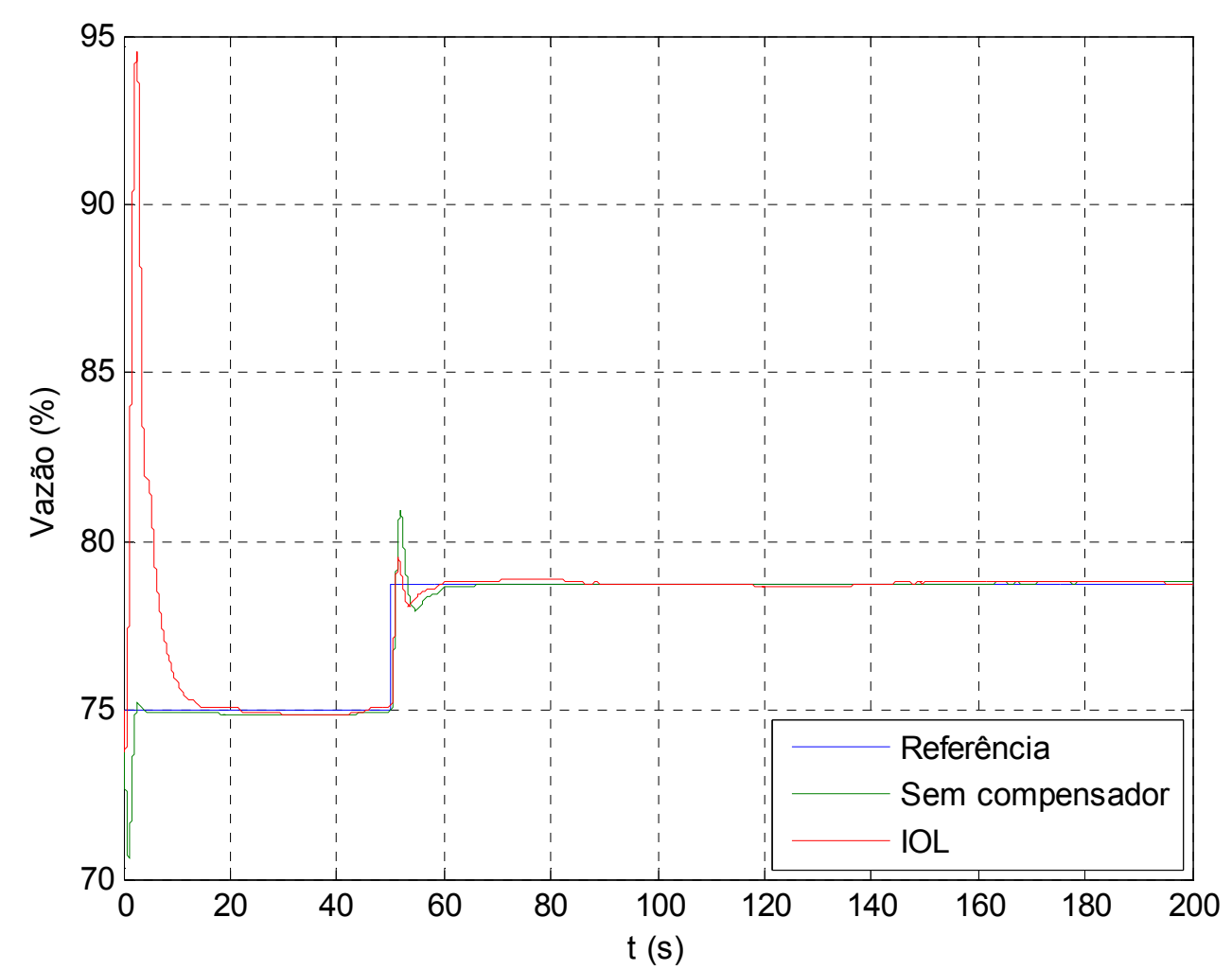

Figura 15: Compensador IOL x sem compensador, atrito low, HIL, degrau

Analisando-se a Figura 15, é possível perceber que no ambiente HIL, tanto na presença quanto na ausência do compensador, ocorre um pico no início do ensaio. Isto acontece porque as condições iniciais do HIL não estavam bem ajustadas, gerando este comportamento inicial do sistema.

No instante $t=50 \mathrm{~s}$, o sistema está praticamente estabilizado em torno da condição inicial de processo. Neste instante, o degrau de $5 \%$ no sinal de referência é aplicado. Pode-se notar, através da Figura 15 que, no ambiente HIL, a resposta do sistema, tanto no sistema com compensador quanto no sistema sem compensador, é estável, ou seja, a variável de processo consegue atingir o valor de referência. A grande diferença que se pode observar entre o sistema sem compensador e o sistema com compensador neste ensaio é o valor do sobressinal, que é menor quando o compensador é utilizado.

Os próximos ensaios, ilustrados nas Figuras 16 e 17, mostram os resultados obtidos com o uso do compensador IOL, no ambiente $100 \%$ e no ambiente HIL respectivamente, para o nível de atrito high. 


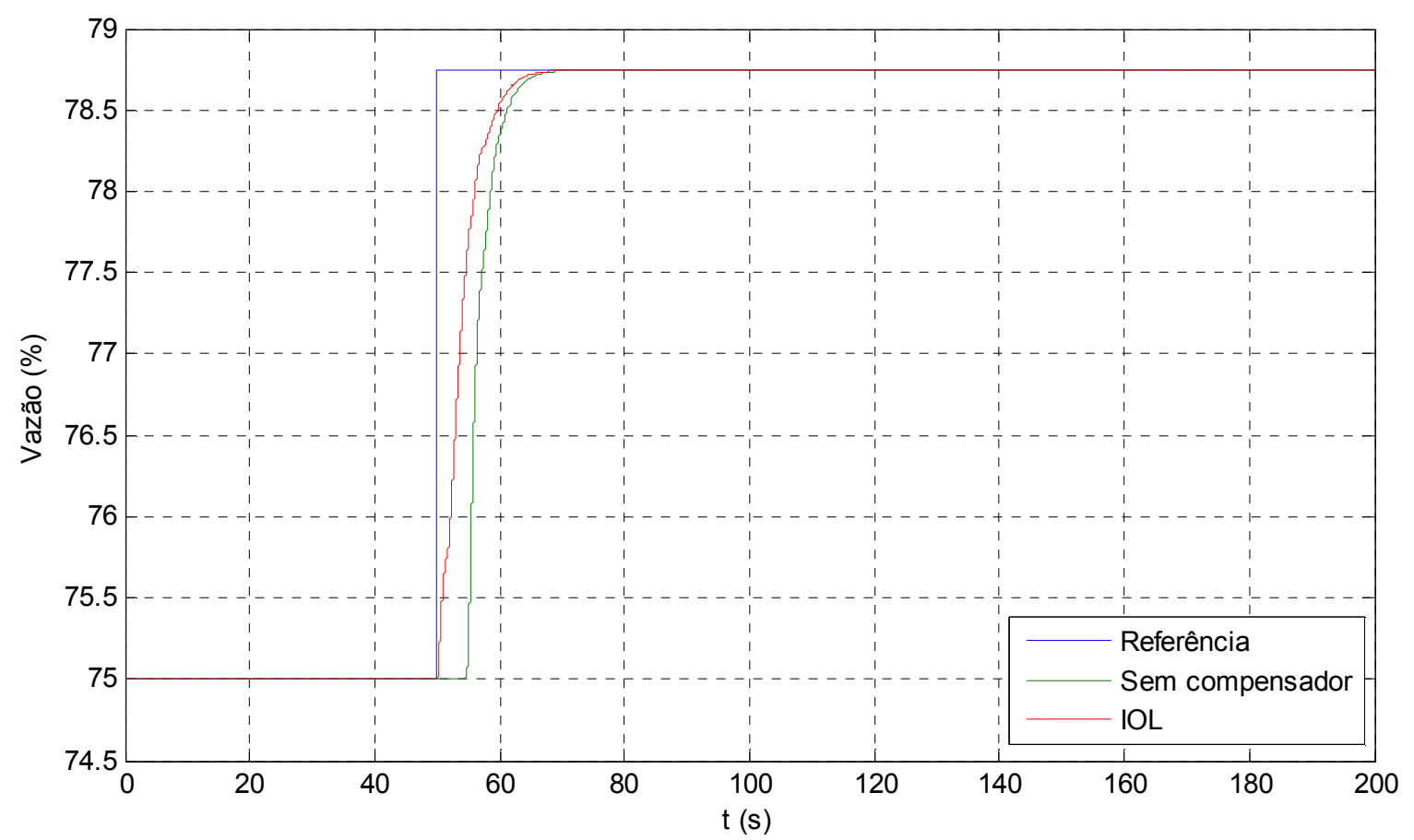

Figura 16: Compensador IOL x sem compensador, atrito high, $100 \%$ simulado, degrau

Conforme mostrado anteriormente, no ensaio em ambiente 100\% simulado, com nível de atrito high, o controlador PI da malha de vazão não era capaz de levar o valor da variável de processo ao valor de referência. Além disso, a resposta da malha apresentava uma demora considerável.

Com a utilização do compensador de atrito $I O L$ neste caso, é possível verificar que a resposta do sistema ao degrau é imediata, eliminando praticamente a demora da resposta, o que indica uma clara melhoria na resposta da malha quando o compensador é utilizado. Além disso, as oscilações são eliminadas.

Na Figura 17, é ilustrado o comportamento do sistema no ambiente $H I L$, para o nível de atrito high. 


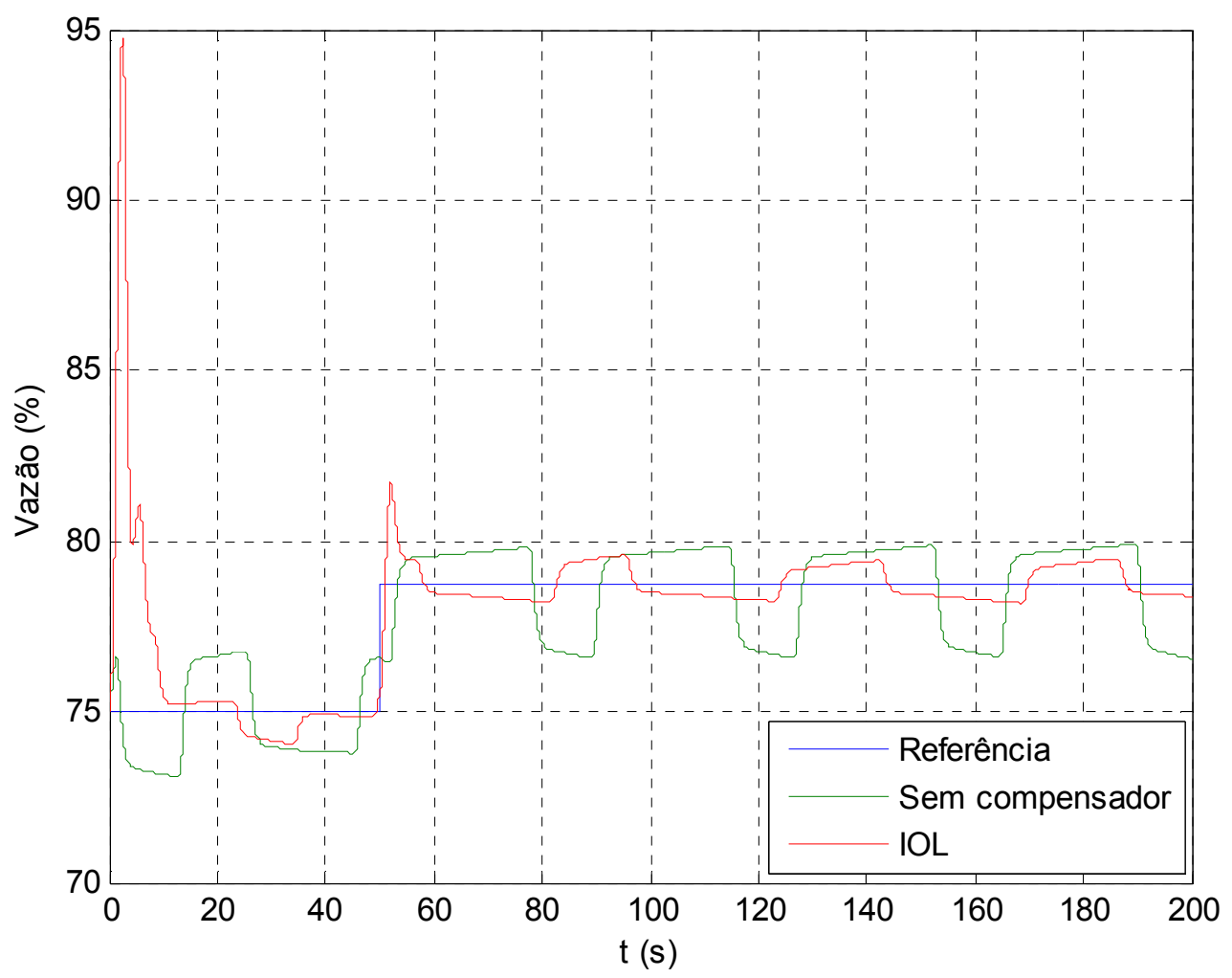

Figura 17: Compensador IOL x sem compensador, atrito high, HIL, degrau

Assim como ocorreu para o nível da atrito low, na simulação com nível de atrito high o ambiente HIL, por não estar com as condições iniciais bem ajustadas, apresenta um pico no início dos ensaios.

Com relação à resposta do sistema no ambiente HIL, para o nível de atrito high, pode-se observar na Figura 17 que, na ausência de compensador, a resposta em malha fechada do sistema apresenta comportamento muito oscilatório, indicando que o controlador PI da malha de vazão não é suficiente para levar a variável de processo ao valor de referência. Por outro lado, com a utilização do compensador $I O L$, as oscilações permanecem, mas com amplitude bem menor, fazendo com que a variável de processo fique por mais tempo próxima do valor de referência. Desta forma, pode-se dizer que a resposta do sistema em malha fechada ficou bem melhor com a presença do compensador IOL.

Por tudo que foi apresentado neste item, pode-se concluir que o compensador $I O L$, tanto no ambiente $100 \%$ simulado quanto no ambiente HIL, consegue melhorar o desempenho da malha de vazão. 


\subsubsection{Ensaios em degrau com o uso de compensador de atrito Knocker}

O próximo compensador avaliado no ensaio em degrau é o Knocker. Antes de qualquer coisa, assim como foi feito para o compensador $I O L$, os parâmetros de sintonia do compensador Knocker precisam ser apresentados. Novamente pode ser observado que a sintonia utilizada no ambiente $100 \%$ simulado é diferente da sintonia utilizada no ambiente HIL. Ao contrário do que aconteceu na sintonia do compensador $I O L$, os parâmetros de sintonia variam tanto entre os tipos de ensaio (100\% simulado e $H I L)$ quanto entre os níveis de atrito (low e high). A seguir, na Tabela 3, são apresentados os valores de $a, \tau$ e $h_{k}$ para cada uma das condições simuladas.

Tabela 3: Parâmetros de sintonia do compensador Knocker

\begin{tabular}{|c|c|c|c|c|}
\hline Parâmetro & $\begin{array}{c}100 \% \text { simulado } \\
\text { Low }\end{array}$ & $\begin{array}{c}100 \% \text { simulado } \\
\text { High }\end{array}$ & $\begin{array}{l}\text { HIL } \\
\text { Low }\end{array}$ & $\begin{array}{l}\text { HIL } \\
\text { High }\end{array}$ \\
\hline$A$ & 0,5 & 1 & 0,7 & 4 \\
\hline$\tau$ & $0,5 \mathrm{~s}$ & $4 \mathrm{~s}$ & $2 \mathrm{~s}$ & $1 \mathrm{~s}$ \\
\hline$h_{k}$ & $0,25 \mathrm{~s}$ & $2 \mathrm{~s}$ & $1 \mathrm{~s}$ & $0,5 \mathrm{~s}$ \\
\hline
\end{tabular}

Os parâmetros de sintonia do compensador Knocker foram obtidos seguindo-se basicamente os critérios propostos por (HÄGGLUND, 2002). Estes critérios indicam uma espécie de roteiro a ser seguido para a sintonia do compensador. Entretanto, a sintonia não é tão simples assim, e variou bastante entre os níveis de atrito e os ambientes de simulação, o que indica que não é possível utilizar uma sintoniapadrão para este compensador.

Uma vez definidos os parâmetros $a, \tau$ e $h_{k}$ do compensador Knocker, o próximo passo é a análise gráfica dos resultados obtidos a partir da utilização do compensador.

A seguir, na Figura 18, é ilustrada a resposta a degrau do sistema, em ambiente $100 \%$ simulado, quando o compensador Knocker é utilizado, comparada com a resposta do sistema sem a presença de compensador, para o nível de atrito low, no ambiente $100 \%$ simulado: 


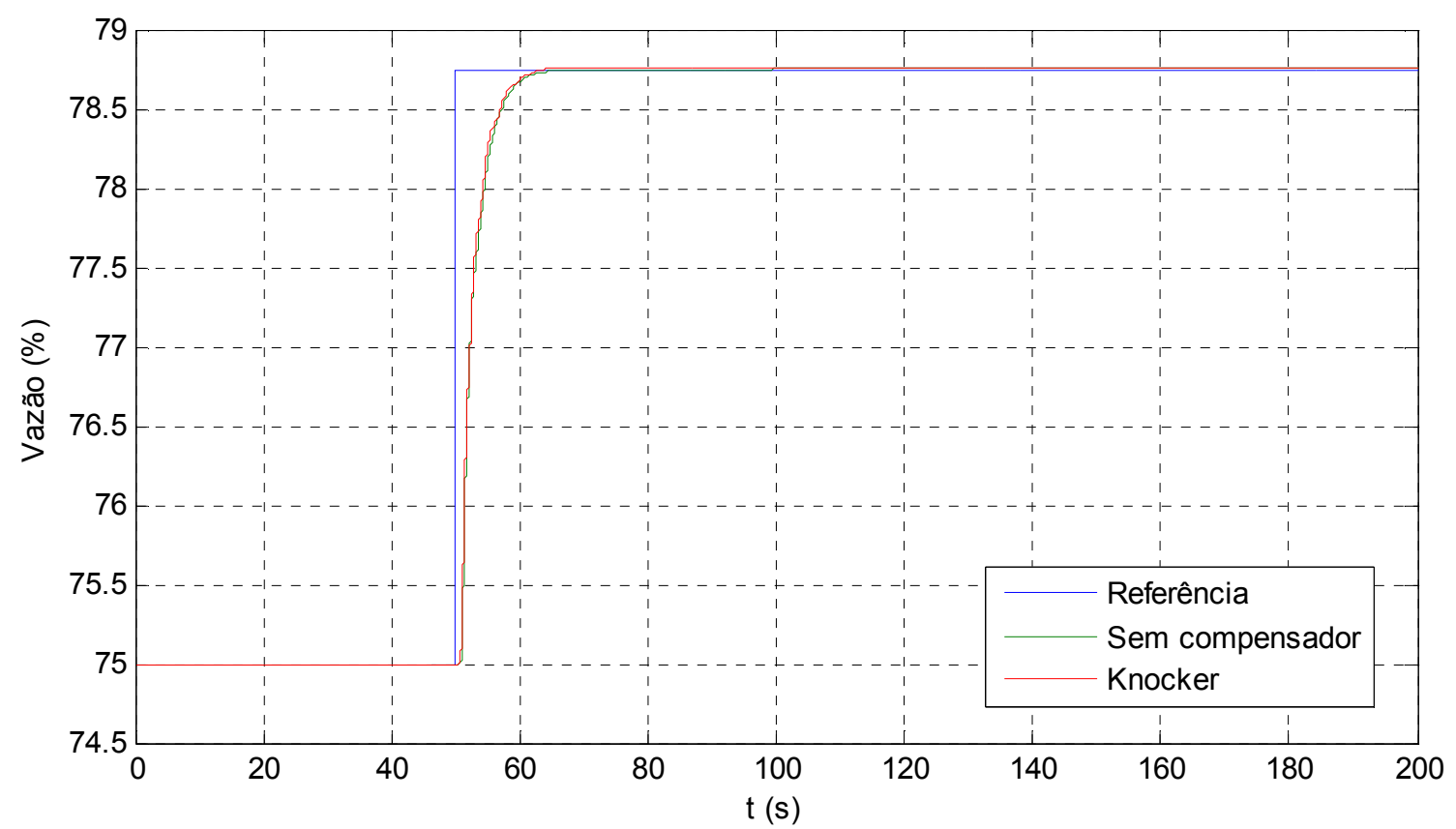

Figura 18: Compensador Knocker x sem compensador, atrito low, 100\% simulado, degrau

A análise da Figura 18 indica que não aconteceu nenhum melhora significativa quando se utilizou o compensador Knocker, no ambiente 100\% simulado, para nível de atrito low.

A seguir, na Figura 19, são apresentados os resultados obtidos no ambiente HIL, para nível de atrito low. 


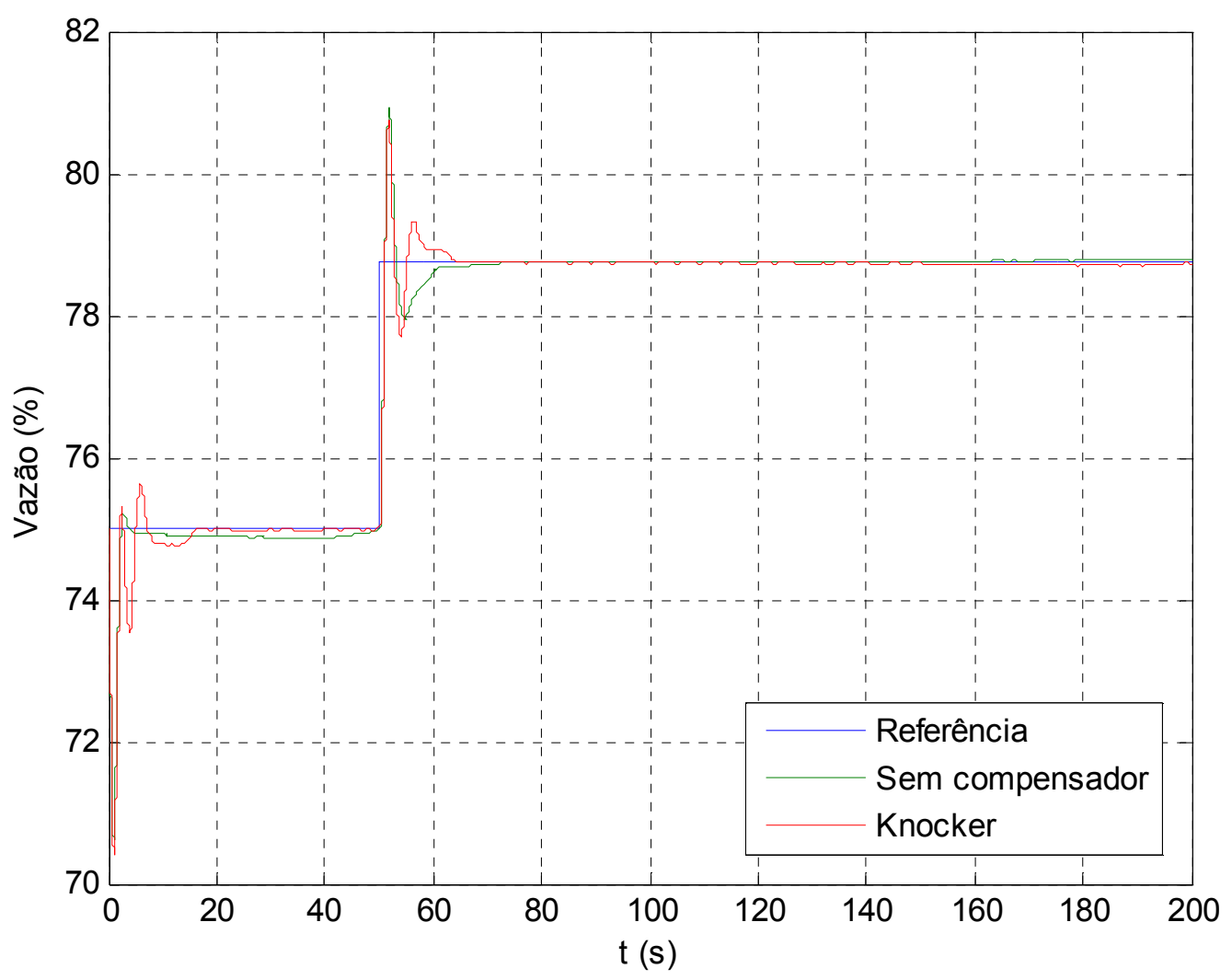

Figura 19: Compensador Knocker x sem compensador, atrito low, HIL, degrau

A análise da Figura 19 indica que, assim como o que foi observado no ambiente $100 \%$ simulado, o resultado obtido no ambiente $H I L$, para o nível de atrito low aponta uma melhora muito pequena na resposta do sistema quando o compensador Knocker é utilizado.

Além disso, pode-se dizer que, analisando-se somente as Figuras 18 e 19, não hoje melhora discernível com o uso do compensador Knocker, tanto no ambiente $100 \%$ simulado quanto no ambiente HIL, considerando-se o nível de atrito low.

O próximo ensaio avalia o comportamento do compensador Knocker, em ambiente $100 \%$ simulado, para o nível de atrito high. A Figura 20 a seguir ilustra os resultados obtidos neste ensaio. 


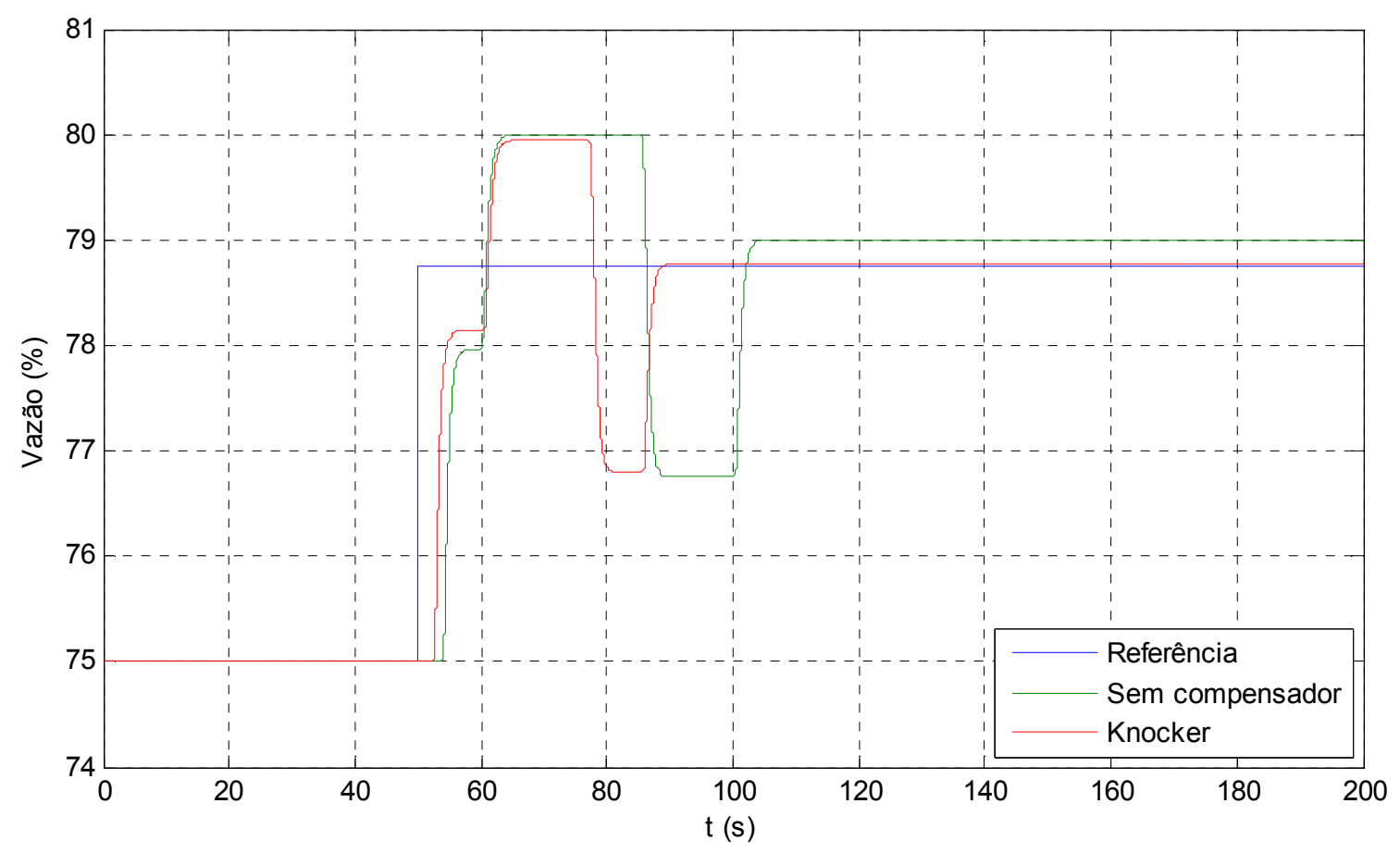

Figura 20: Compensador Knocker $\mathrm{x}$ sem compensador, atrito high, $100 \%$ simulado, degrau

A análise da Figura 20 indica que aconteceu uma pequena melhora com relação à demora da resposta quando se utilizou o compensador Knocker, no ambiente $100 \%$ simulado, para nível de atrito high. Outro resultado que pode ser observado é que a haste da válvula se movimenta antes do que ela se movimentaria na ausência do compensador. Além disso, graficamente, fica impossível determinar a presença de erro estacionário, indicando que ele foi praticamente eliminado.

Por fim, seguem, na Figura 21, os resultados obtidos para o ensaio do compensador Knocker, no ambiente HIL, com nível de atrito high. 


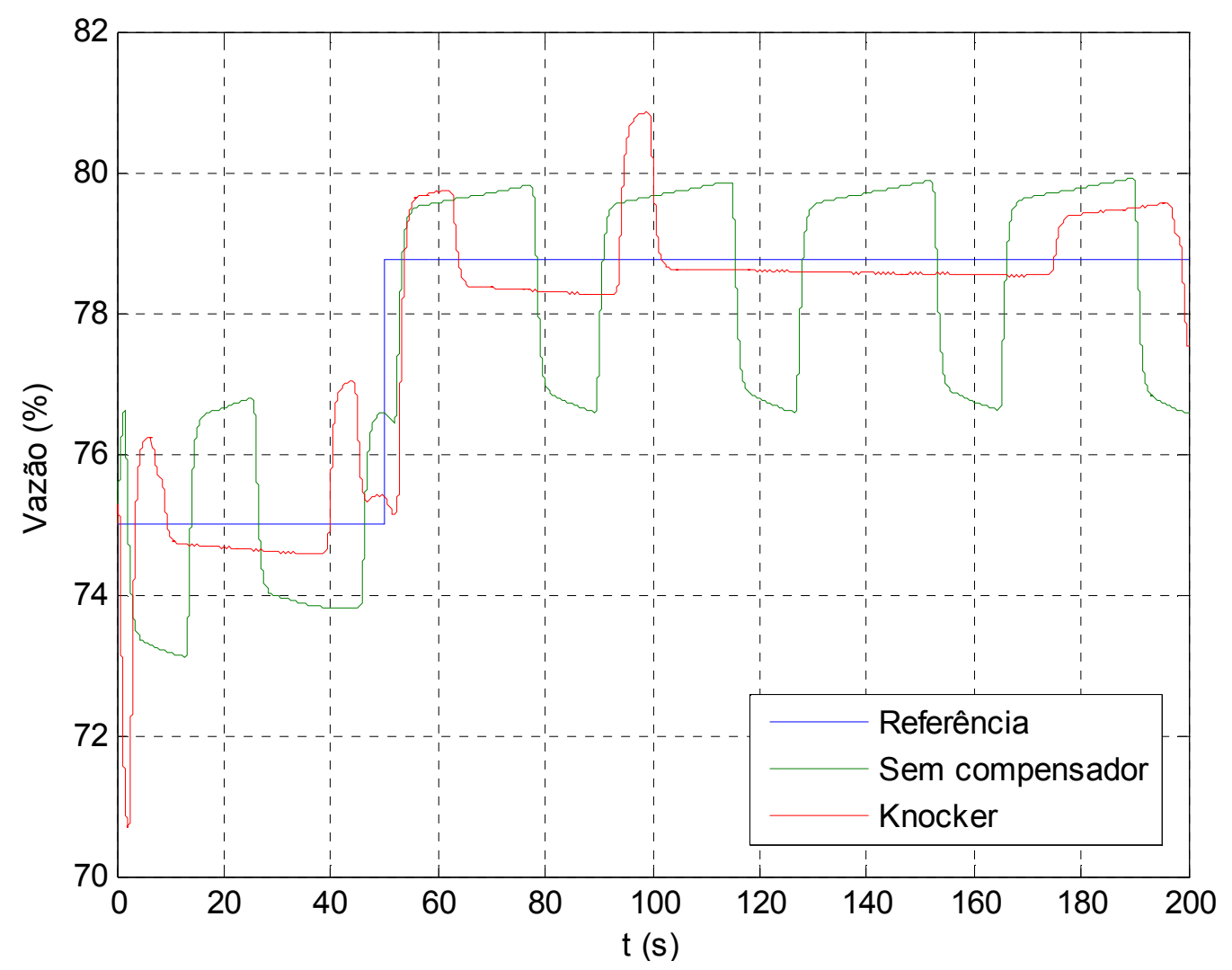

Figura 21: Compensador Knocker $x$ sem compensador, atrito high, HIL, degrau

A melhora obtida através do uso do compensador Knocker para o nível de atrito high é nítida no ambiente HIL, similar ao que foi observado no mesmo ensaio em ambiente $100 \%$ simulado.

Pelo que foi apresentado neste item, pode-se concluir que o compensador Knocker apresentou uma melhora significativa para o nível de atrito high.

\subsubsection{Ensaios em degrau com o uso de compensador de atrito 2 move}

O próximo compensador avaliado no ensaio em degrau é o 2 move. Este compensador é um pouco diferente dos compensadores apresentados até agora. Ao invés de possuir parâmetros, como o IOL e Knocker apresentam, o compensador 2 move possui basicamente duas escolhas a serem feitas: o instante do primeiro movimento e o instante do segundo movimento. Além disso, este compensador exige o conhecimento do nível estimado de atrito $d$. As diversas simulações realizadas mostraram que $d=0,2$ ou $20 \%$ foi um valor mais que suficiente, em todos os casos, para possibilitar que o compensador 2 move realizasse o primeiro movimento. 
Por outro lado, não se pode dizer o mesmo da escolha do instante de tempo em que os dois movimentos devem acontecer. $\mathrm{O}$ instante do primeiro movimento foi o mesmo para todos os ensaios. Já o instante do segundo movimento variou entre os ensaios para atrito low e atrito high, já que, quando se tentou manter o mesmo instante de tempo para o segundo movimento em todos os casos, verificou-se que o sistema não ficava estabilizado. Desta forma, adotaram-se, através de tentativa e erro, os valores apresentados na Tabela 4 de instante de tempo para os movimentos nos ensaios, lembrando que o compensador 2 move, assim como os compensadores anteriores, é acionado em $\mathrm{t}=70 \mathrm{~s}$.

Tabela 4: Instante dos movimentos do controlador 2 move

\begin{tabular}{|l|c|c|}
\hline Nível de atrito & Primeiro Movimento & Segundo Movimento \\
\hline Low & $70,02 \mathrm{~s}$ & $70,94 \mathrm{~s}$ \\
\hline High & $70,02 \mathrm{~s}$ & $70,50 \mathrm{~s}$ \\
\hline
\end{tabular}

A escolha do instante do segundo movimento se mostrou bastante difícil no ambiente HIL. Muitos ensaios foram realizados até obterem-se os valores acima. Os valores utilizados no ambiente HIL se mostraram válidos no ambiente $100 \%$ simulado, e por isso foram mantidos.

Uma vez definidos os instantes dos movimentos do compensador 2 move, o próximo passo é a análise gráfica dos resultados obtidos a partir da utilização do compensador.

A seguir, na Figura 22, é ilustrada a resposta a degrau do sistema, em ambiente $100 \%$ simulado, quando o compensador 2move é utilizado, comparada com a resposta do sistema sem a presença de compensador, para o nível de atrito low. 


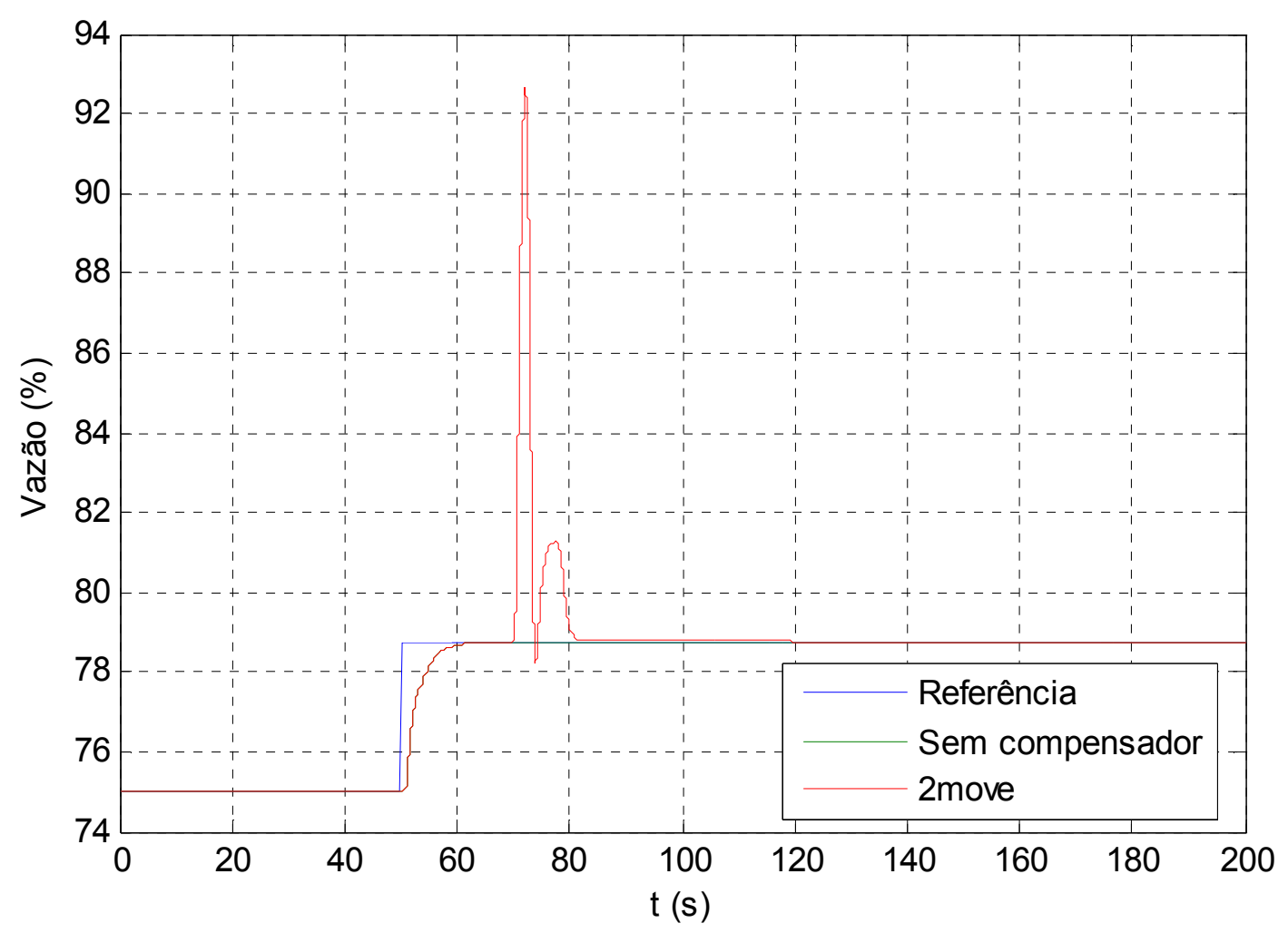

Figura 22: Compensador 2 move x sem compensador, atrito low, $100 \%$ simulado, degrau

A análise da Figura 22 indica que a utilização do compensador 2 move para nível de atrito low em ambiente 100\% simulado gera uma oscilação momentânea na resposta da planta. Como o próprio controlador PI da malha de vazão já é suficiente para estabilizar a planta neste ensaio, a utilização do compensador não se justifica, já que a resposta fica inclusive pior quando o compensador é acionado.

A seguir, na Figura 23, são apresentados os resultados obtidos no ambiente $H I L$, para nível de atrito low. 


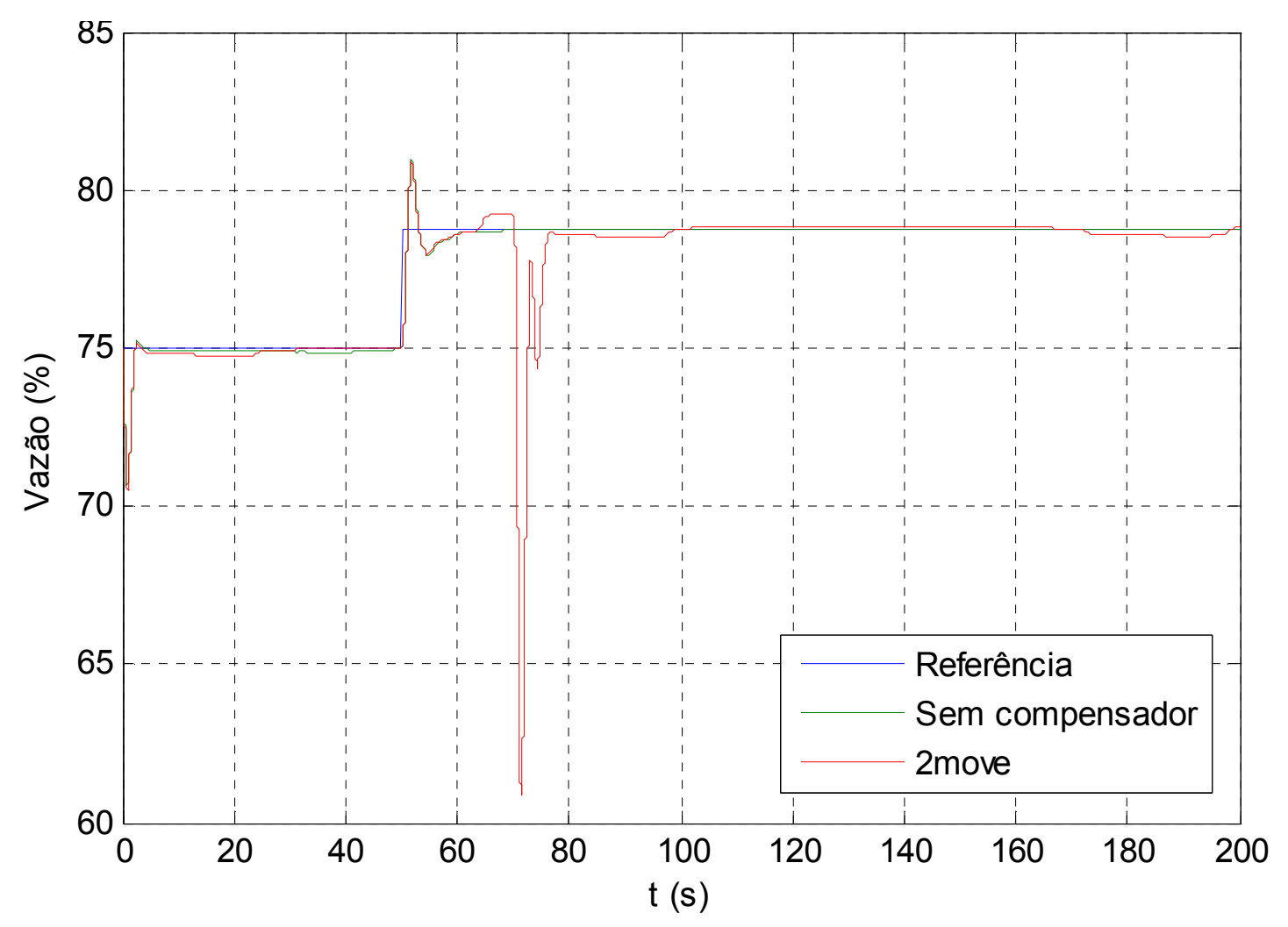

Figura 23: Compensador $2 m o v e x$ sem compensador, atrito low, HIL, degrau

A análise da Figura 23 indica que, assim como o que foi observado no ambiente $100 \%$ simulado, o resultado obtido no ambiente $H I L$, para o nível de atrito low é pior quando o compensador 2 move é utilizado.

O próximo ensaio avalia o comportamento do compensador $2 m o v e$, em ambiente 100\% simulado, para o nível de atrito high. A Figura 24 a seguir ilustra os resultados obtidos neste ensaio. 


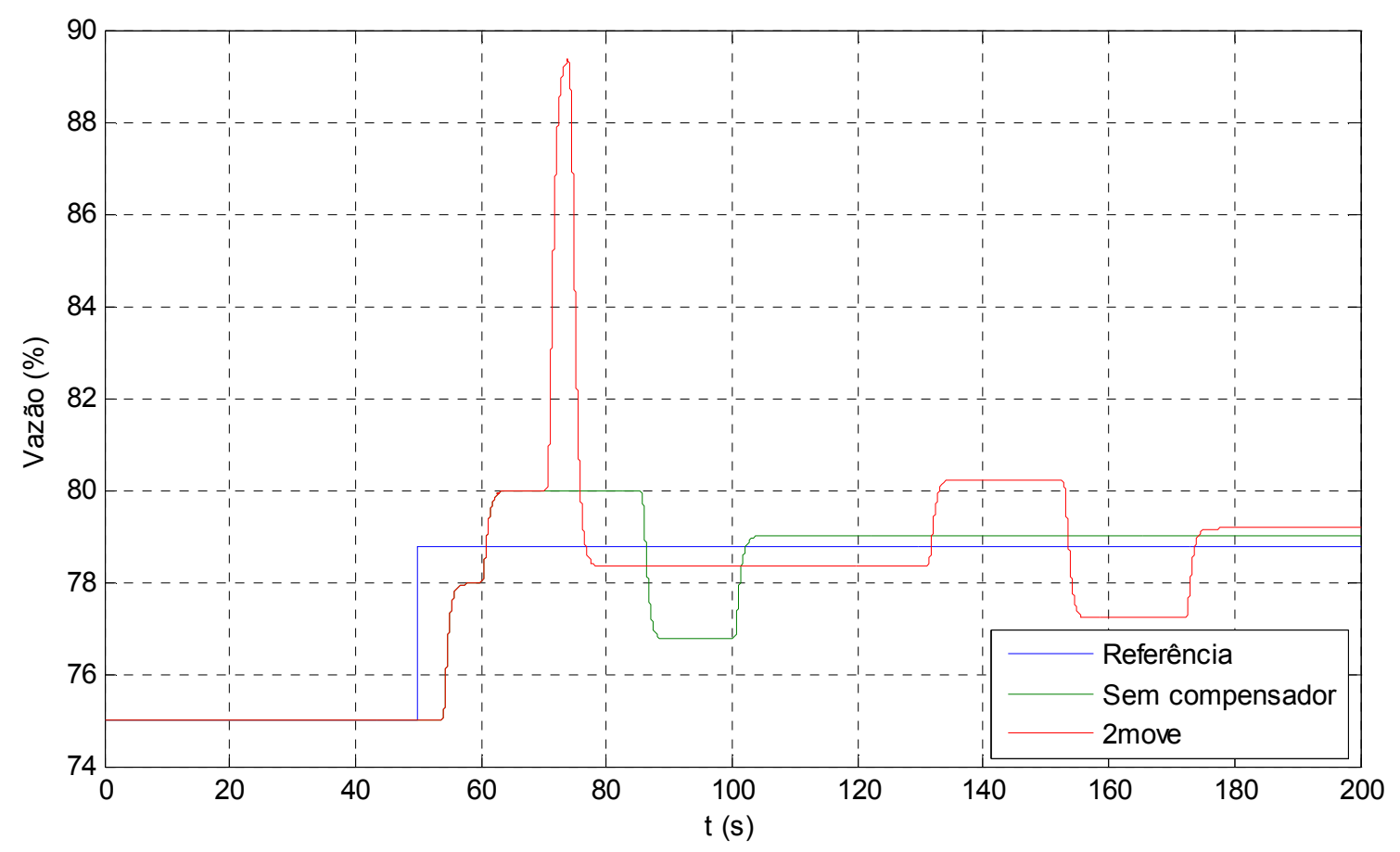

Figura 24: Compensador 2 move $x$ sem compensador, atrito high, $100 \%$ simulado, degrau

A análise da Figura 24 indica que, assim como ocorreu para o nível de atrito low, a utilização do compensador 2 move em ambiente $100 \%$ simulado gera uma oscilação momentânea na resposta da planta. Ao contrário do que foi observado neste ensaio, com nível de atrito low, o compensador 2move não é eficiente em estabilizar a resposta do sistema. Além disso, a resposta do sistema apenas com o controlador PI da malha de vazão é melhor do que a resposta quando o compensador é acionado.

Por fim, seguem, na Figura 25, os resultados obtidos para o ensaio do compensador 2 move, no ambiente HIL, com nível de atrito high: 


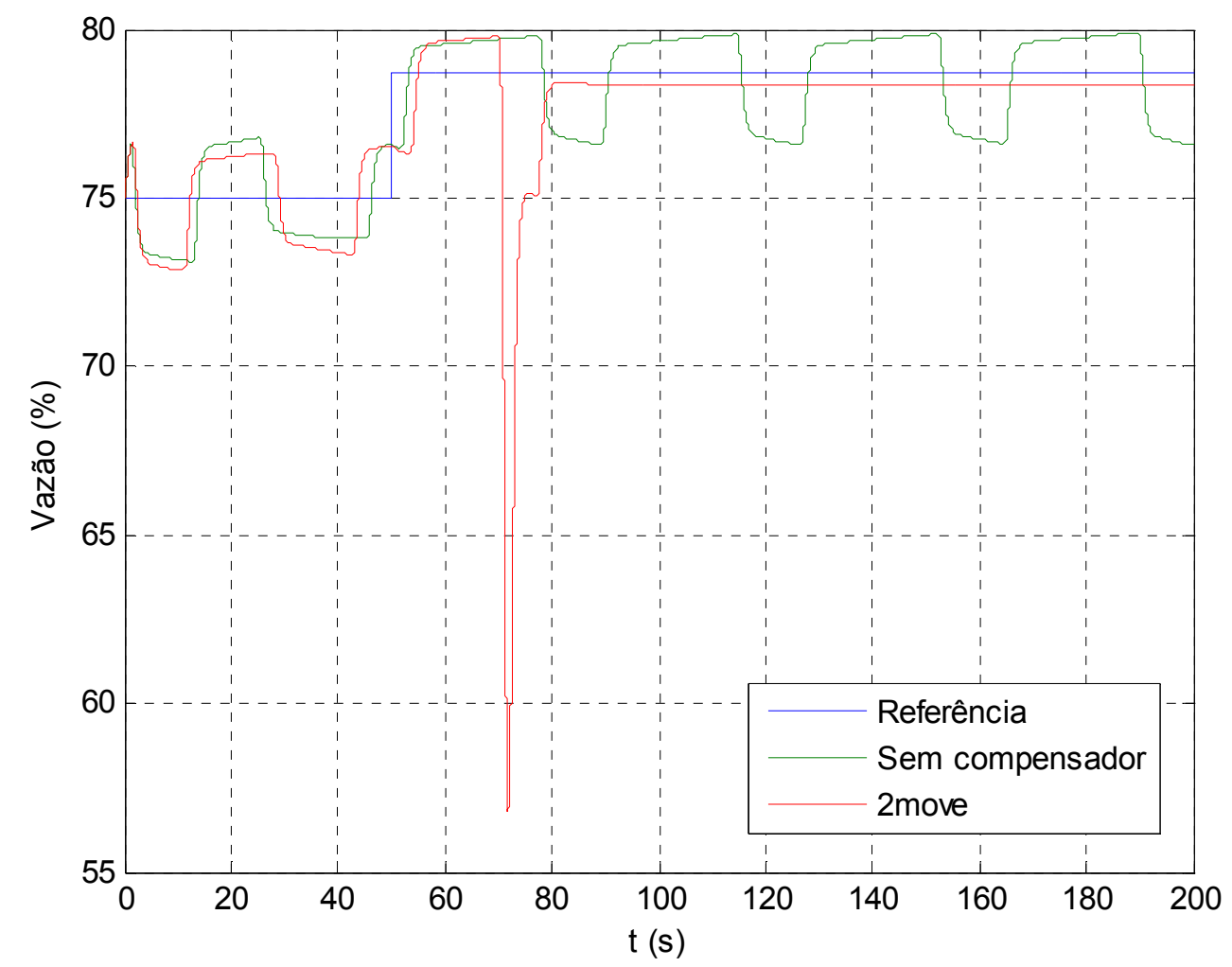

Figura 25: Compensador 2 move x sem compensador, atrito high, HIL, degrau

Finalmente, no ensaio com nível de atrito high no ambiente HIL, é possível observar uma melhora através do uso do compensador 2 move, ao contrário do que foi observado no mesmo ensaio em ambiente $100 \%$ simulado.

De todos os compensadores estudados, o compensador 2 move foi aquele que apresentou os piores resultados e as maiores dificuldades de ajuste de parâmetros. Este resultado é interessante, pois se trata do compensador mais recente proposto va literatura. Esperavam-se melhores resultados do que os obtidos. Uma possível explicação para o mau desempenho deste compensador são os ensaios realizados pelos criadores do compensador. A maioria dos ensaios apresentados no trabalho de (SRINIVASAN; RENGASWAMY, 2007) foi realizado em plantas discretas simuladas, bem diferentes do que é proposto neste trabalho. Além disso, neste trabalho, o compensador 2 move é implementado em uma malha de vazão, que possui constante de tempo dominante da ordem de $1 \mathrm{~s}$. Um passo futuro para verificar se esta suspeita está correta é a utilização deste compensador em plantas com dinâmicas diferentes. 


\subsubsection{Análise comparativa do ISE entre os compensadores para o ensaio de} degrau

A análise gráfica muita vezes já é por si só, conclusiva. Entretanto, para tornar mais evidentes os resultados obtidos através dos compensadores, uma tabela foi montada com os valores de ISE obtido para cada um dos compensadores, com relação ao sistema sem nenhum compensador, para os dois ambientes de simulação e para os dois níveis de atrito. Para os resultados entre os compensadores poderem ser comparados de maneira mais justa, o ISE é avaliado entre $t=80 \mathrm{~s}$ e $t=200 \mathrm{~s}$, já que, neste intervalo, o sistema já está trabalhando novamente num regime estacionário. Os resultados obtidos no ensaio de degrau estão descritos a seguir, na Tabela 5 e nas Figuras 26, 27, 28 e 29.

Tabela 5: ISE - Ensaio de degrau

\begin{tabular}{|l|c|c|}
\hline \multicolumn{1}{|c|}{ Nível de atrito } & Atrito Low & Atrito High \\
\hline Sem compensador - 100\% simulado & $7,91 \mathrm{E}-10$ & $6,98 \mathrm{E}+01$ \\
\hline IOL - 100\% simulado & $1,12 \mathrm{E}-09$ & $1,84 \mathrm{E}-08$ \\
\hline Knocker-100\% simulado & $3,40 \mathrm{E}-04$ & $2,42 \mathrm{E}+01$ \\
\hline 2 move - 100\% simulado & $1,63 \mathrm{E}-01$ & $1,01 \mathrm{E}+02$ \\
\hline Sem compensador - HIL & $3,70 \mathrm{E}-02$ & $2,32 \mathrm{E}+02$ \\
\hline IOL - HIL & $2,33 \mathrm{E}-01$ & $2,79 \mathrm{E}+01$ \\
\hline Knocker - HIL & $7,60 \mathrm{E}-02$ & $3,84 \mathrm{E}+01$ \\
\hline \multirow{2}{*}{2 move - HIL } & $2,05 \mathrm{E}+00$ & $1,63 \mathrm{E}+01$ \\
\hline
\end{tabular}




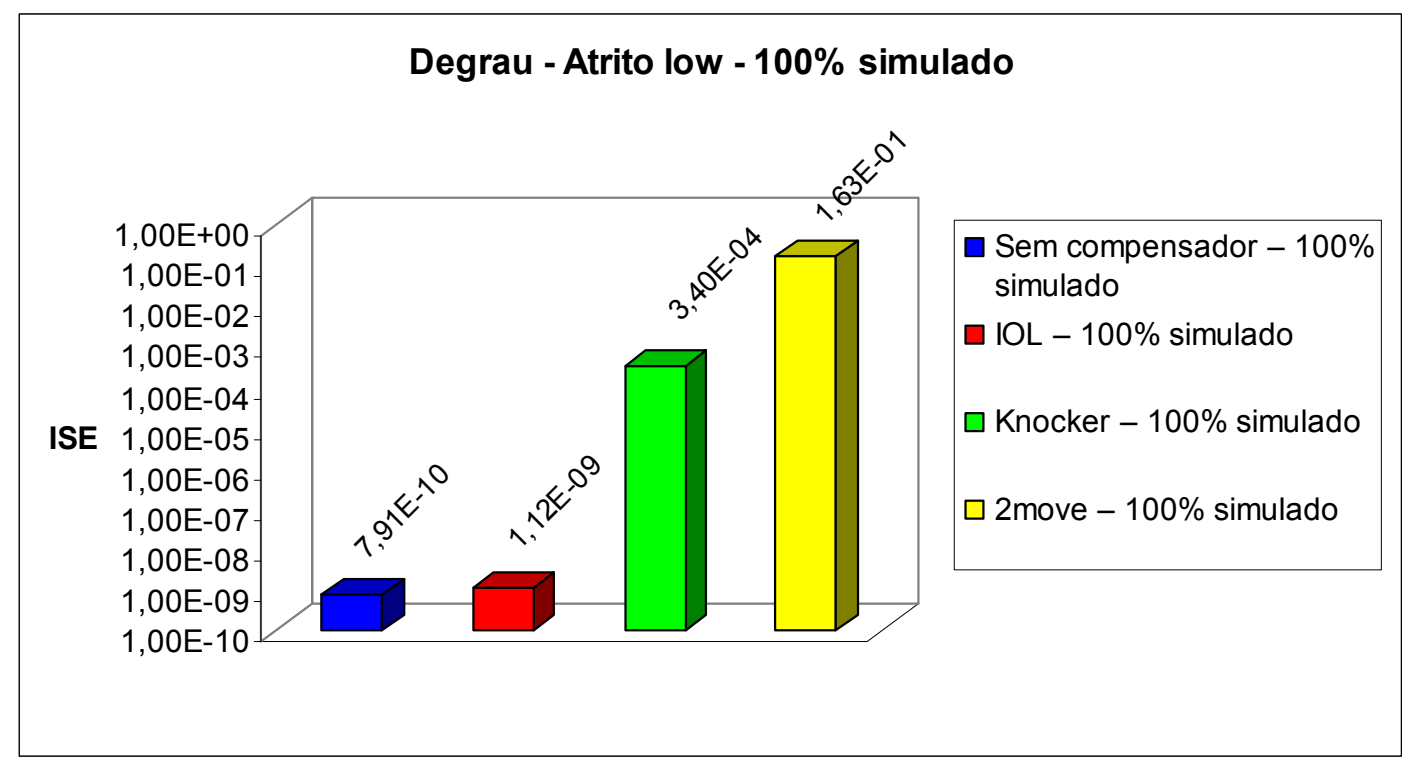

Figura 26: Gráfico de ISE, ensaio em degrau, atrito low, ambiente $100 \%$ simulado

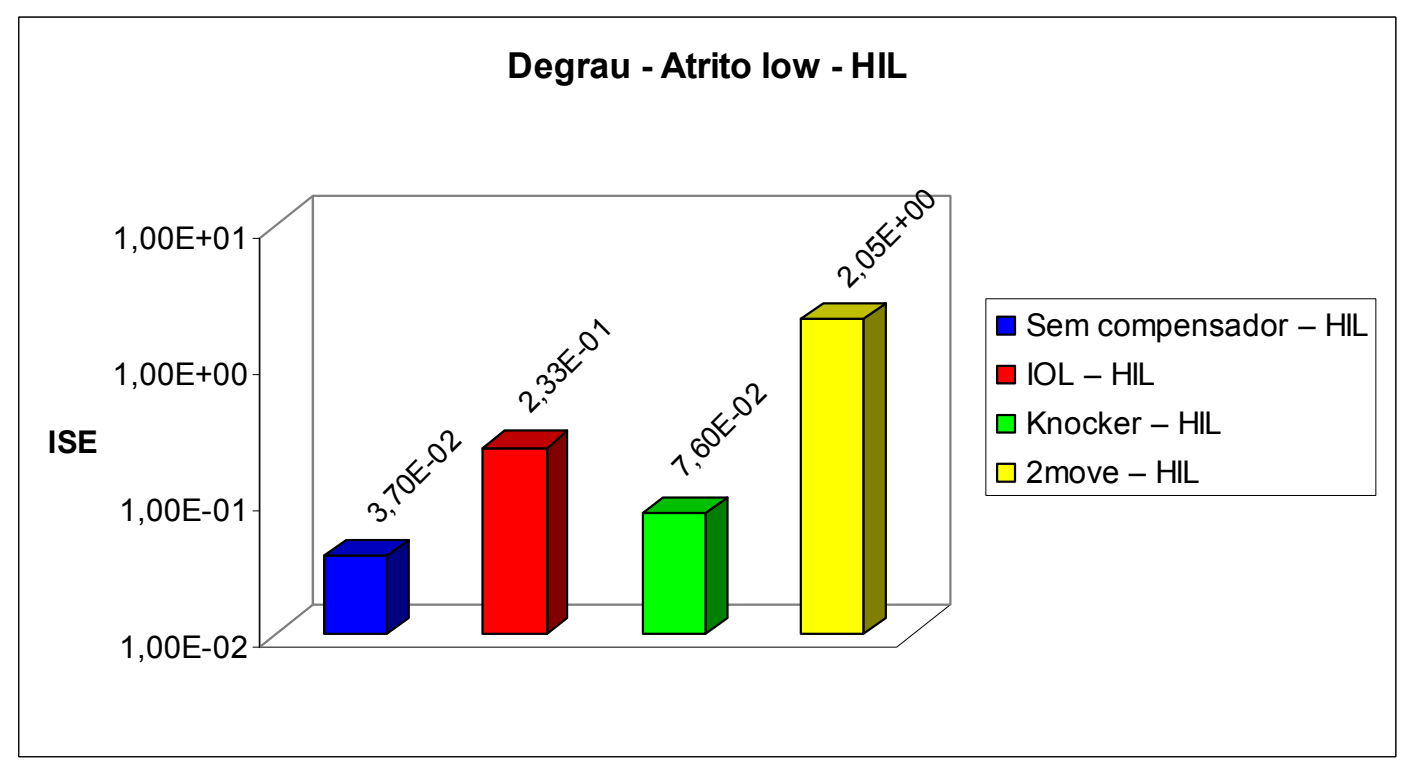

Figura 27: Gráfico de ISE, ensaio em degrau, atrito low, ambiente HIL 


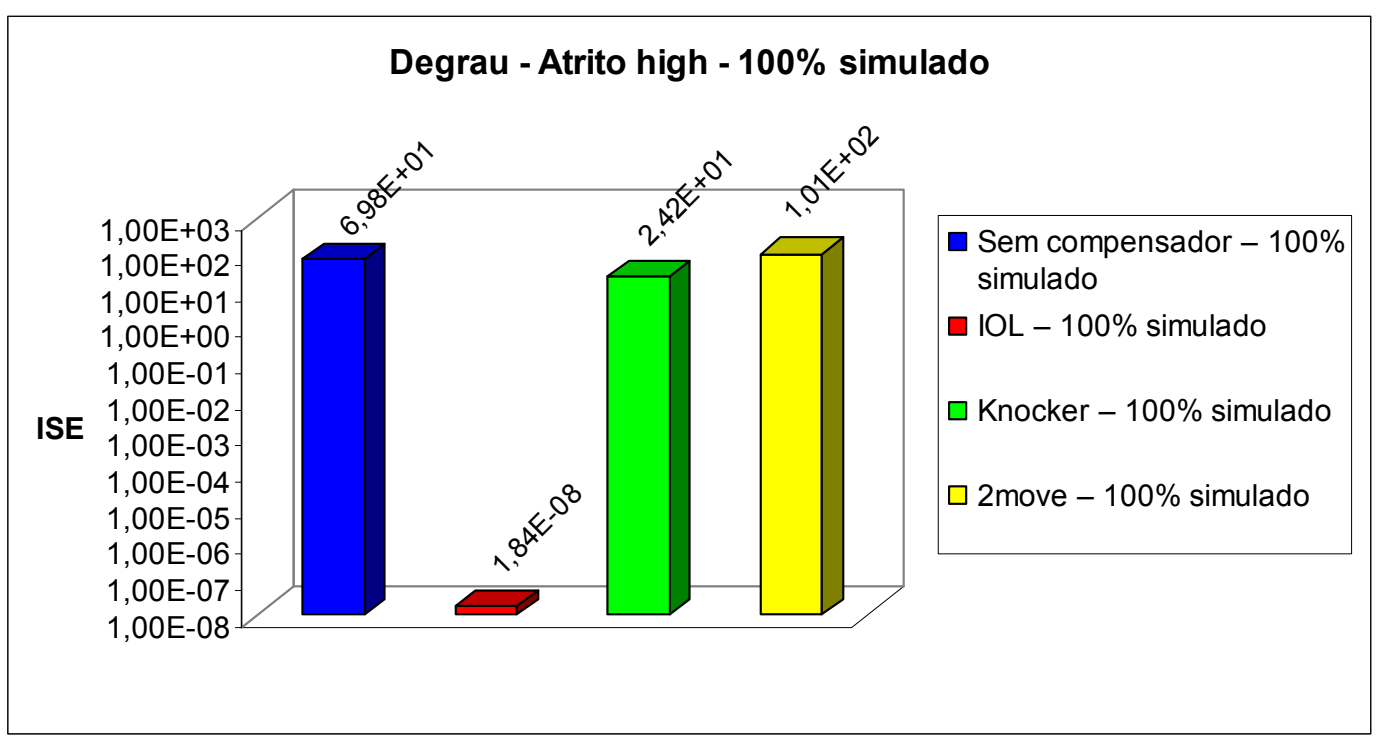

Figura 28: Gráfico de ISE, ensaio em degrau, atrito high, ambiente $100 \%$ simulado

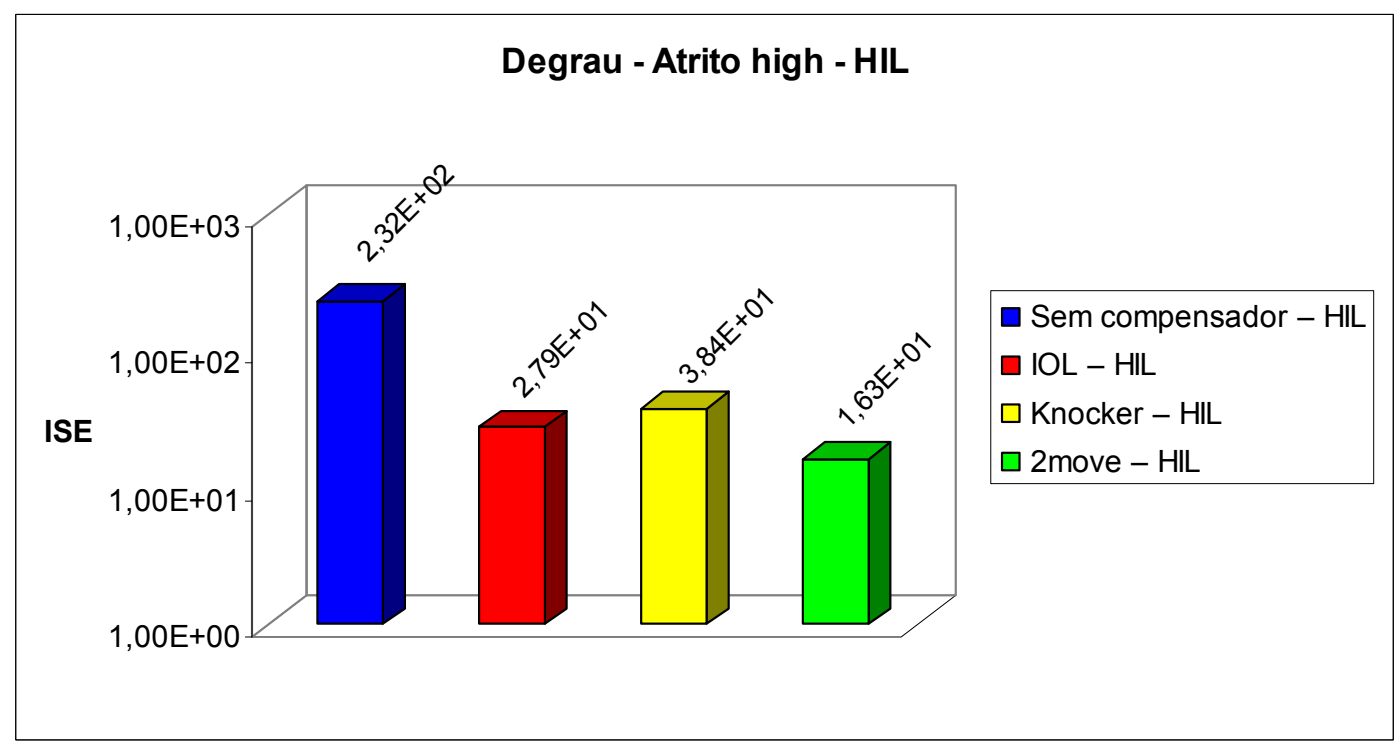

Figura 29: Gráfico de ISE, ensaio em degrau, atrito high, ambiente HIL

Os resultados mostrados na Tabela 5 e nas Figuras 26, 27, 28 e 29 indicam que, para o nível de atrito low, tanto no ambiente $100 \%$ simulado quanto no ambiente $H I L$, a utilização dos compensadores acaba piorando o desempenho da malha de controle.

Por outro lado, para o nível de atrito high, os resultados obtidos tanto no ambiente $100 \%$ simulado quanto no ambiente $H I L$ indicam que os três compensadores melhoraram o desempenho da malha quando utilizados, exceto o compensador 2 move no ambiente $100 \%$ simulado. 
Os resultados obtidos são muito interessantes, pois indicam que, para um nível de atrito mais baixo, manter os compensadores ativados, além de não fazer sentido, pode piorar o desempenho da malha de controle, o que pode representar maior consumo de energia e, conseqüentemente, maiores despesas na planta. 


\subsection{Ensaios de perturbação no processo}

No item 4.1 deste trabalho, todos os ensaios em degrau realizados consideraram somente o processo, sem a presença de perturbações. Neste caso, os compensadores foram testados e avaliados.

Do ponto de vista de um ambiente simulado, é perfeitamente possível trabalhar com um processo livre de ruídos. Por outro lado, numa planta real, dificilmente não existirão perturbações. Desta forma, optou-se por realizar ensaios nos quais um sinal de perturbação simulado é adicionado à planta.

O ruído escolhido para os testes foi uma seqüência de ruído branco, gaussiano, com média nula, variância de 0,025 e período de amostragem de $1 \mathrm{~s}$. A seqüência de ruído é a mesmo em todos os ensaios deste item.

\subsubsection{Ensaios de perturbação sem o uso dos compensadores de atrito}

Ao contrário do que foi adotado nos ensaios de degrau, os ensaios de perturbação são realizados com valor de referência constante. Sendo assim, as características em comum dos ensaios realizados no item 4.2 seguem abaixo:

- Duração de simulação $=200$ segundos;

- Passo de integração $=10^{-5}$ segundos;

- Decimação dos pontos $=100$.

Com relação ao controlador $\mathrm{PI}$ da malha de vazão, a sintonia utilizada durante as simulações é a mesma utilizada nos ensaios de degrau, ou seja, ganho do controlador $\left(K_{c}\right)=1,115$ e tempo integral do controlador $\left(T_{i}\right)=1,93 \mathrm{~s} / \mathrm{rep}$.

Uma vez definidas as características acima, o primeiro ensaio realizado é o ensaio de perturbação no ambiente $100 \%$ simulado, sem compensador de atrito, na válvula com níveis de atrito low e high. A Figura 30 mostra o resultado do ensaio de perturbação para os dois níveis de atrito, com relação ao valor de referência. 


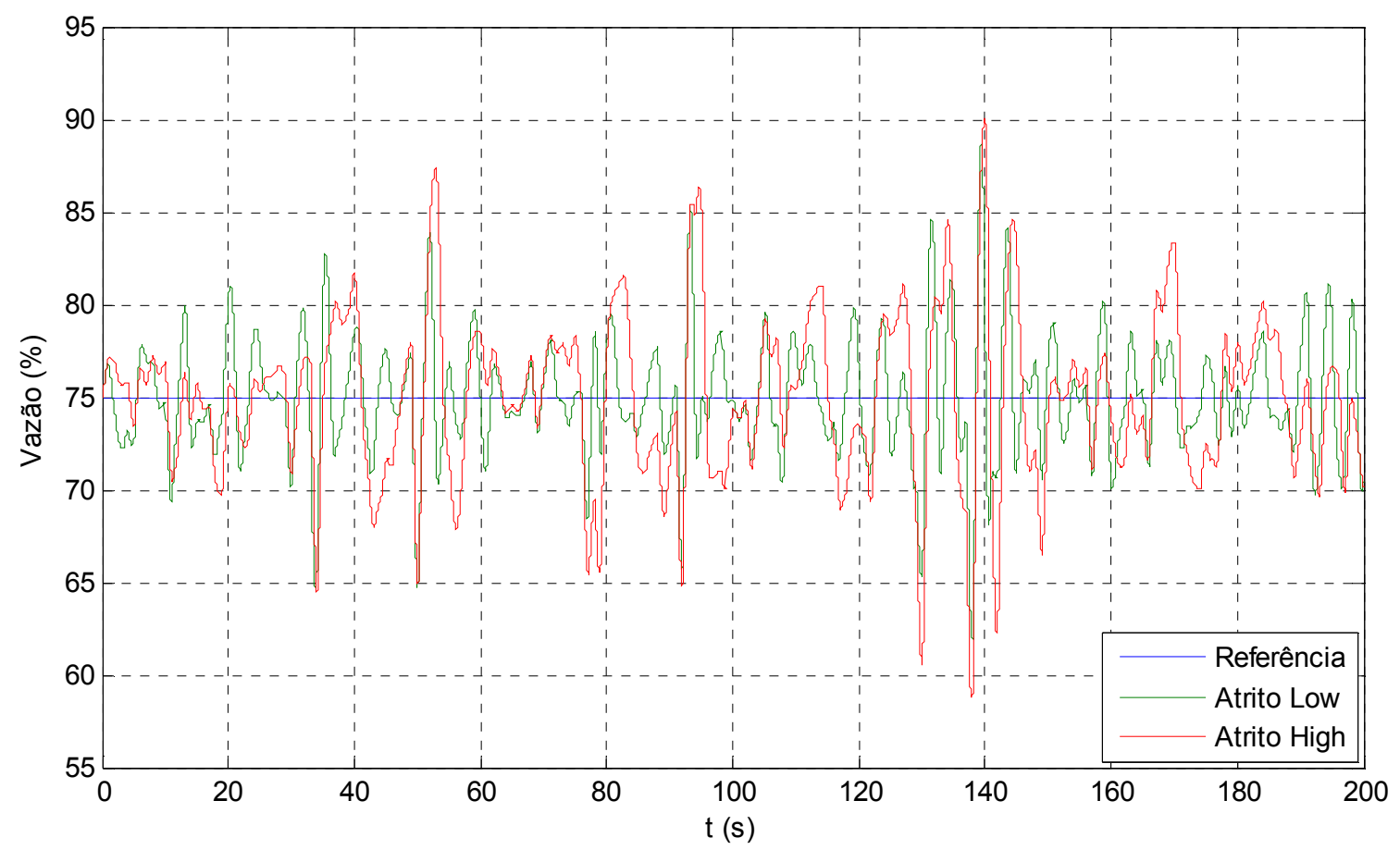

Figura 30: Resposta à perturbação, sem compensadores, ambiente $100 \%$ simulado

A análise da Figura 30 aponta que, tanto para o atrito low quanto para 0 atrito high, a presença da perturbação atrapalha bastante a resposta do sistema.

Mantendo a seqüência de ensaios estabelecida para este trabalho, a Figura 31 representa o comportamento da resposta à perturbação, sem compensadores, no ambiente HIL, para os dois níveis de atrito. 


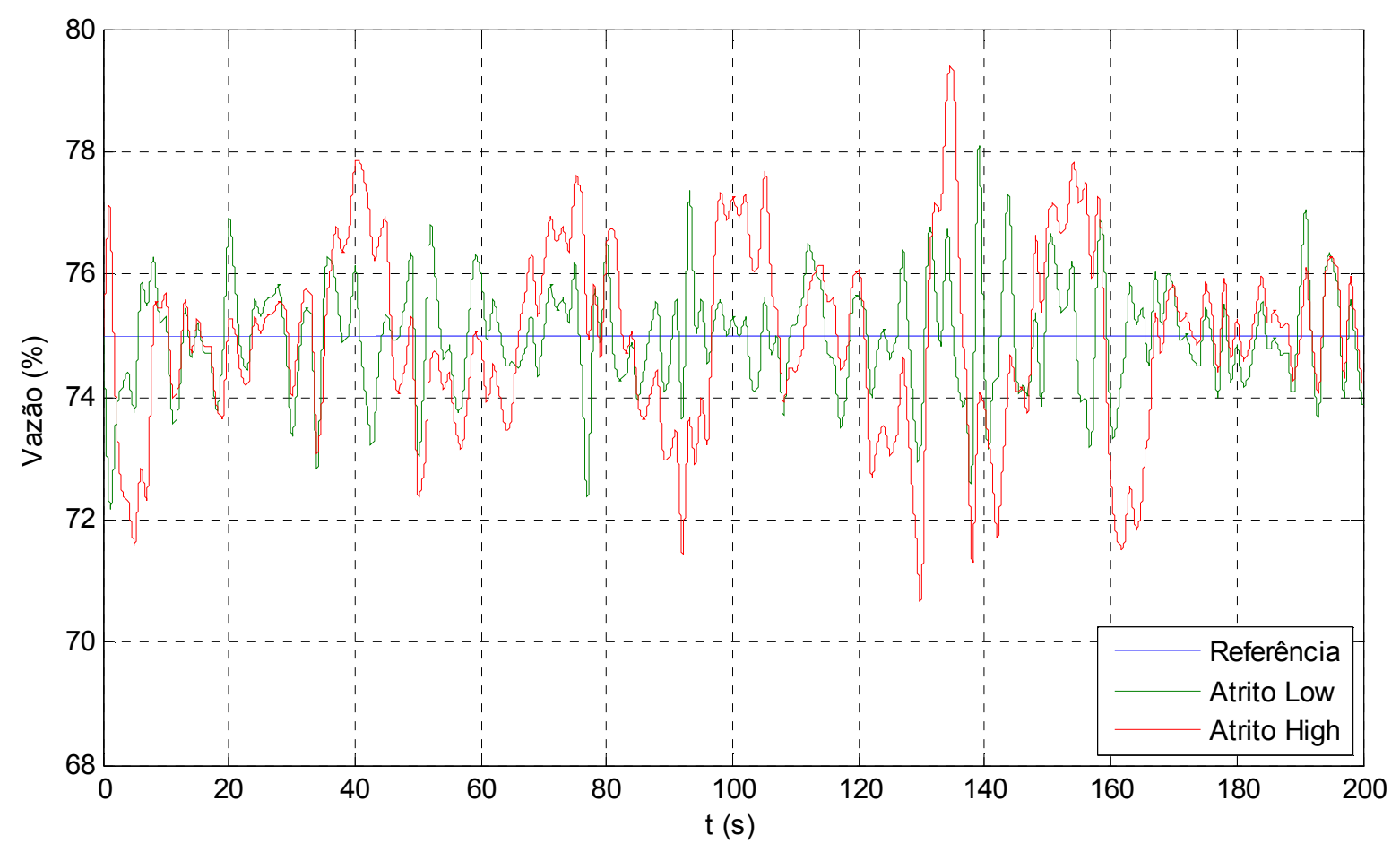

Figura 31: Resposta à perturbação, sem compensadores, ambiente HIL

Assim como no ambiente 100\% simulado, a análise da Figura 31 aponta que, tanto para o atrito low quanto para o atrito high, a presença da perturbação atrapalha bastante a resposta do sistema.

\subsubsection{Resposta à perturbação com o uso de compensador de atrito $I O L$}

Foi possível notar no item anterior que a presença de perturbação realmente atrapalha a resposta do sistema em malha fechada. Aproveitando a implementação dos compensadores de atrito, é testado agora o desempenho de cada um dos três compensadores, na presença desta perturbação.

Com relação aos parâmetros de sintonia $k 0$ e $k 1$ do controlador interno do $I O L$, optou-se por manter os mesmos valores adotados na Tabela 2. Esta parece ser a escolha mais acertada, pois desta forma é possível avaliar se, mesmo na presença de perturbação, a sintonia adotada para a malha sem perturbação ainda é capaz de estabilizar a planta.

A seguir, na Figura 32, é ilustrada a resposta à perturbação no sistema, em ambiente $100 \%$ simulado, quando o compensador IOL é utilizado, comparada com a 
resposta do sistema sem a presença de compensador, para o nível de atrito low, no ambiente $100 \%$ simulado.

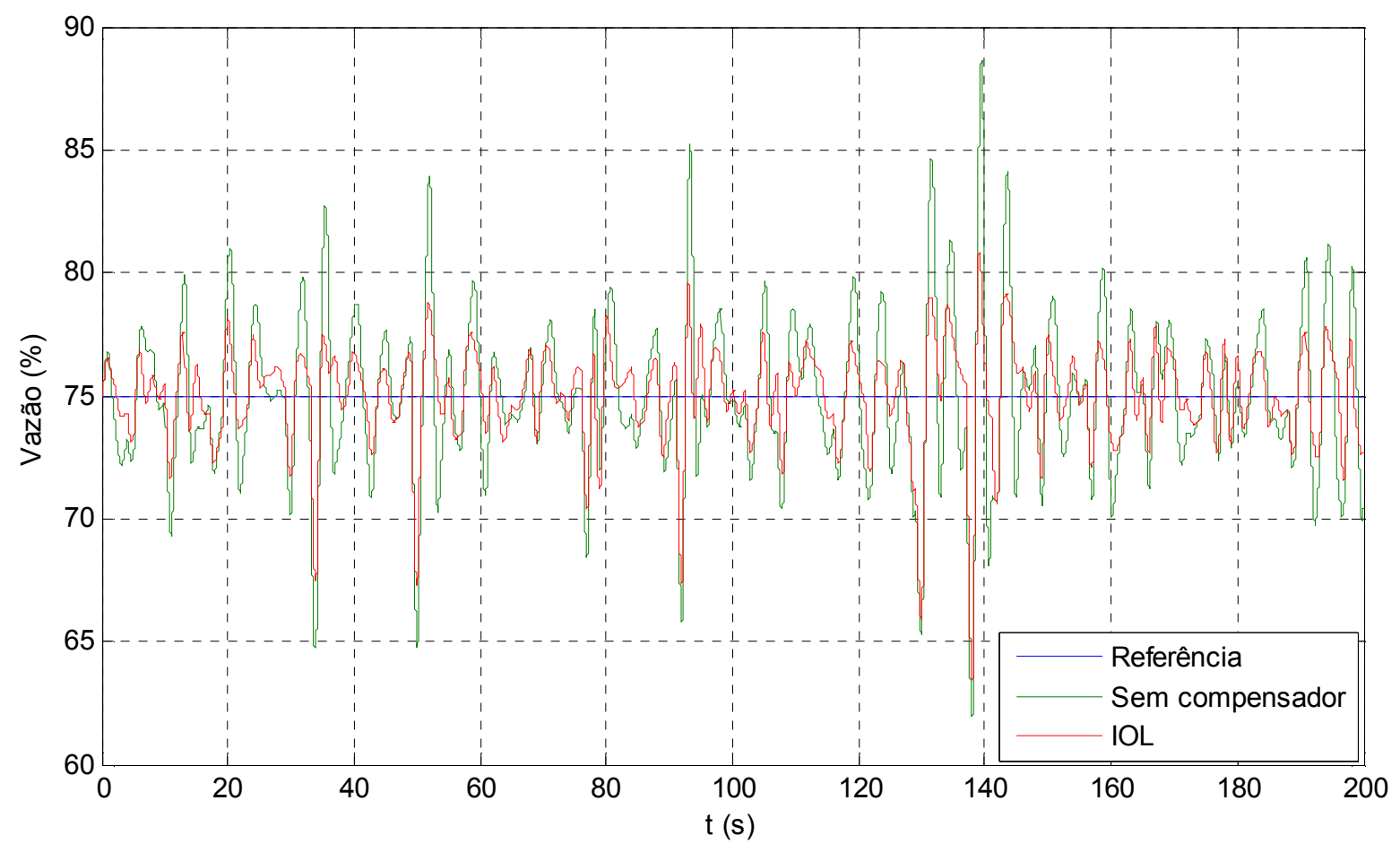

Figura 32: Compensador IOL x sem compensador, atrito low, $100 \%$ simulado, perturbação

Pela análise da Figura 32, pode-se notar que a amplitude da perturbação fica reduzida quando o compensador $I O L$ é utilizado. Resultados quantitativos desta melhora podem ser vistos a seguir, na análise de ISE do sistema na presença de perturbação.

A seguir, na Figura 33, apresentam-se os resultados obtidos no HIL, para nível de atrito low, na presença de perturbação. 


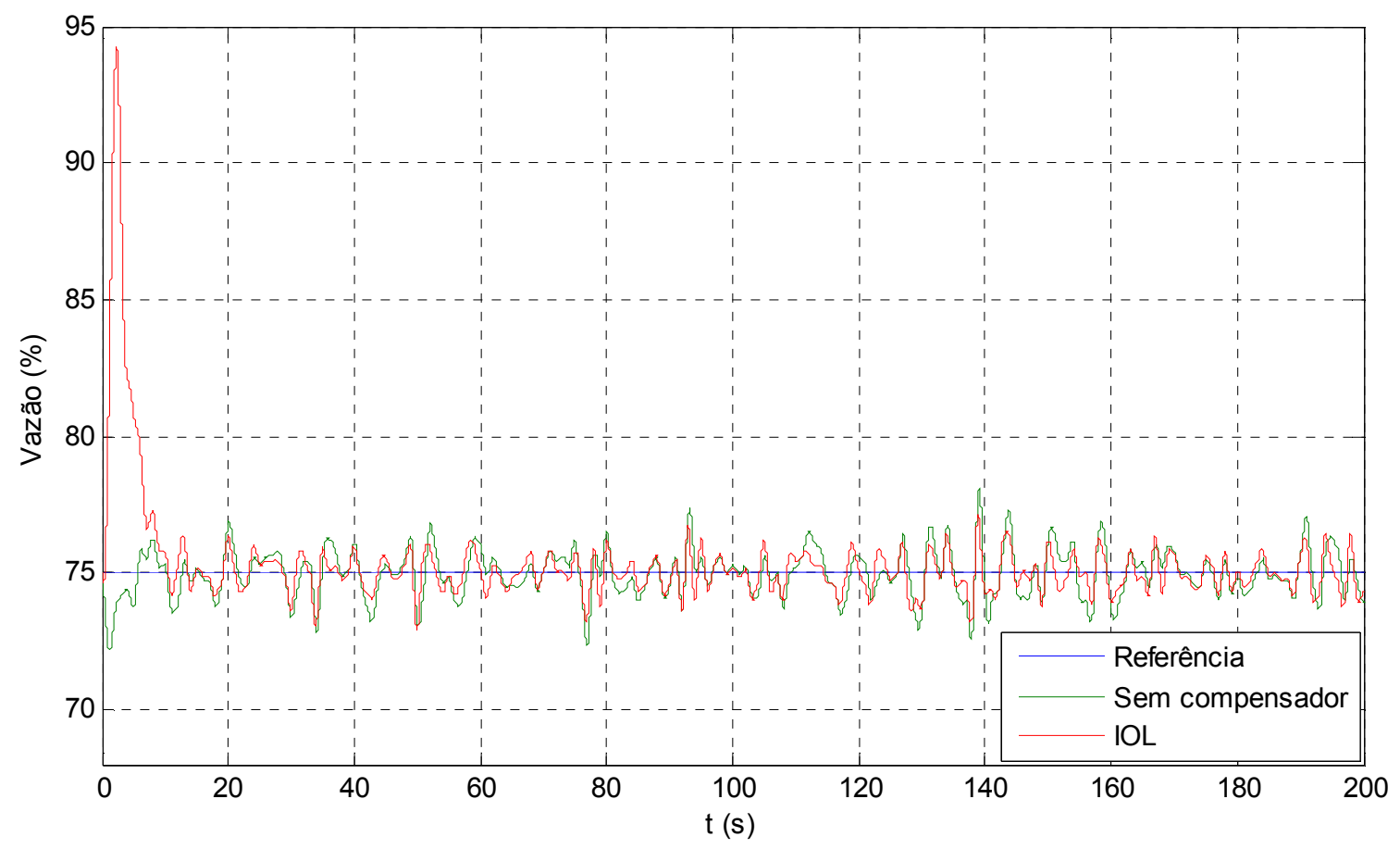

Figura 33: Compensador IOL x sem compensador, atrito low, HIL, perturbação

Assim como na Figura 32, a Figura 33 apresenta uma redução, ainda que pequena, na amplitude da perturbação quando o compensador IOL é acionado.

Os próximos ensaios, ilustrados nas Figuras 34 e 35, mostram os resultados obtidos com o uso do compensador $I O L$, no ambiente $100 \%$ simulado e no ambiente HIL respectivamente, para o nível de atrito high. 


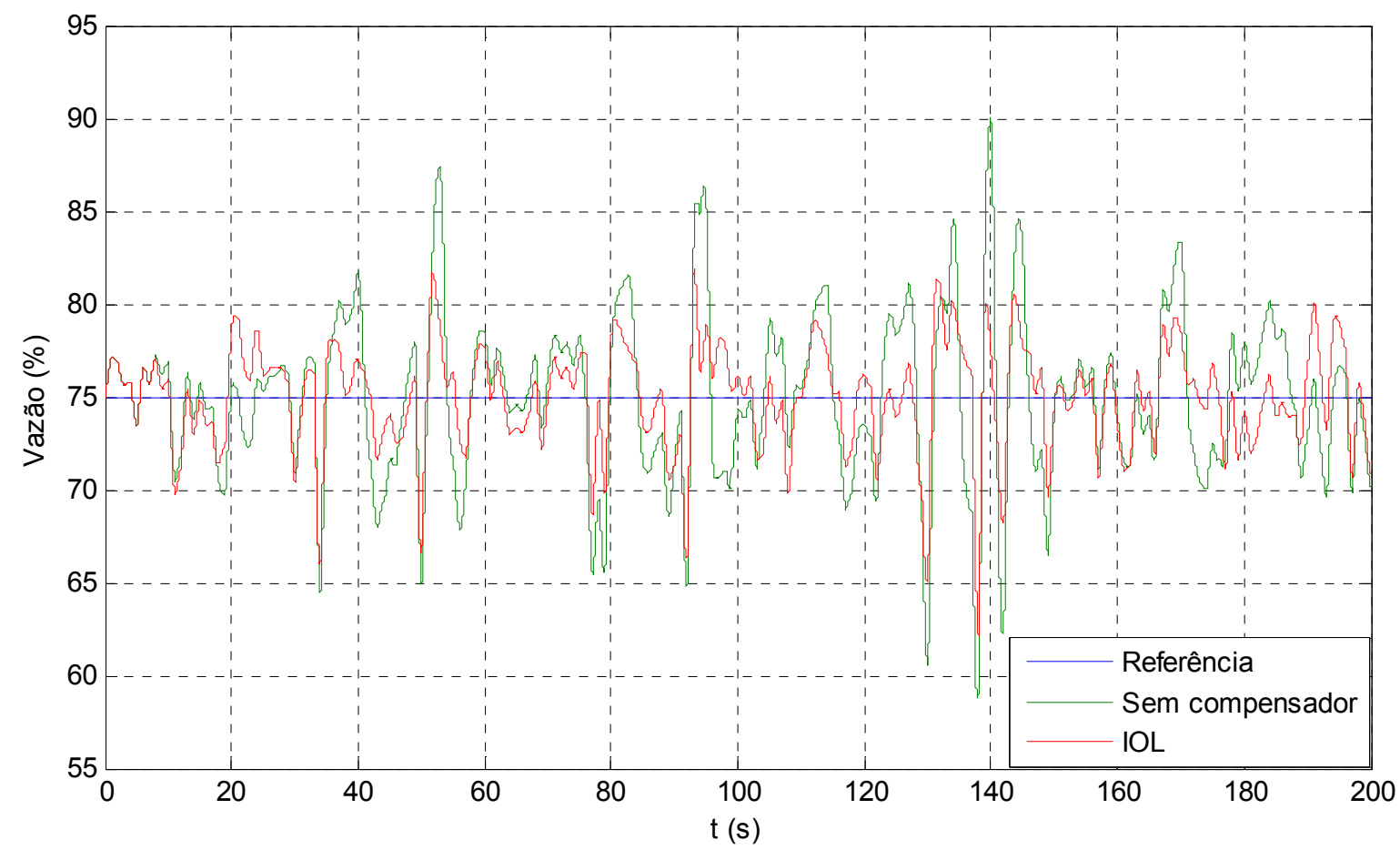

Figura 34: Compensador IOL x sem compensador, atrito high, $100 \%$ simulado, perturbação

Assim como já foi mostrado nos ensaios anteriores, o uso do compensador IOL reduziu a amplitude da perturbação.

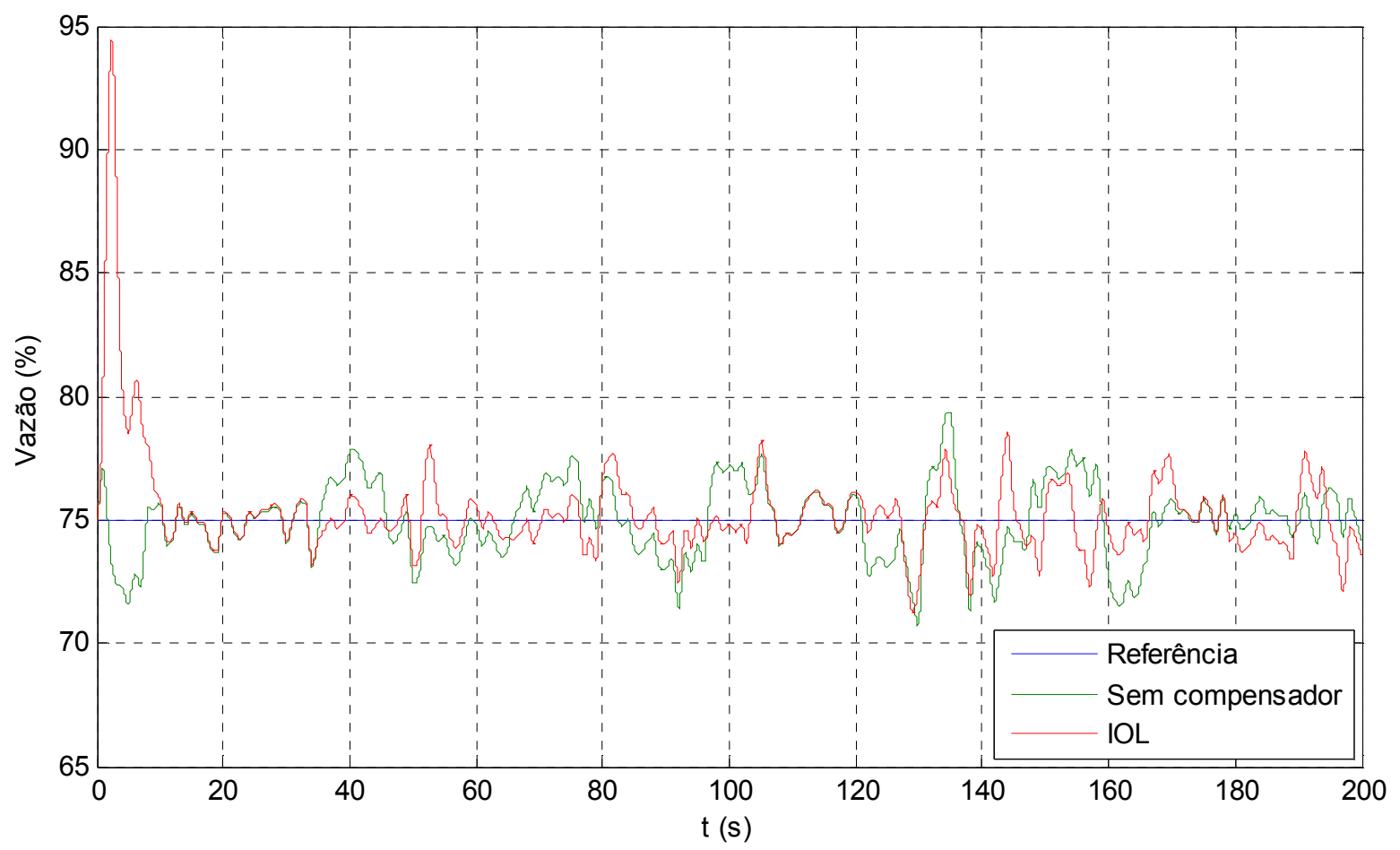

Figura 35: Compensador IOL x sem compensador, atrito high, HIL, perturbação 
A análise da Figura 35 aponta que, para a maior parte do tempo, o compensador $I O L$ diminui a amplitude da oscilação, exceto em alguns pequenos trechos. $\mathrm{O}$ resultado exato da melhora só poderá ser obtido a partir da análise do ISE.

Os resultados obtidos nos ensaios do compensador $I O L$ na presença de perturbação indicam que o compensador $I O L$ foi capaz de melhorar o desempenho da malha, através da diminuição da amplitude da perturbação.

\subsubsection{Resposta à perturbação com o uso de compensador de atrito Knocker}

O próximo compensador avaliado no ensaio de perturbação é o Knocker. Assim como foi feito no compensador $I O L$, os parâmetros de sintonia utilizados no compensador Knocker são os mesmos parâmetros adotados para este compensador na Tabela 3.

A seguir, na Figura 36, é ilustrada a resposta do sistema à perturbação, em ambiente $100 \%$ simulado, quando o compensador Knocker é utilizado, comparada com a resposta do sistema sem a presença do compensador, para o nível de atrito low, no mesmo ambiente.

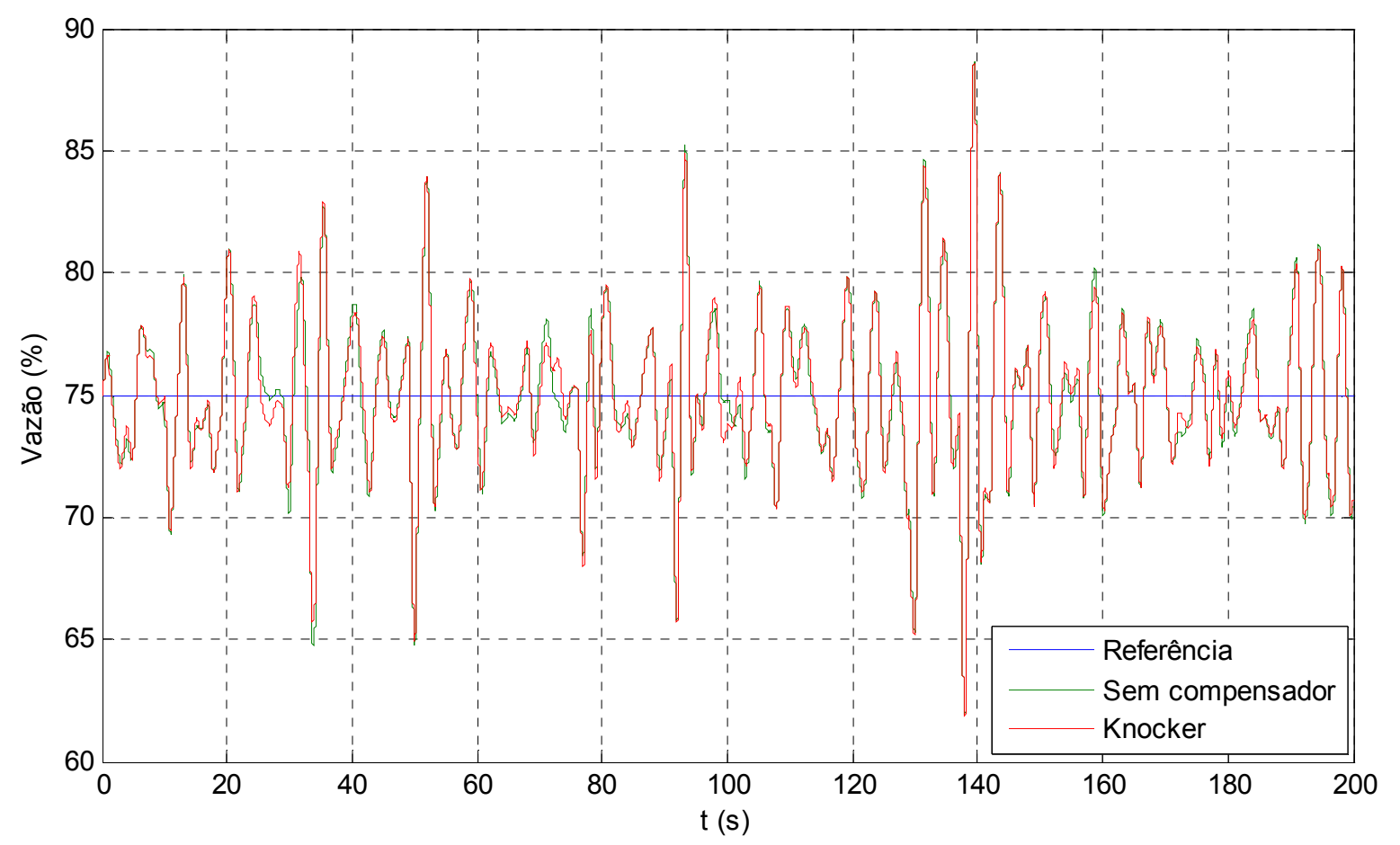

Figura 36: Compensador Knocker x sem compensador, atrito low, 100\% simulado, perturbação 
Através da análise da Figura 36, não é possível afirmar se o compensador Knocker apresentou melhora de desempenho neste ensaio com relação ao sistema sem compensador, na presença de perturbação.

Dando continuidade aos ensaios e seus resultados, a seguir, na Figura 37, são apresentados os resultados obtidos no ambiente HIL, para nível de atrito low, na presença de perturbação.

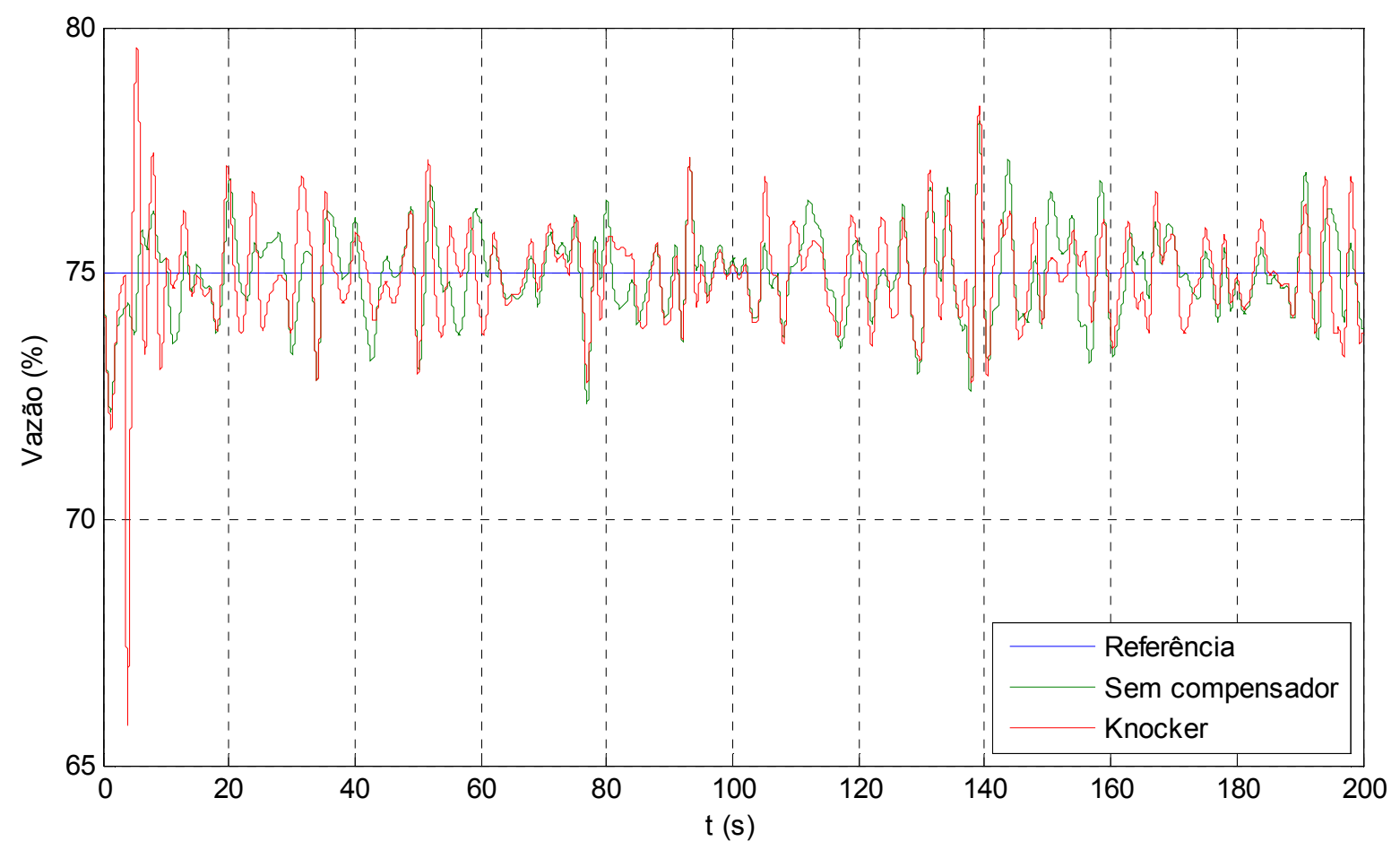

Figura 37: Compensador Knocker x sem compensador, atrito low, HIL, perturbação

Assim como no ambiente 100\% simulado, a análise da Figura 37 indica que o resultado obtido no ambiente $H I L$, para o nível de atrito low, não apresenta uma melhora significativa na resposta do sistema quando o compensador Knocker é utilizado.

Além disso, pode-se dizer que, analisando somente as Figuras 36 e 37, é impossível avaliar qual o nível de melhora apresentado pelo compensador Knocker, tanto no ambiente $100 \%$ simulado quanto no ambiente HIL, considerando-se o nível de atrito Iow. Para isso, a ISE será utilizada a seguir. 
Os próximos ensaios avaliam o comportamento do compensador Knocker, em ambiente $100 \%$ simulado, para o nível de atrito high, na presença de perturbação. A Figura 38 a seguir ilustra os resultados obtidos neste ensaio.

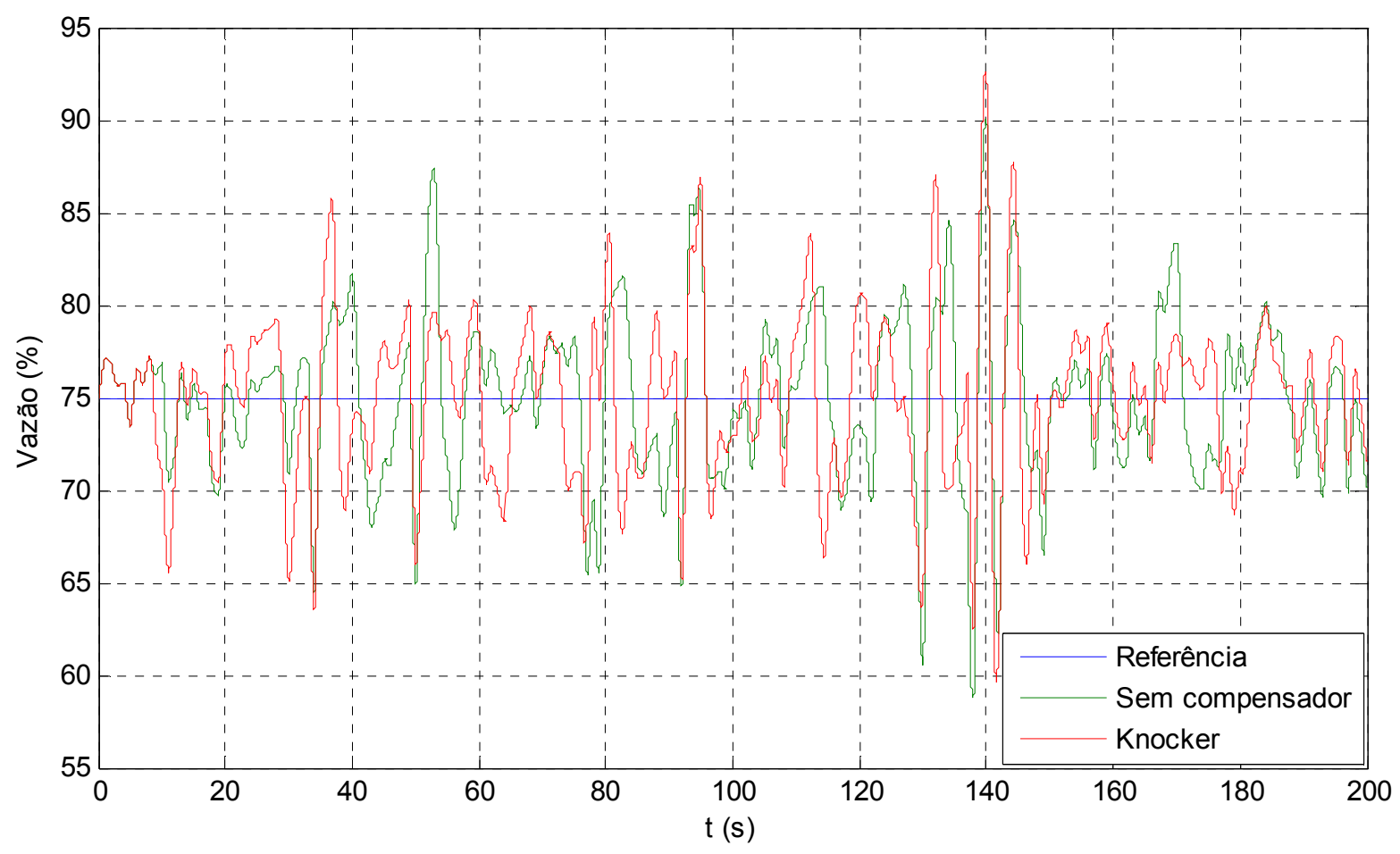

Figura 38: Compensador Knocker $\mathrm{x}$ sem compensador, atrito high, 100\% simulado, perturbação

Através da análise da Figura 38, não é possível afirmar se a resposta dos sistema melhorou com a utilização do compensador Knocker.

Até este momento, o compensador Knocker aparentemente não está se mostrando eficiente quando existe perturbação na malha de controle. O último ensaio referente ao compensador Knocker é o ensaio no ambiente HIL, com nível de atrito high. A seguir, são apresentados na Figura 39, os resultados obtidos neste último ensaio do compensador Knocker, na presença de perturbação. 


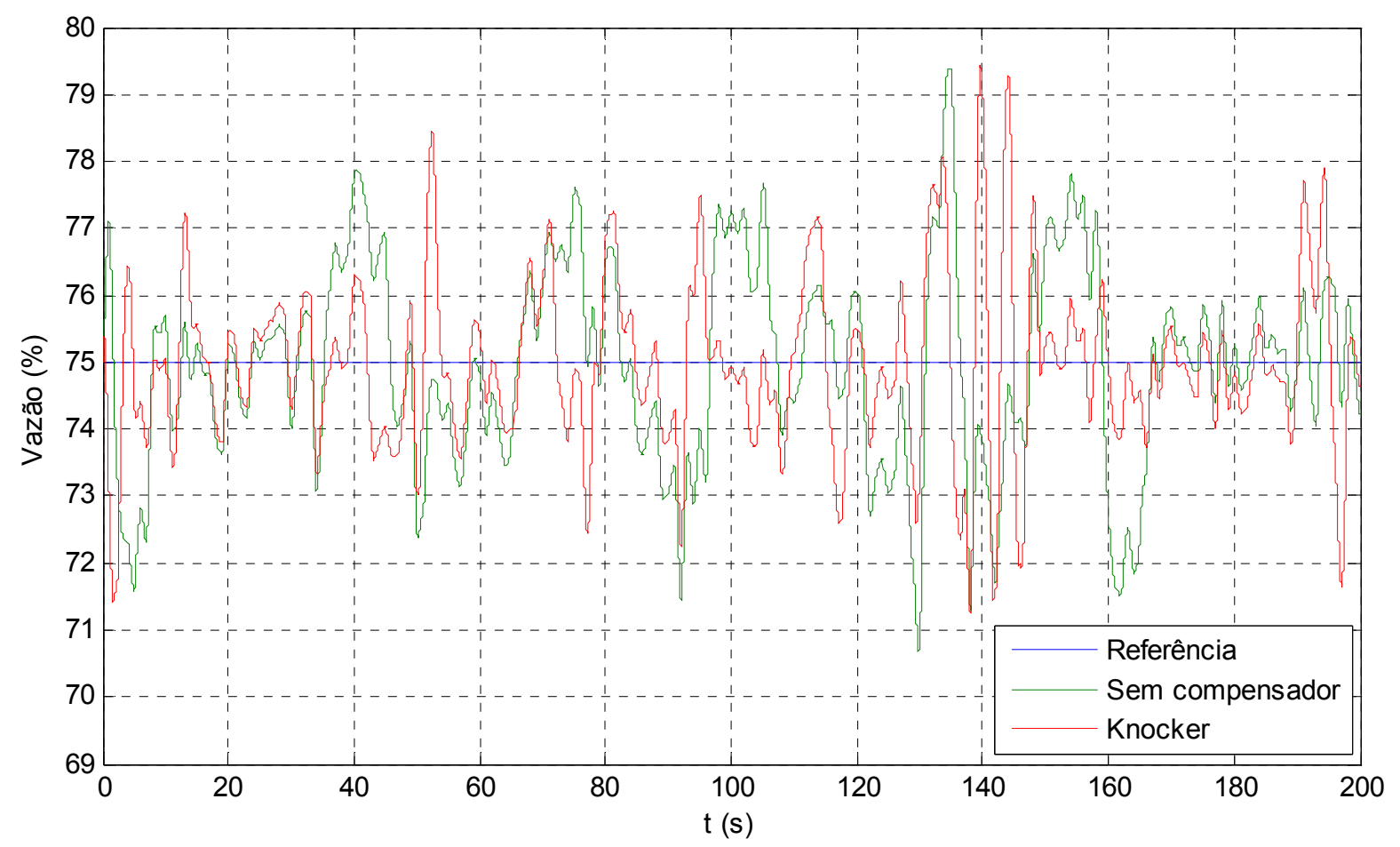

Figura 39: Compensador Knocker x sem compensador, atrito high, HIL, perturbação

Novamente, não foi possível observar, de maneira clara, uma melhora com a utilização do compensador Knocker, na presença de perturbação.

Pelo que foi apresentado neste item, pode-se concluir que o compensador Knocker não apresentou melhora no desempenho da malha em nenhum dos ensaios realizados na presença de perturbação.

\subsubsection{Resposta à perturbação com o uso de compensador de atrito 2 move}

O próximo compensador avaliado no ensaio de resposta à perturbação é o 2move. Seguindo a metodologia adotada até agora nos ensaios do item 4.2, são mantidos os instantes de tempo em que ocorrem os dois movimentos, conforme descrito na Tabela 4, assim como o valor do nível de atrito estimado $d=0,2$ ou $20 \%$.

A seguir, na Figura 40, é ilustrada a resposta à perturbação do sistema, em ambiente $100 \%$ simulado, para nível de atrito low, quando o compensador 2 move é utilizado, comparada com a resposta do sistema, nas mesmas condições, sem a presença de compensador. 


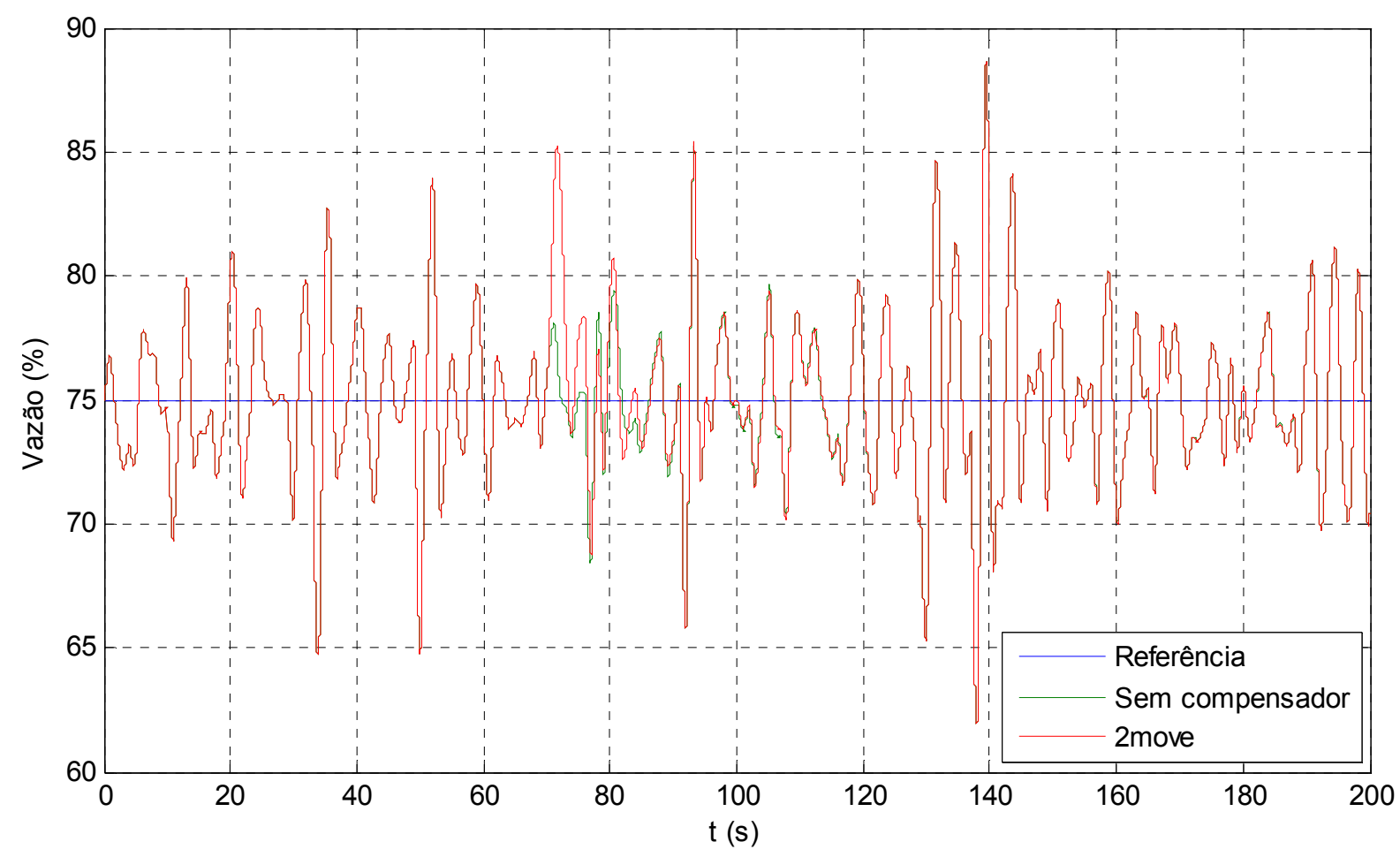

Figura 40: Compensador 2 move x sem compensador, atrito low, $100 \%$ simulado, perturbação

A Figura 40 não aponta nenhuma melhora a partir do instante em que o compensador 2move é acionado $(t=70 \mathrm{~s}$ ). Dando continuidade aos ensaios, a seguir, na Figura 41, são apresentados os resultados obtidos no ambiente HIL, para nível de atrito low. 


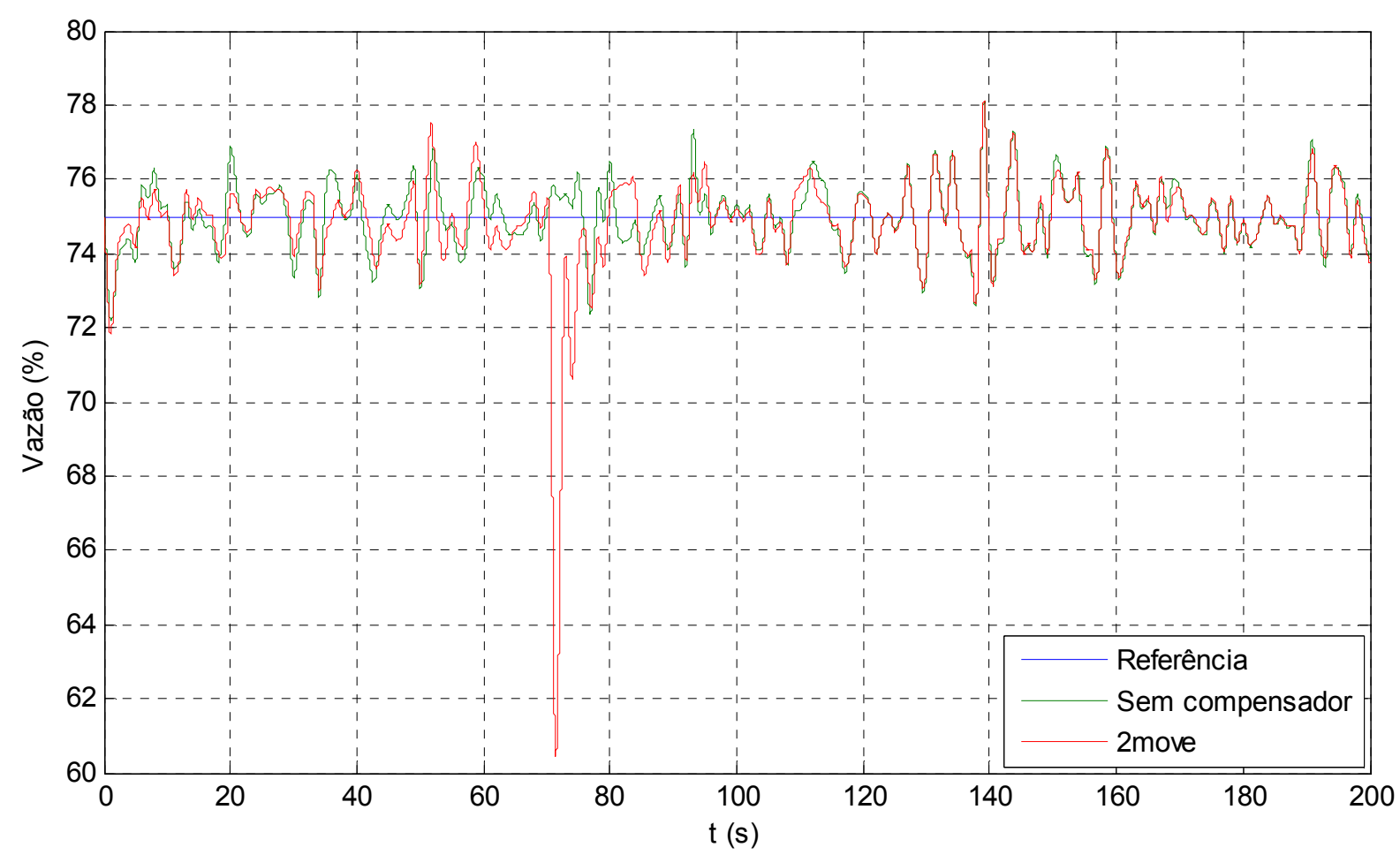

Figura 41: Compensador 2move x sem compensador, atrito low, HIL, perturbação

Assim como no ensaio em ambiente $100 \%$ simulado, a utilização do compensador 2 move na presença de perturbação não apresentou nenhuma melhora no ambiente HIL, para o nível de atrito low.

Mantendo a seqüência dos ensaios, no próximo ensaio é avaliado o comportamento do compensador 2 move, em ambiente $100 \%$ simulado, para o nível de atrito high. Os resultados obtidos durante este ensaio são apresentados a seguir, na Figura 42. 


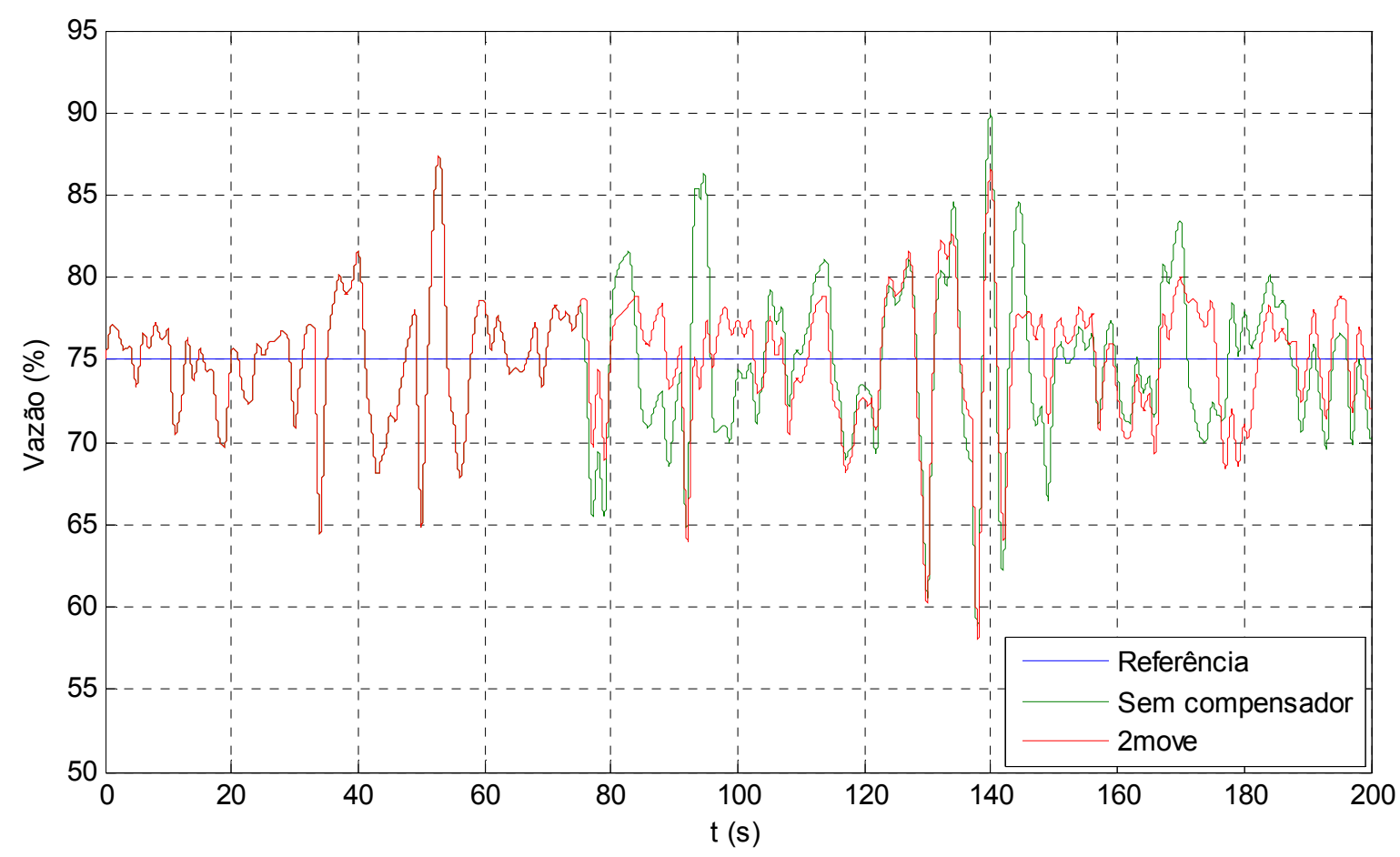

Figura 42: Compensador 2 move $x$ sem compensador, atrito high, $100 \%$ simulado, perturbação

Novamente, na Figura 42 é possível verificar que a utilização do compensador 2move na presença de perturbação não apresentou melhoria perceptível no desempenho da malha, assim como já havia acontecido nos ensaios anteriores.

Finalizando os ensaios com o compensador 2move, a seguir, na Figura 43, são apresentados os resultados obtidos no ensaio em ambiente HIL, na presença de perturbação, para o nível de atrito high. 


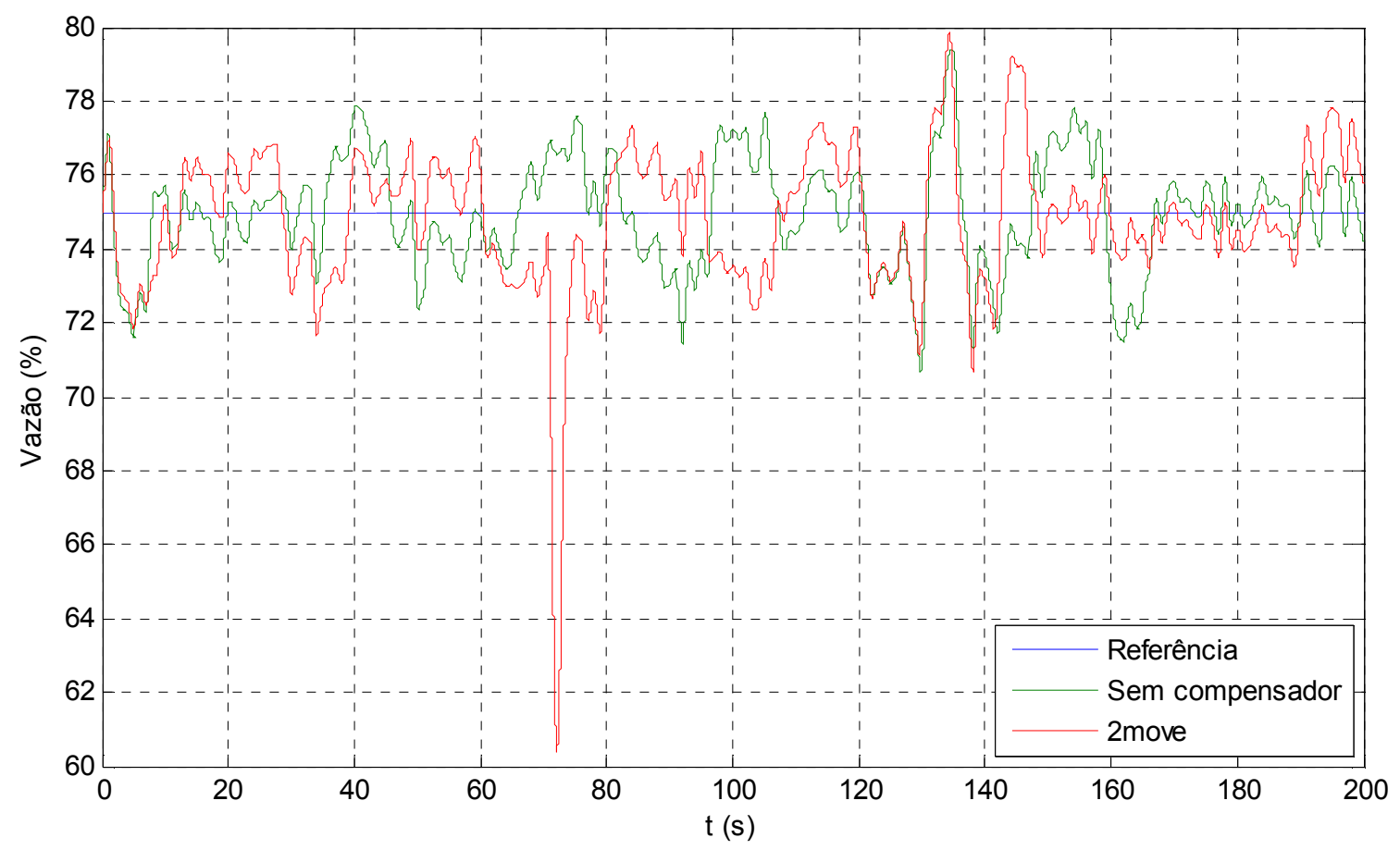

Figura 43: Compensador 2 move x sem compensador, atrito high, HIL, perturbação

Novamente, no ensaio com nível de atrito high no ambiente HIL, não é possível observar melhora na resposta do sistema com a utilização do compensador 2 move.

O compensador 2 move não apresentou melhora perceptível no desempenho da malha de vazão, na presença de perturbação. Este resultado geral é muito negativo, pois, do ponto de vista de plantas reais, dificilmente um processo estará livre de perturbações. Por outro lado, talvez o tipo de perturbação adotado tenha gerado os maus resultados, já que, no caso de plantas reais, as perturbações ocorrem com freqüências mais lentas, sendo que apenas o ruído de medição pode ser de alta freqüência, mas normalmente com baixa variância.

\subsubsection{Análise comparativa do ISE entre os compensadores para o ensaio de perturbação}

Assim como foi feito no ensaio em degrau, seguem na Tabela 6 e nas Figuras 44, 45, 46 e 47 os resultados obtidos para cada um dos compensadores, com relação ao sistema sem nenhum compensador, para os dois ambientes de simulação e para os dois níveis de atrito. 
Tabela 6: ISE - Ensaio de perturbação

\begin{tabular}{|l|c|c|}
\hline \multicolumn{1}{|c|}{ Nível de atrito } & Atrito Low & Atrito High \\
\hline Sem compensador - 100\% simulado & $1,37 \mathrm{E}+03$ & $2,68 \mathrm{E}+03$ \\
\hline IOL - 100\% simulado & $5,34 \mathrm{E}+02$ & $1,01 \mathrm{E}+03$ \\
\hline Knocker-100\% simulado & $1,31 \mathrm{E}+03$ & $2,61 \mathrm{E}+03$ \\
\hline $2 m o v e-100 \%$ simulado & $1,37 \mathrm{E}+03$ & $1,85 \mathrm{E}+03$ \\
\hline Sem compensador $-H I L$ & $8,91 \mathrm{E}+01$ & $3,08 \mathrm{E}+02$ \\
\hline IOL - HIL & $8,39 \mathrm{E}+01$ & $3,15 \mathrm{E}+02$ \\
\hline Knocker - HIL & $5,38 \mathrm{E}+01$ & $1,93 \mathrm{E}+02$ \\
\hline \multirow{2}{*}{2 move - HIL } & & $2,27 \mathrm{E}+02$ \\
\hline
\end{tabular}




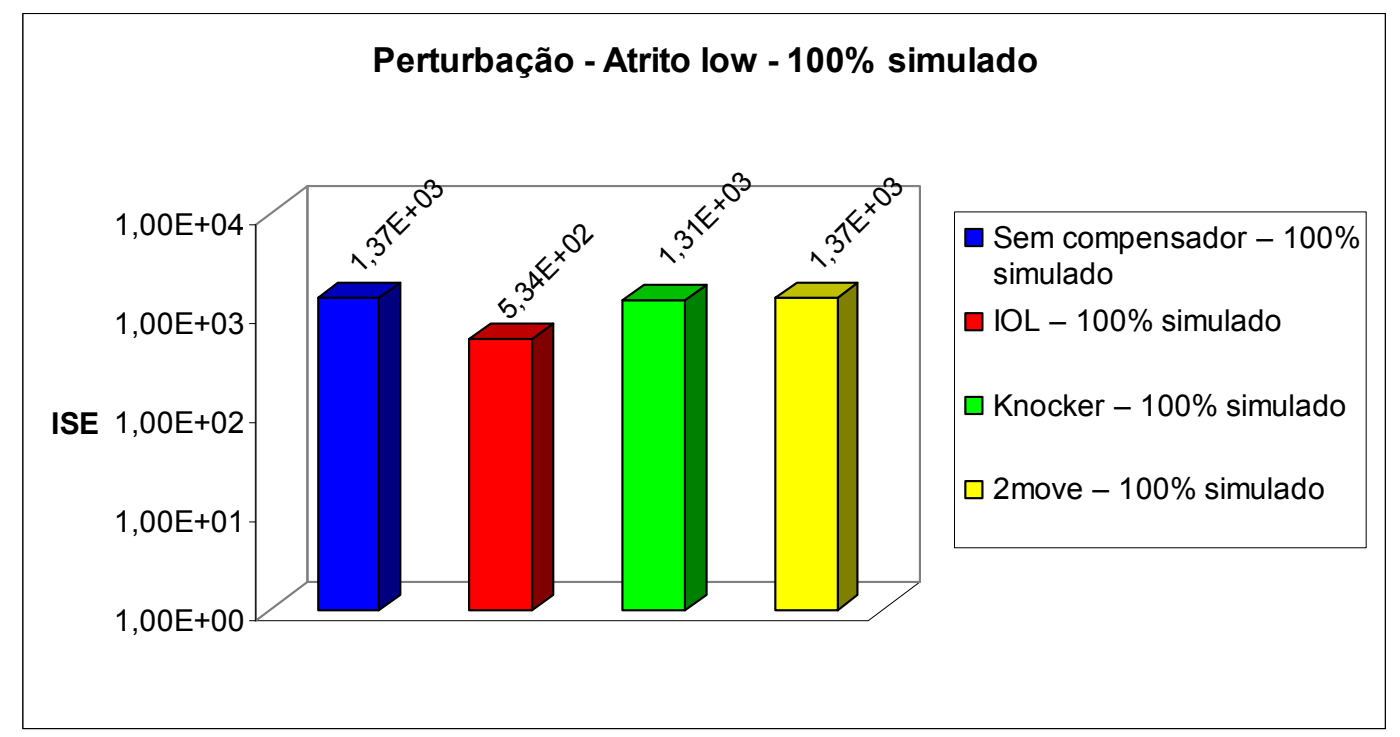

Figura 44: Gráfico de ISE, ensaio de perturbação, atrito low, ambiente $100 \%$ simulado

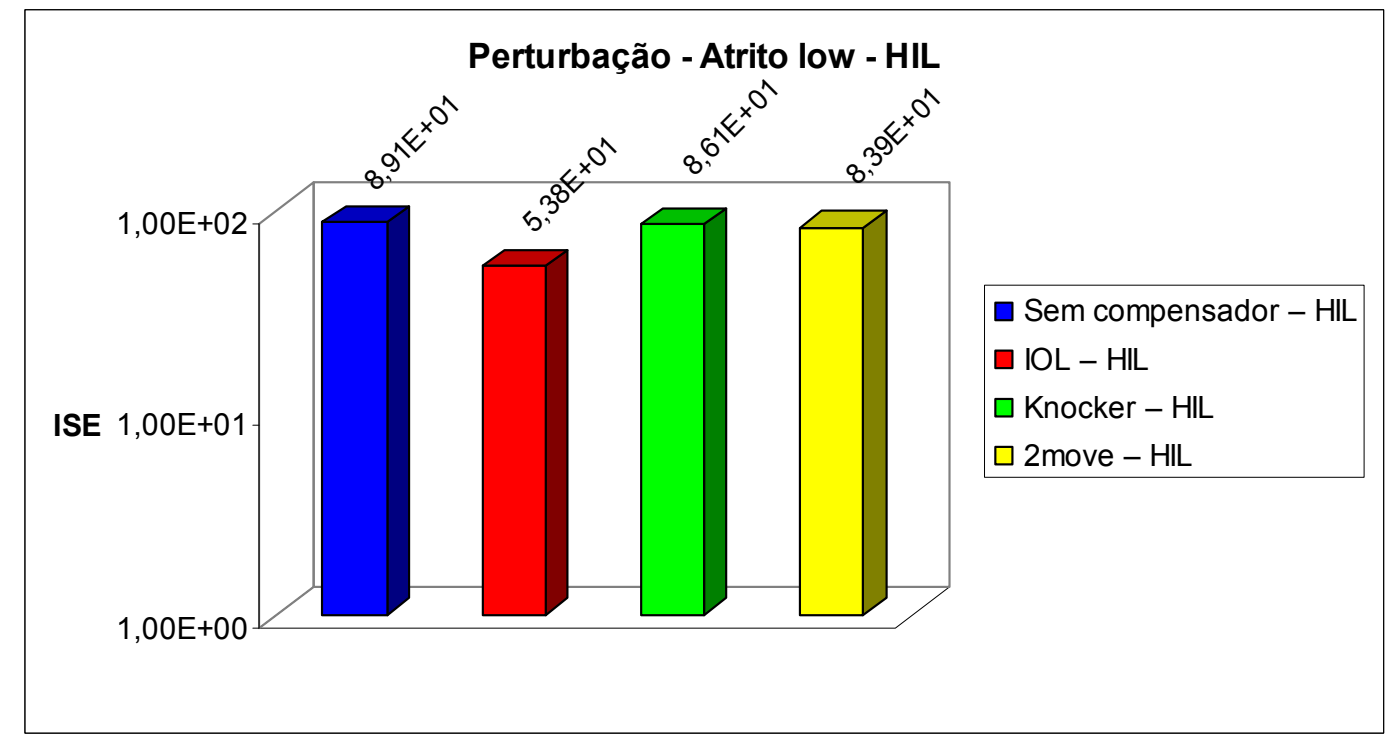

Figura 45: Gráfico de ISE, ensaio de perturbação, atrito low, ambiente HIL 


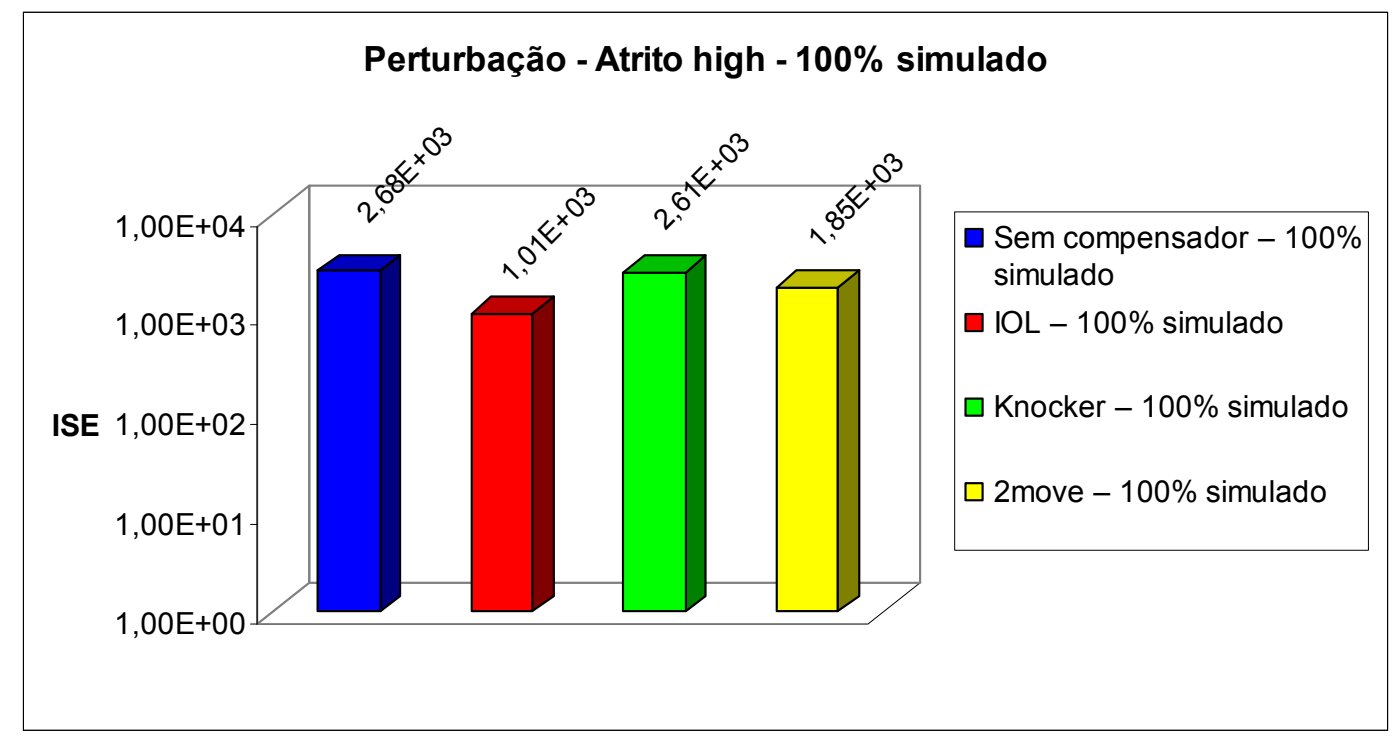

Figura 46: Gráfico de ISE, ensaio de perturbação, atrito high, ambiente $100 \%$ simulado

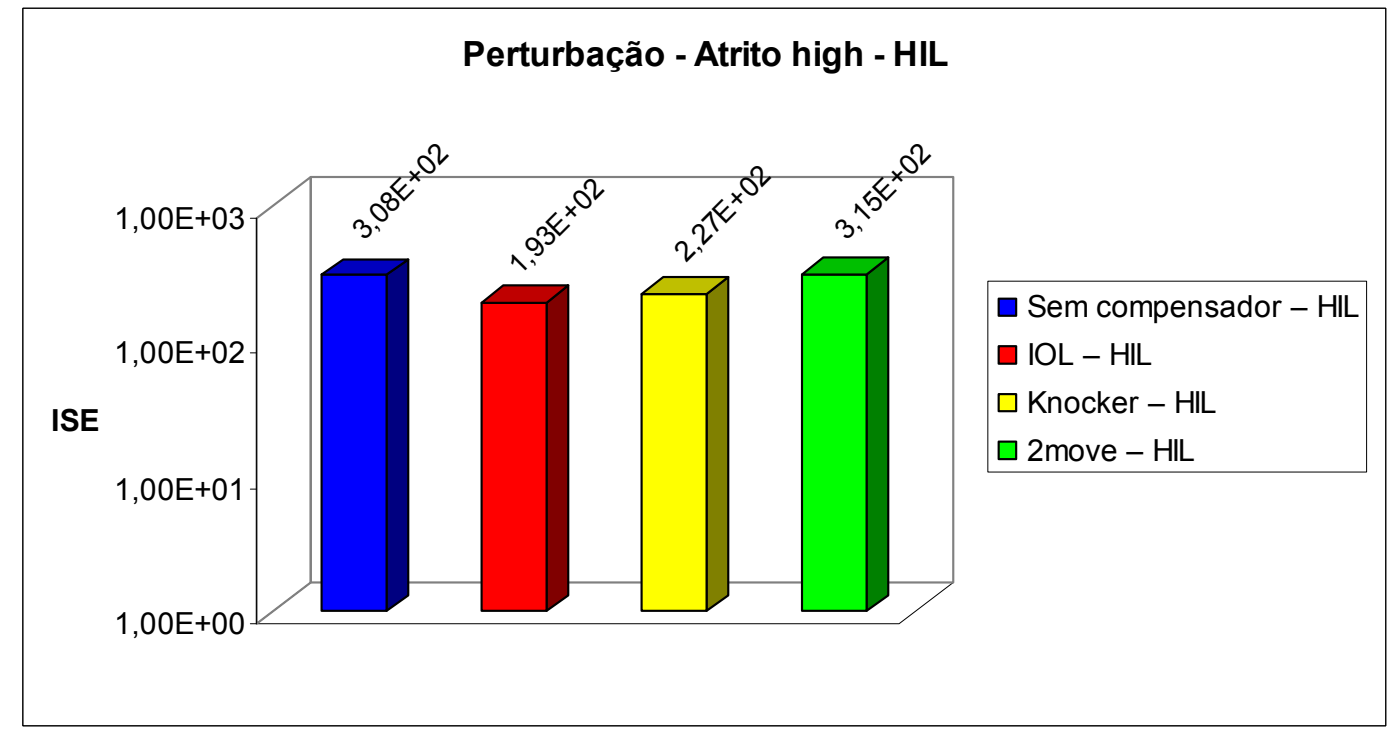

Figura 47: Gráfico de ISE, ensaio de perturbação, atrito high, ambiente HIL

O primeiro comentário com relação à Tabela 6 e às Figuras 44, 45, 46 e 47 é que, no ensaio de perturbação, alguns resultados gráficos não foram conclusivos, pois, visualmente, é muito difícil, neste caso, determinar o nível de melhora obtido ou não com os compensadores.

Os resultados mostrados na Tabela 6 e nas Figuras 44, 45, 46 e 47 indicam que, para o nível de atrito low, tanto no ambiente $100 \%$ simulado quanto no ambiente $H I L$, exceto para o compensador 2 move no ambiente $100 \%$ simulado, a utilização dos compensadores melhora o desempenho da malha de controle. 
Para o nível de atrito high, os resultados indicam que apenas o compensador 2move, no ambiente HIL, não produziu melhoras no desempenho da malha.

\subsection{Ensaios de má-sintonia no controlador PI da malha de vazão}

Foi dito anteriormente neste trabalho que a presença de atrito pode gerar oscilações no processo. Realmente, estes resultados foram observados nos ensaios em degrau, principalmente no ambiente HIL, com nível de atrito high. Porém, em alguns casos, as oscilações no processo também podem ser causadas pela másintonia do próprio controlador da planta. O intuito dos ensaios do item 4.3 é avaliar o desempenho dos compensadores quando, além do atrito, o controlador da planta estiver mal-sintonizado.

\subsubsection{Ensaios de má-sintonia do controlador sem o uso dos compensadores} de atrito

Os ensaios de má-sintonia possuem as seguintes características em comum:

- Duração de simulação $=200$ segundos;

- Passo de integração $=10^{-5}$ segundos;

- Decimação dos pontos $=100$.

Com relação ao controlador $\mathrm{PI}$ da malha de vazão, a sintonia utilizada durante as simulações do item 4.3 é diferente da sintonia utilizada nos ensaios anteriores. Além disso, a sintonia utilizada para gerar as oscilações no ambiente $100 \%$ simulado foi diferente da sintonia utilizada para gerar as oscilações no ambiente HIL. A seguir, na Tabela 7, estão descritos os valores de $K c$ para cada um dos ambientes de simulação. Com relação ao tempo integral do controlador $\left(T_{i}\right)$, o valor é o mesmo em todos os ensaios: $1,93 \mathrm{~s} / \mathrm{rep}$. 
Tabela 7: Sintonia do Controlador PI da malha para ensaios do item 4.3

\begin{tabular}{|l|c|c|}
\hline Ambiente de Simulação & Kc & $\boldsymbol{T i}$ (s/rep) \\
\hline $100 \%$ simulado - Atrito Low & 5 & 1,93 \\
\hline $100 \%$ simulado - Atrito High & 5 & 1,93 \\
\hline HIL - Atrito Low & 2,4530 & 1,93 \\
\hline HIL - Atrito High & 1,115 & 0,7 \\
\hline
\end{tabular}

Uma vez definidas as características acima, o primeiro ensaio realizado é o ensaio de má-sintonia no ambiente $100 \%$ simulado, sem compensador de atrito, na válvula com níveis de atrito low e high. A Figura 48 mostra o resultado deste ensaio para os dois níveis de atrito, com relação ao valor de referência. Para facilitar a visualização do resultado, a Figura 48 está dividida em duas sub-figuras, caso contrário ficaria muito difícil observar o comportamento da saída do sistema.
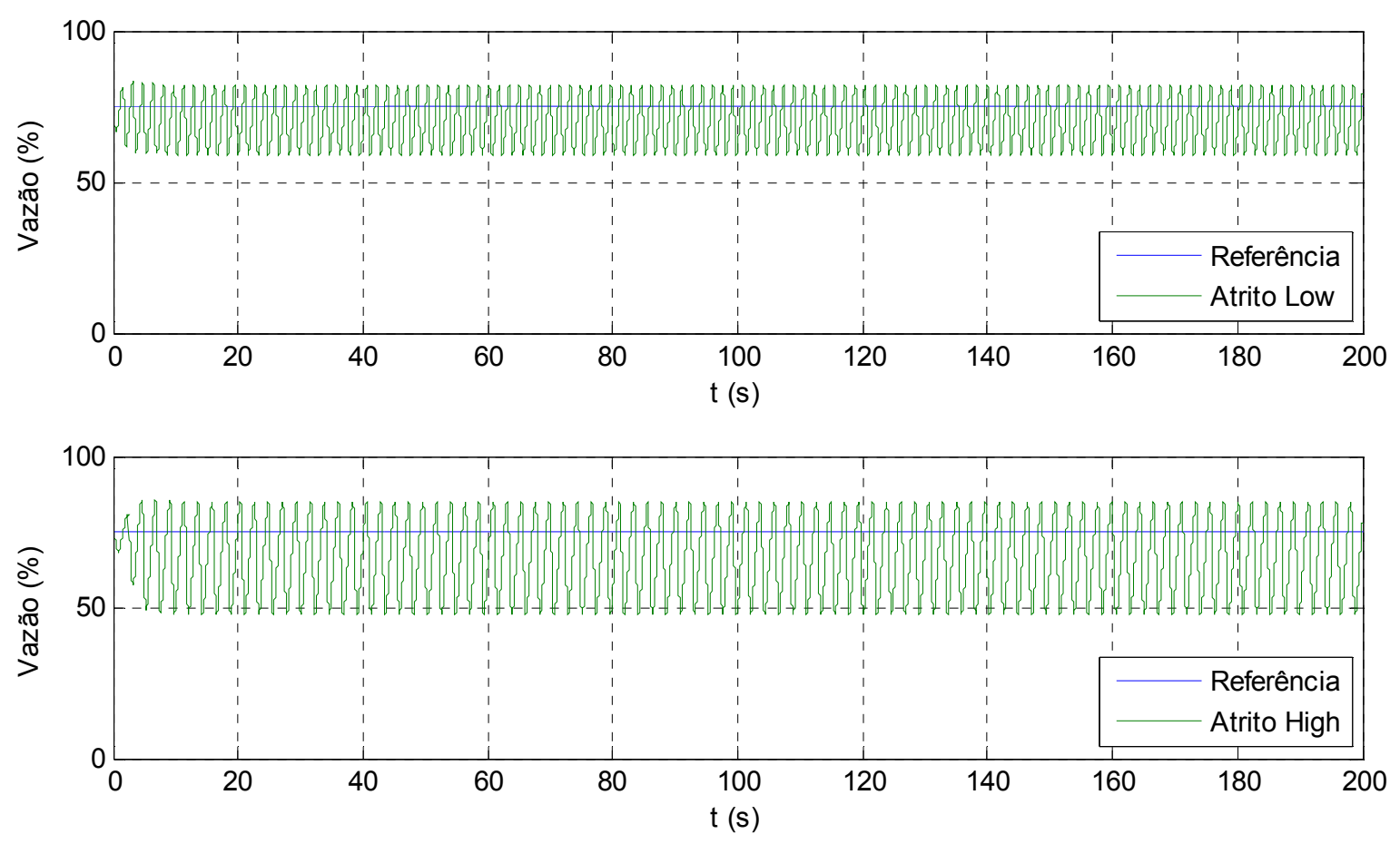

Figura 48: Resposta à má-sintonia, sem compensadores, ambiente $100 \%$ simulado

Antes de qualquer coisa, é importante destacar que, no ambiente 100\% simulado, o sistema não oscilaria, mesmo com a alteração do ganho $K c$ do controlador, já que, idealmente, o sistema sempre parte de uma condição inicial estacionária. Entretanto, 
forçou-se uma condição inicial diferente para que o sistema não partisse da condição estacionária. Desta forma, o controlador da malha de vazão começa a funcionar e tenta levar a variável de processo ao valor de referência.

A análise dos dois gráficos presentes na Figura 48 indica que, com a alteração do ganho do controlador PI da malha de vazão, é possível introduzir oscilações na resposta do processo, quando se trabalha no ambiente $100 \%$ simulado. Para que o sistema oscilasse, o ganho $K c$ foi aumentado gradativamente até um valor que produzisse oscilações para ambos os níveis de atrito estudados. A Figura 48 também aponta que a amplitude de oscilação do sistema é maior para o nível de atrito high, enquanto que a freqüência de oscilação é maior para o nível de atrito low.

Espera-se que o mesmo padrão de resultados seja observado no ambiente HIL. Novamente mantendo a apresentação dos resultados em dois sub-gráficos, têm-se, a seguir, na Figura 49, os resultados obtidos no ambiente HIL, para os níveis de atrito low e high, na ausência dos compensadores.
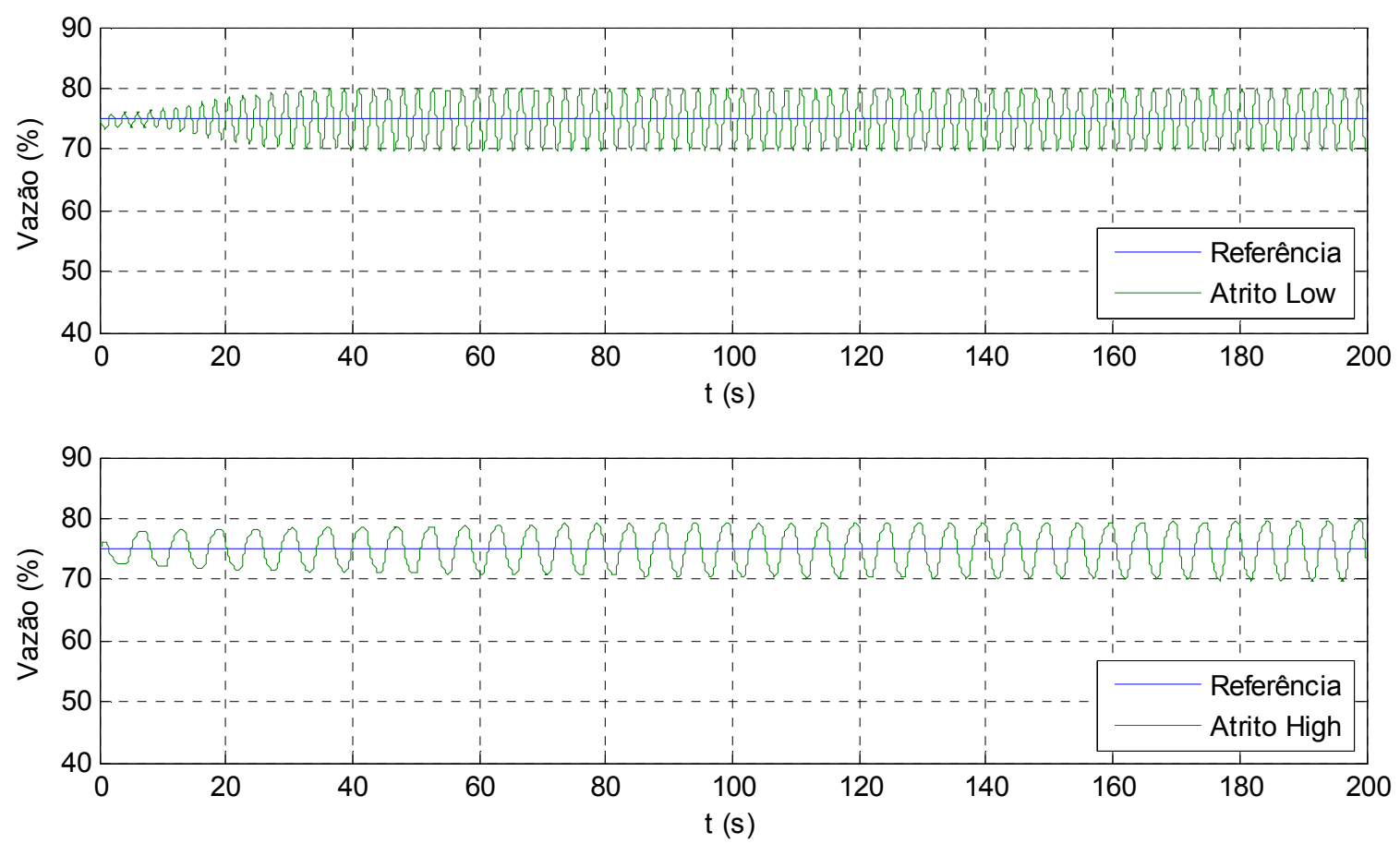

Figura 49: Resposta à má-sintonia, sem compensadores, ambiente $H I L$

A análise da Figura 49 aponta que em ambos os níveis de atrito, o sistema oscila devido à sintonia do controlador. A principal diferença entre os resultados obtidos entre o ambiente $100 \%$ simulado e o ambiente HIL é a amplitude das oscilações. 
Uma possível explicação para este fato é a diferença entre os valores dos parâmetros $\mathrm{Kc}$ e Ti entre os ambientes de ensaio.

\subsubsection{Resposta à má-sintonia com o uso de compensador de atrito $I O L$}

No item anterior, mostrou-se que a má-sintonia do controlador da planta pode realmente gerar oscilações no processo. Os trabalhos propostos na literatura nada falam na possibilidade de utilizar compensadores de atrito para compensar perturbações no processo, tampouco compensar as oscilações geradas por um controlador de processo mal-sintonizado.

Ainda assim, decidiu-se que, neste trabalho, cada um dos compensadores seria ensaiado sob perturbação e má-sintonia do controlador. Os resultados obtidos pelos compensadores na presença de perturbação já foram apresentados no item 4.2. A partir de agora, os compensadores são avaliados na condição de má-sintonia do controlador, começando-se pelo compensador IOL.

Da mesma forma que do que foi adotado no item 4.2, os parâmetros de sintonia k0 e k1 do controlador interno do IOL, são os mesmos valores adotados na Tabela 2. Esta parece ser a escolha mais acertada, pois desta forma é possível avaliar se, mesmo na presença de má-sintonia do controlador da planta, a sintonia adotada para o compensador na malha sem perturbação ainda é capaz de estabilizar a planta.

A seguir, na Figura 50, é ilustrada a resposta à má-sintonia do sistema, em ambiente $100 \%$ simulado, quando o compensador IOL é utilizado, comparada com a resposta do sistema sem a presença de compensador, para o nível de atrito low, no ambiente $100 \%$ simulado. Assim como já foi adotado anteriormente, a figura é dividida em dois sub-gráficos para possibilitar melhor visualização dos resultados. 

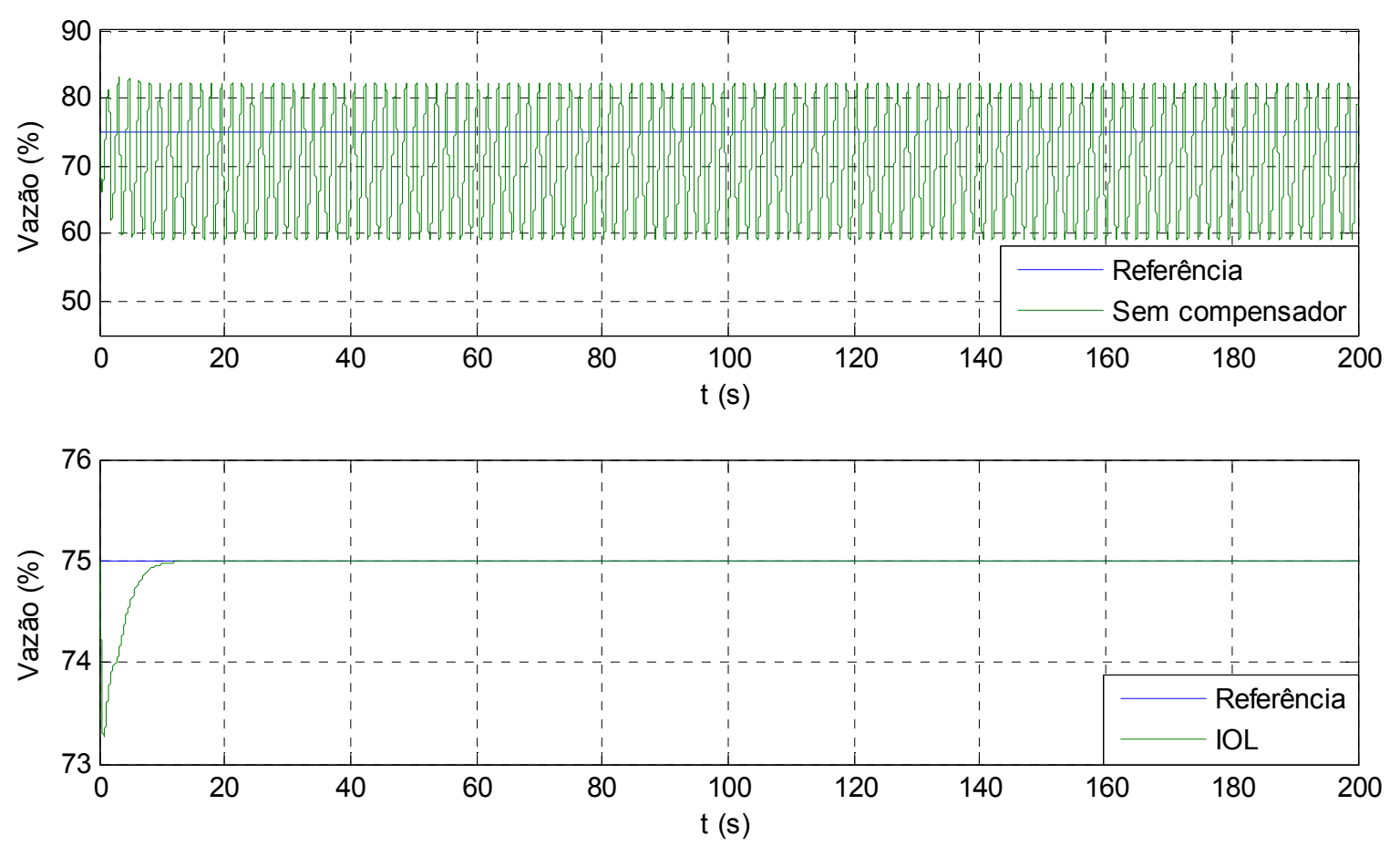

Figura 50: Compensador IOL x sem compensador, atrito low, $100 \%$ simulado, másintonia

A Figura 50 aponta um resultado muito interessante: o compensador $I O L$, neste ensaio, foi capaz de compensar as oscilações geradas no processo pelo controlador mal-sintonizado. A melhoria é claramente perceptível.

A seguir, na Figura 51, apresentam-se os resultados obtidos no HIL, para nível de atrito low, na presença de má-sintonia do controlador: 

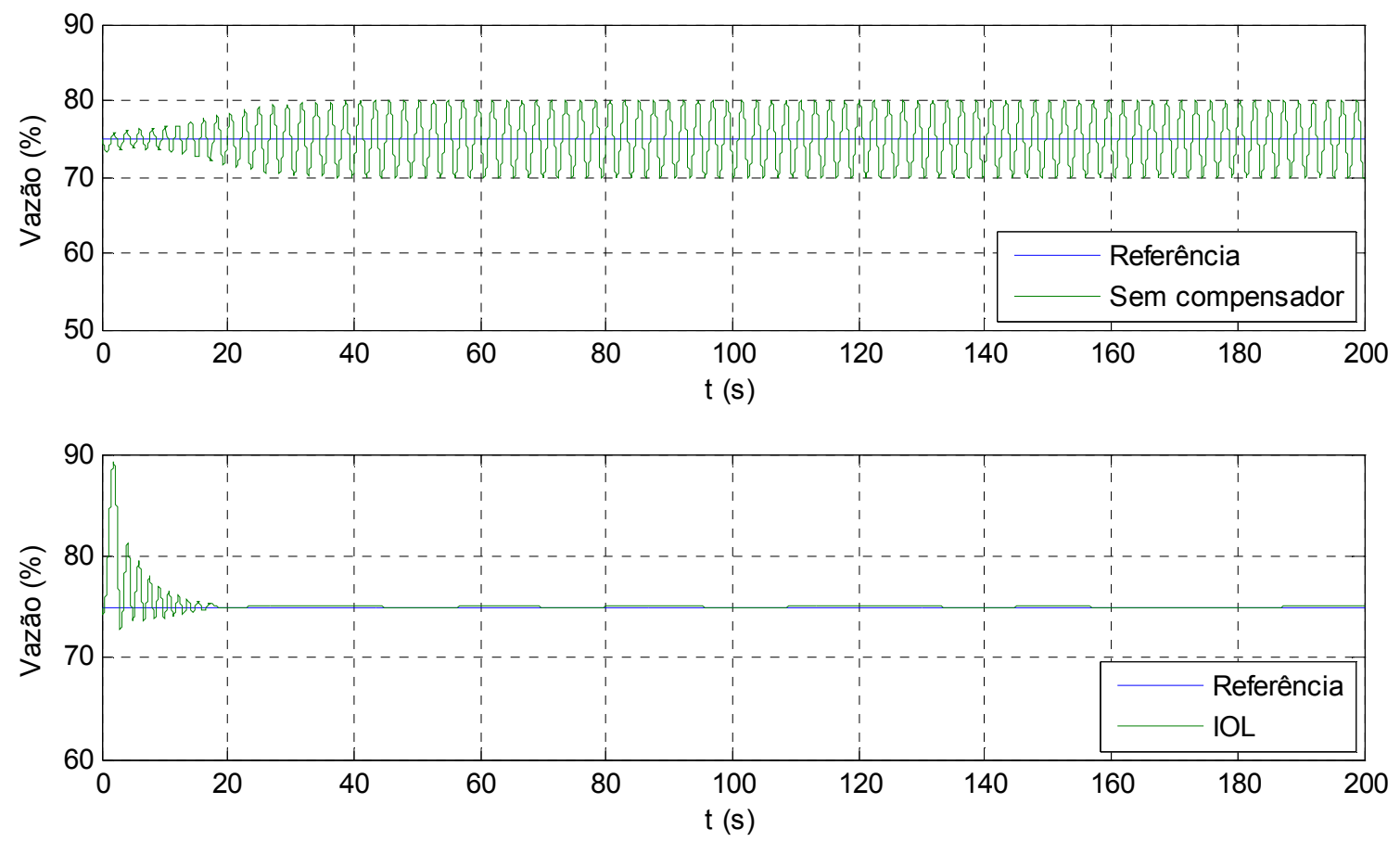

Figura 51: Compensador IOL x sem compensador, atrito low, HIL, má-sintonia

Assim como o que foi observado no ambiente 100\% simulado, o resultado do ensaio no ambiente $H I L$ também mostrou que o compensador $I O L$, para o nível de atrito low, consegue melhorar claramente o desempenho da planta.

Os próximos ensaios, ilustrados nas Figuras 52 e 53, mostram os resultados obtidos com o uso do compensador $I O L$, no ambiente $100 \%$ simulado e no ambiente HIL, respectivamente, para o nível de atrito high. 

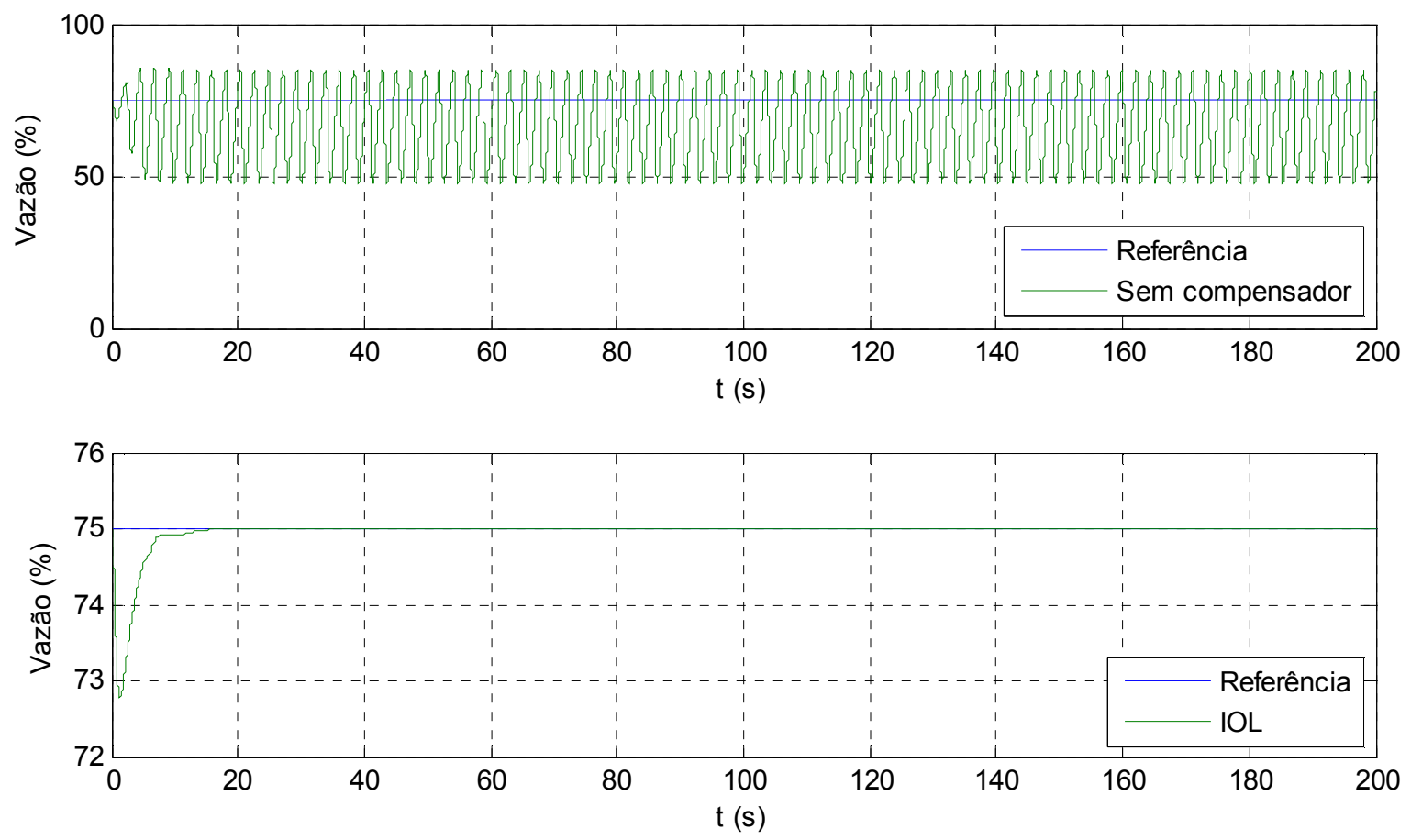

Figura 52: Compensador IOL x sem compensador, atrito high, $100 \%$ simulado, másintonia

Novamente, o compensador $I O L$, agora para o nível de atrito high, apresentou grande melhoria no comportamento do sistema.
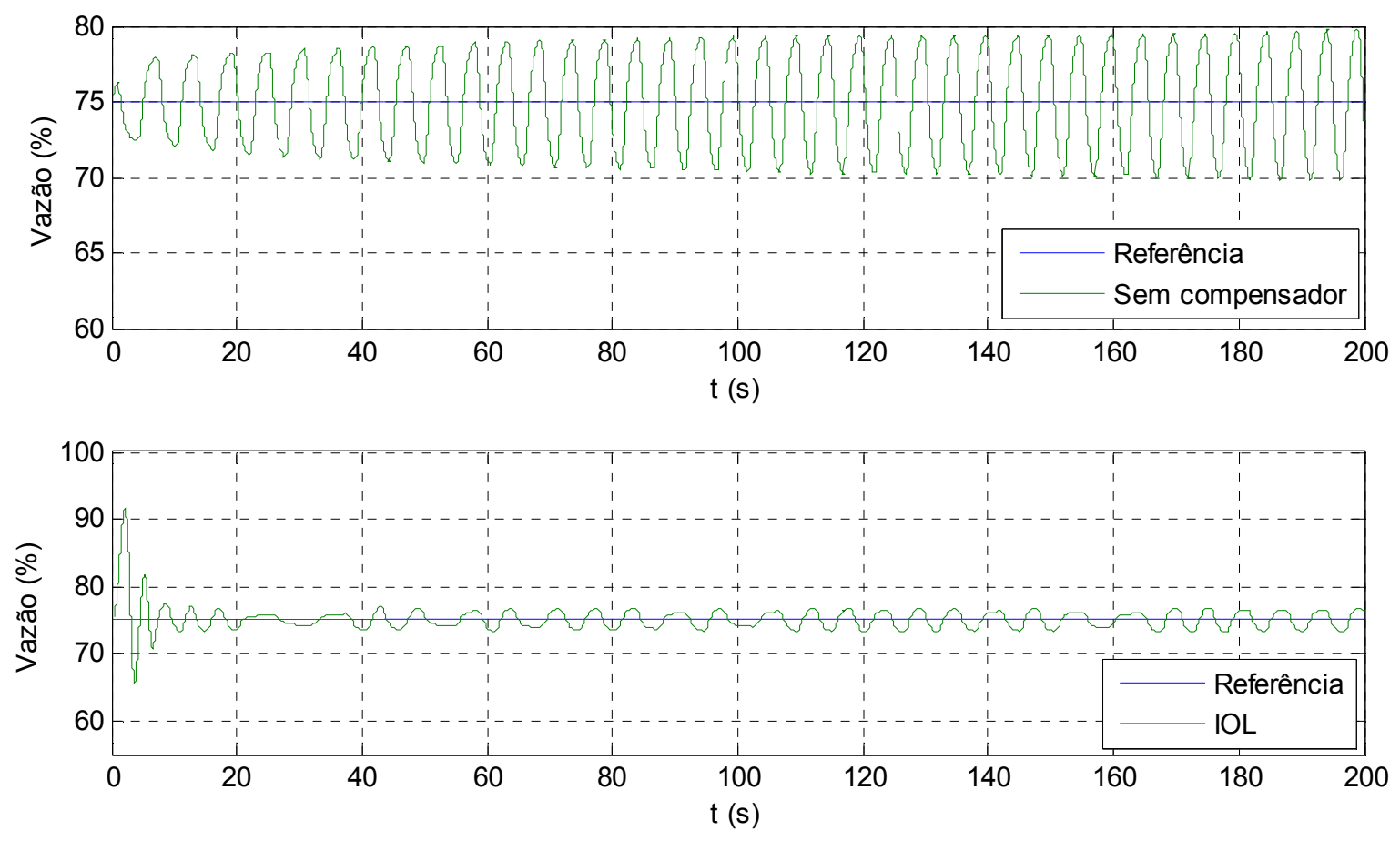

Figura 53: Compensador IOL x sem compensador, atrito high, HIL, má-sintonia 
Pode-se observar a partir da Figura 53 que a utilização do compensador IOL na presença de má-sintonia traz melhorias no desempenho da malha. Entretanto, o compensador teve mais dificuldade para acompanhar o sinal de referência neste ensaio do que nos demais.

Os resultados obtidos nos ensaios do compensador $I O L$ na presença má-sintonia do controlador da planta indicam que, em todos os casos, o compensador IOL foi capaz de melhorar de forma considerável o desempenho da malha.

\subsubsection{Resposta à má-sintonia com o uso de compensador de atrito Knocker}

O próximo compensador avaliado no ensaio de má-sintonia é o Knocker. Assim como foi feito no compensador $I O L$, os parâmetros de sintonia utilizados no compensador Knocker são os mesmos parâmetros adotados para este compensador na Tabela 3.

A seguir, na Figura 54, é ilustrada a resposta do sistema à má-sintonia, em ambiente $100 \%$ simulado, quando o compensador Knocker é utilizado, comparada com a resposta do sistema sem a presença do compensador, para o nível de atrito low, no mesmo ambiente:
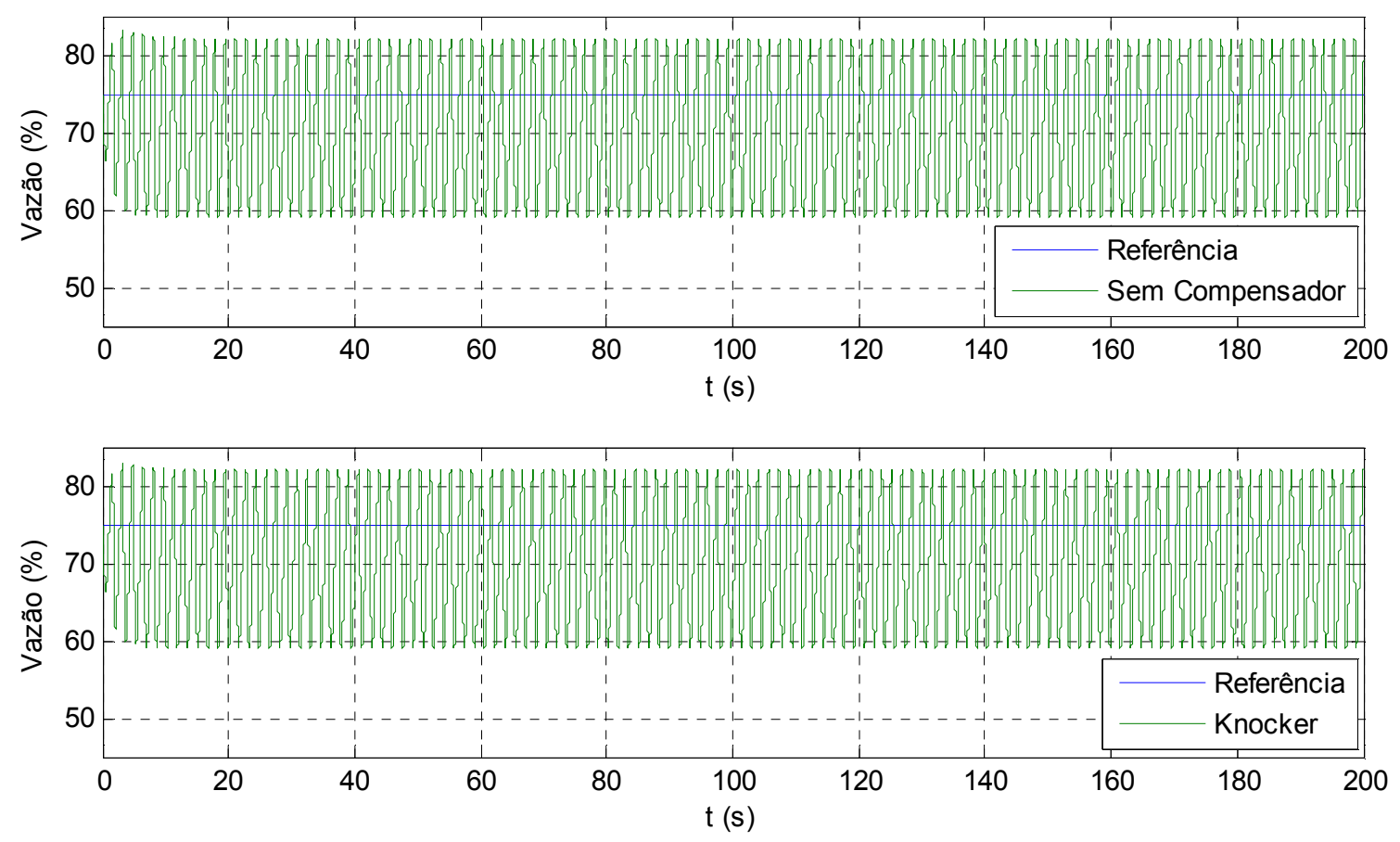

Figura 54: Compensador Knocker $x$ sem compensador, atrito low, 100\% simulado, másintonia 
A Figura 54 indica que a utilização do compensador Knocker neste ensaio não apresentou melhora de desempenho na resposta da malha, com relação ao sistema sem compensador, na presença de má-sintonia.

Dando continuidade aos ensaios e seus resultados, a seguir, na Figura 55, são apresentados os resultados obtidos no ambiente HIL, para nível de atrito low, na presença de má-sintonia.
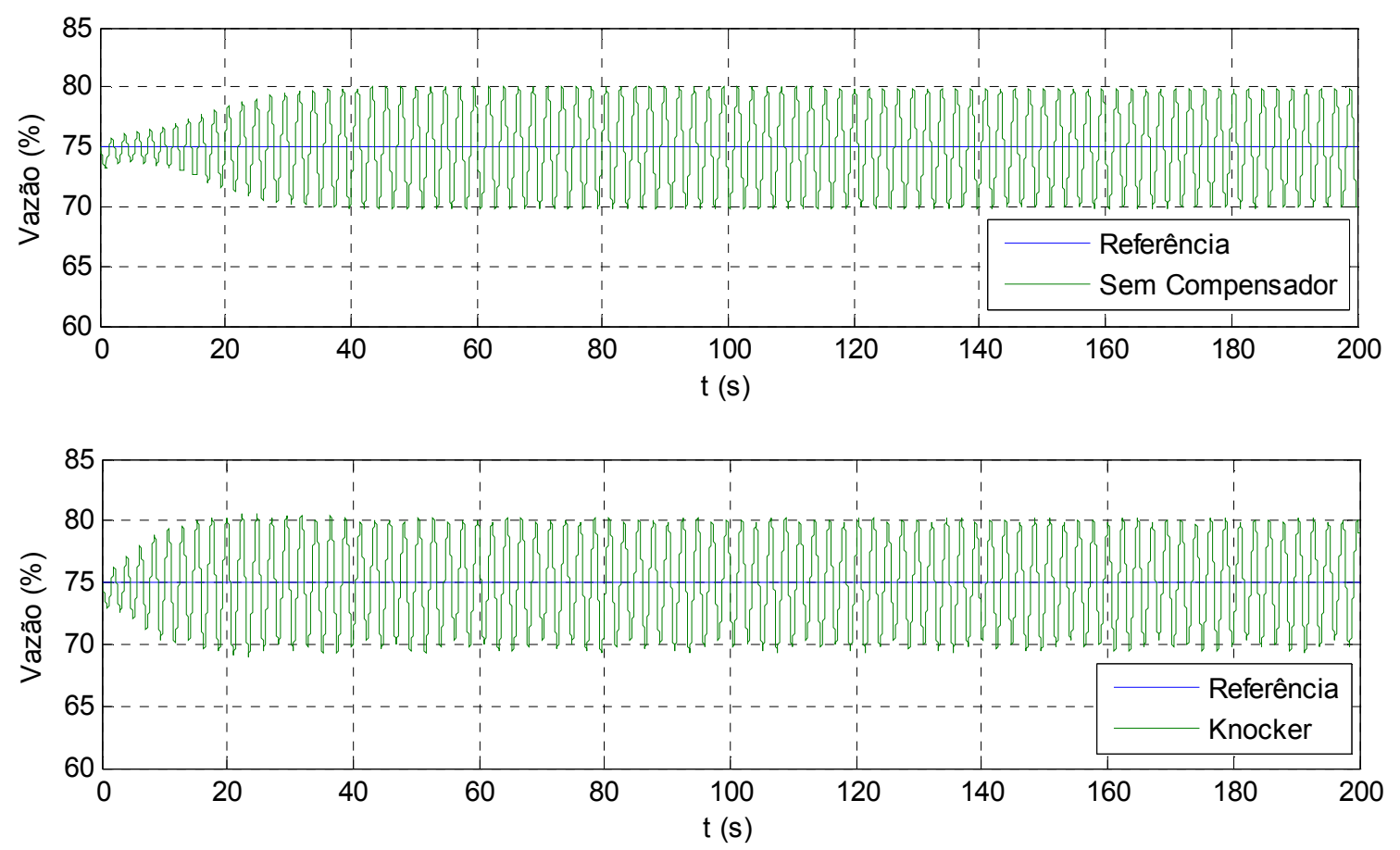

Figura 55: Compensador Knocker x sem compensador, atrito low, HIL, má-sintonia

Assim como foi observado no ambiente 100\% simulado, a análise da Figura 55 indica que o resultado obtido no ambiente $H I L$, para o nível de atrito low, não apresenta melhora na resposta do sistema quando o compensador Knocker é utilizado.

O próximo ensaio avalia o comportamento do compensador Knocker, em ambiente $100 \%$ simulado, para o nível de atrito high, na presença de má sintonia. A Figura 56 ilustra os resultados obtidos neste ensaio. 

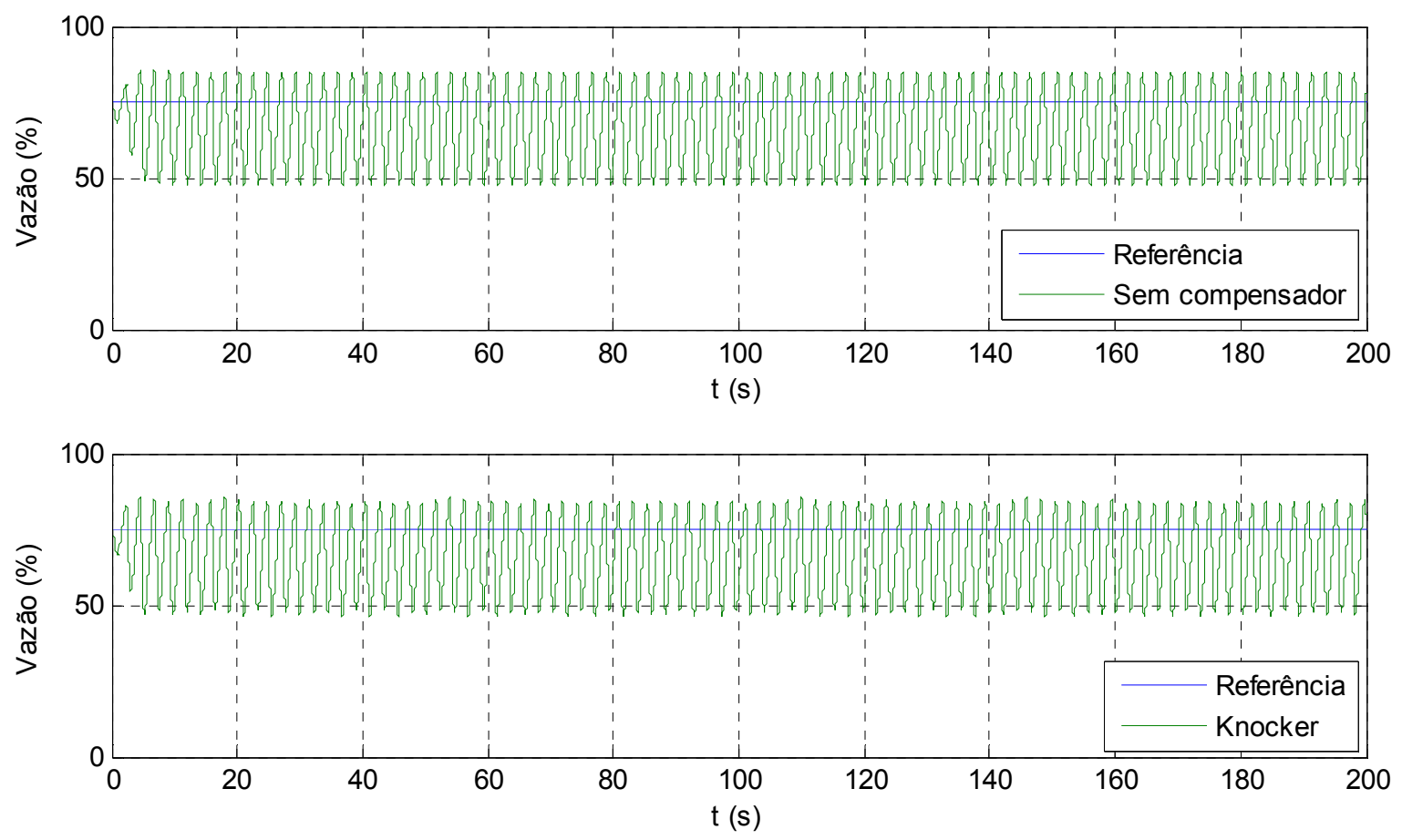

Figura 56: Compensador Knocker $x$ sem compensador, atrito high, $100 \%$ simulado, má-sintonia

A análise da Figura 56 indica que não houve nenhuma melhora com relação ao sistema sem compensador neste ensaio, ou seja, o sistema continua apresentando oscilações.

O compensador Knocker está apresentando, até aqui, um desempenho muito ruim na compensação de oscilações geradas por má-sintonia no controlador da planta. O último ensaio referente ao compensador Knocker é o ensaio no ambiente HIL, com nível de atrito high. A seguir, são apresentados na Figura 57 os resultados obtidos neste último ensaio do compensador Knocker, na presença de má-sintonia. 

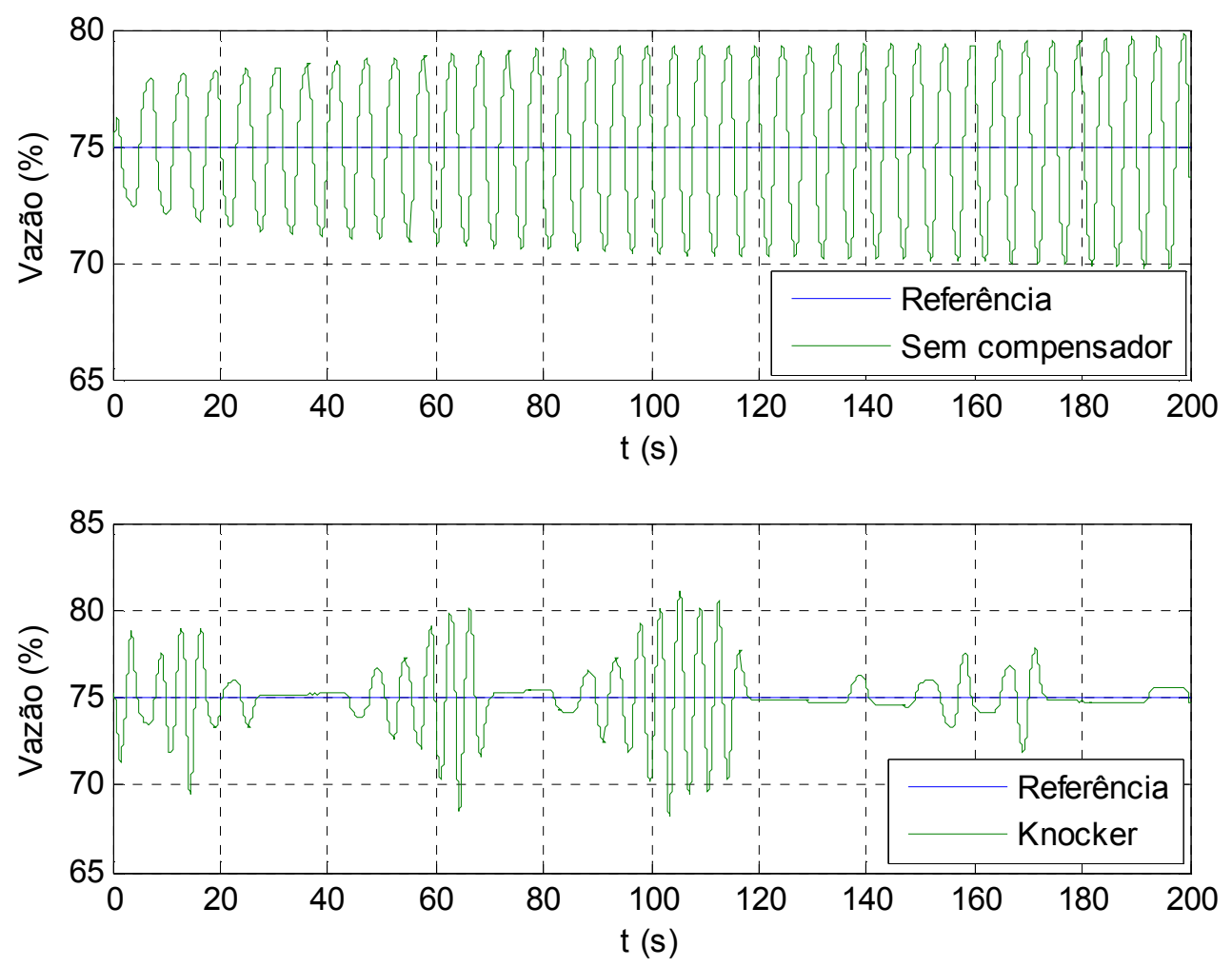

Figura 57: Compensador Knocker x sem compensador, atrito high, HIL, má-sintonia

Neste ensaio, foi possível observar melhora com a utilização do compensador Knocker, na presença de má-sintonia.

Pelo que foi apresentado neste item, pode-se concluir que o compensador Knocker não apresentou melhora no desempenho da malha nos ensaios realizados na presença de má-sintonia do controlador da planta, exceto no ensaio em ambiente HIL, com nível de atrito high.

\subsubsection{Resposta à má-sintonia com o uso de compensador de atrito 2 move}

O próximo compensador avaliado no ensaio de resposta à má-sintonia é o 2 move. Seguindo a metodologia adotada até agora nos ensaios do item 4.3, são mantidos os instantes de tempo em que ocorrem os dois movimentos, conforme descrito na Tabela 4 , assim como o valor do nível de atrito estimado $d=0,2$ ou $20 \%$.

A seguir, na Figura 58, é apresentada a resposta à má-sintonia, em ambiente $100 \%$ simulado, para nível de atrito low, quando o compensador 2 move é utilizado 
comparada com a resposta do sistema, nas mesmas condições, sem a presença de compensador.
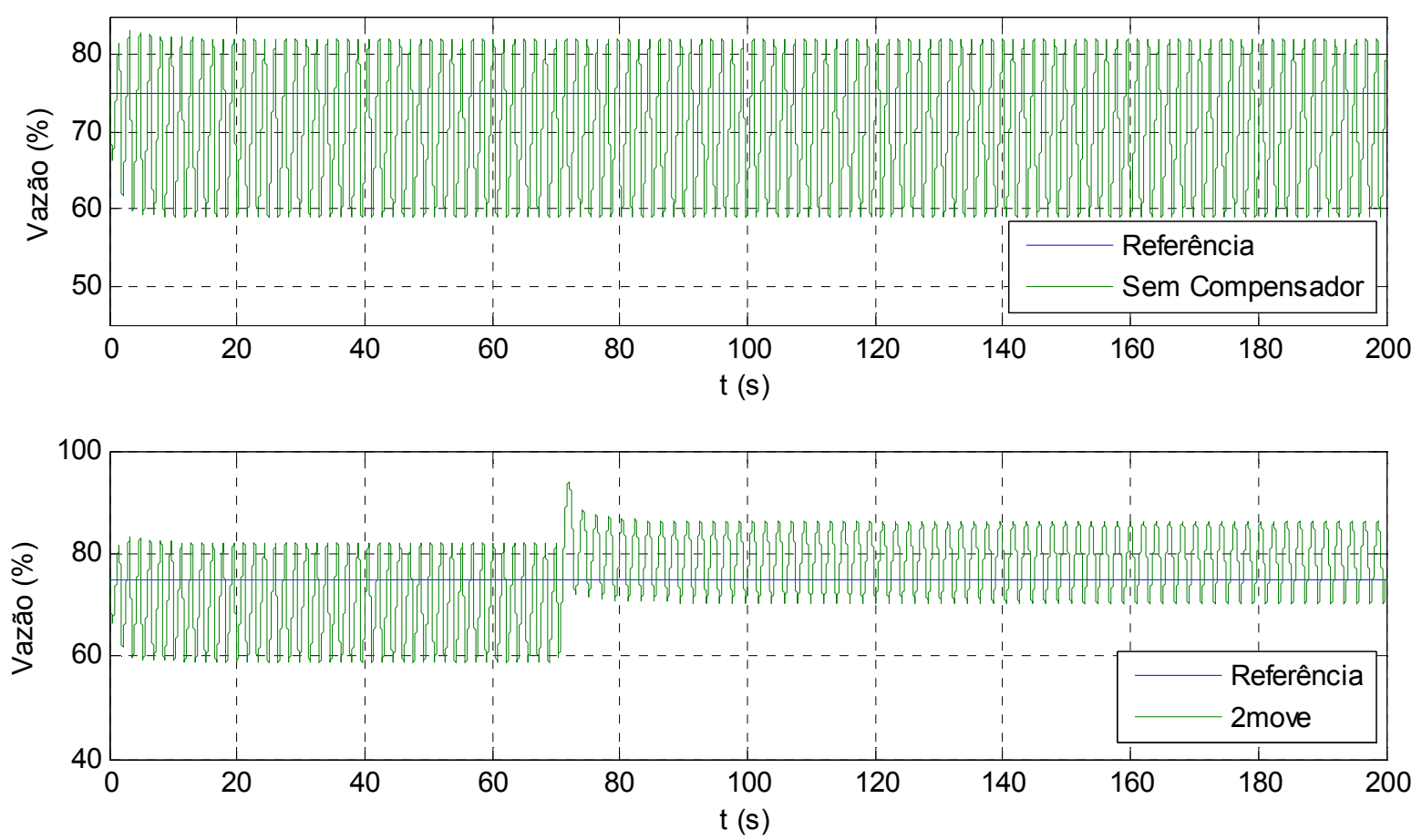

Figura 58: Compensador 2 move x sem compensador, atrito low, $100 \%$ simulado, másintonia

A Figura 58 aponta que, a partir do instante em que o compensador 2 move é acionado $(t=70 \mathrm{~s})$, a amplitude da oscilação em torno do sinal de referência diminui. Dando continuidade aos ensaios, a seguir, na Figura 59, são apresentados os resultados obtidos no ambiente HIL, para nível de atrito low: 

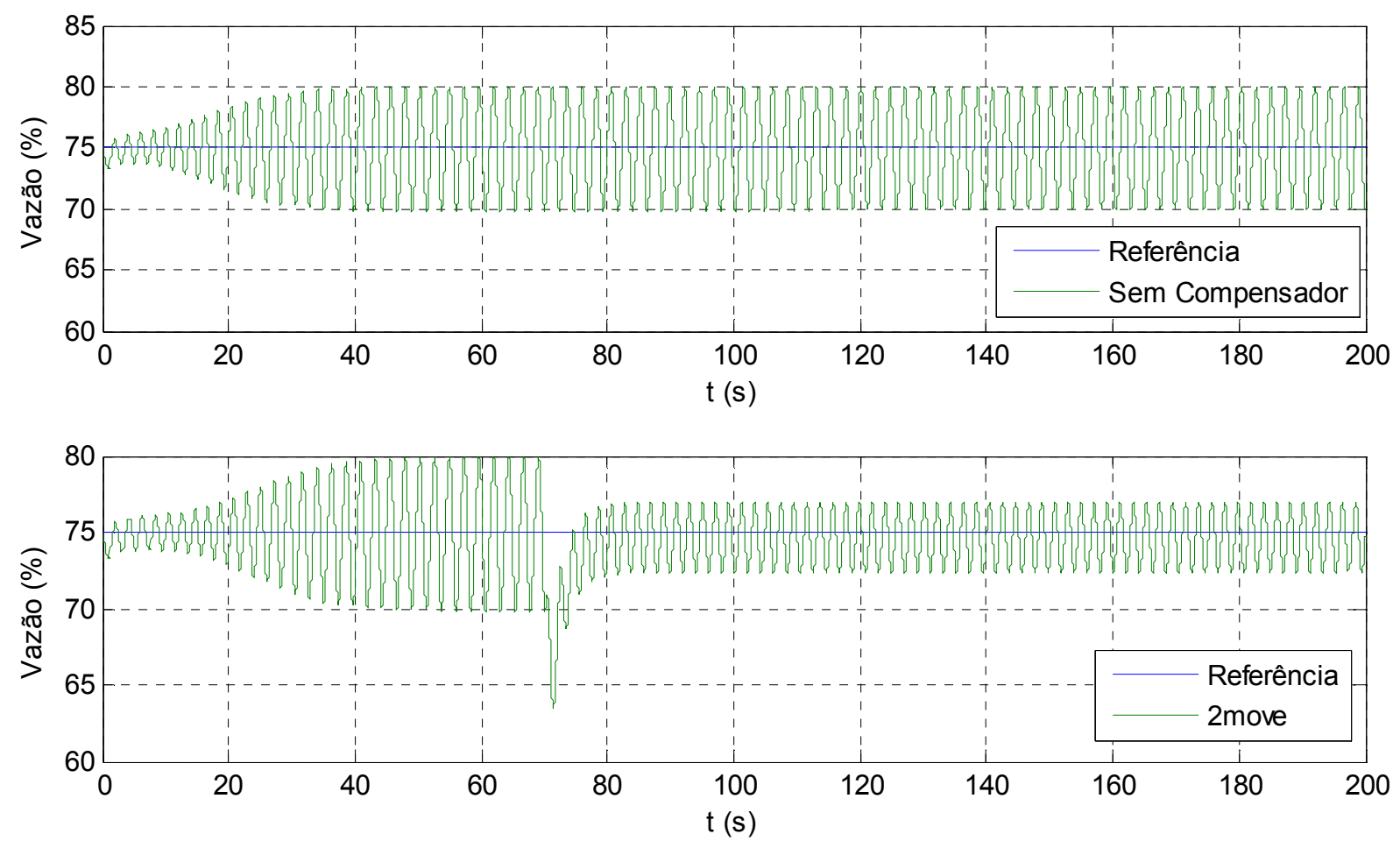

Figura 59: Compensador 2 move x sem compensador, atrito low, HIL, má-sintonia

Assim como no ensaio em ambiente $100 \%$ simulado, a utilização do compensador 2 move na presença de má-sintonia reduziu a amplitude das oscilações quando ele foi acionado.

Mantendo a seqüência dos ensaios, no próximo ensaio é avaliado o comportamento do compensador 2 move, em ambiente $100 \%$ simulado, para o nível de atrito high. Os resultados obtidos neste ensaio são apresentados a seguir, na Figura 60. 

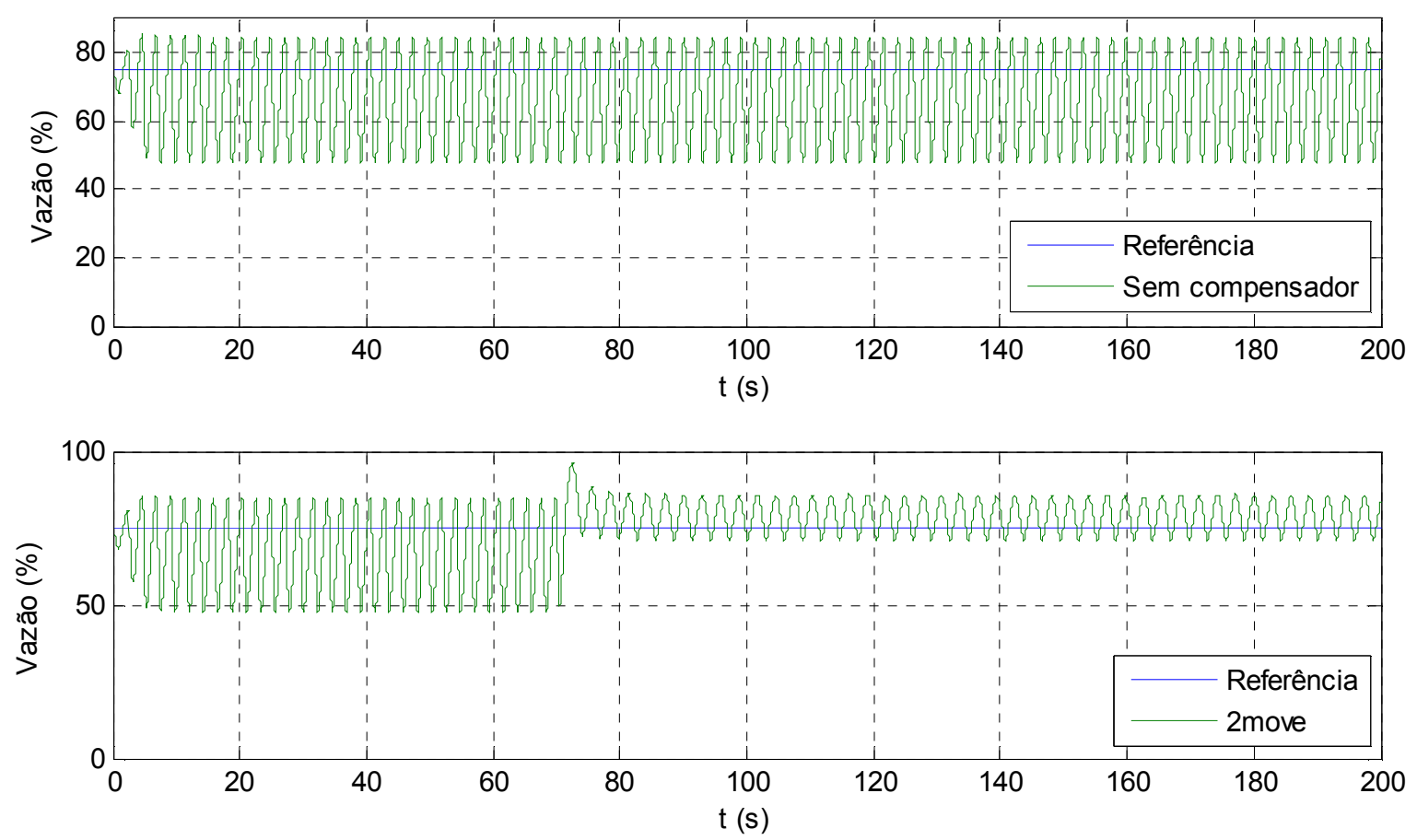

Figura 60: Compensador 2 move $x$ sem compensador, atrito high, 100\% simulado, másintonia

Na Figura 60 é possível verificar que a utilização do compensador 2 move na presença de má-sintonia, para o nível de átrio high, apresentou melhoria no desempenho da malha, através da redução da amplitude das oscilações.

Finalizando os ensaios com o compensador 2 move, a seguir, na Figura 61, são apresentados os resultados obtidos no ensaio em ambiente HIL, na presença de másintonia, para o nível de atrito high. 

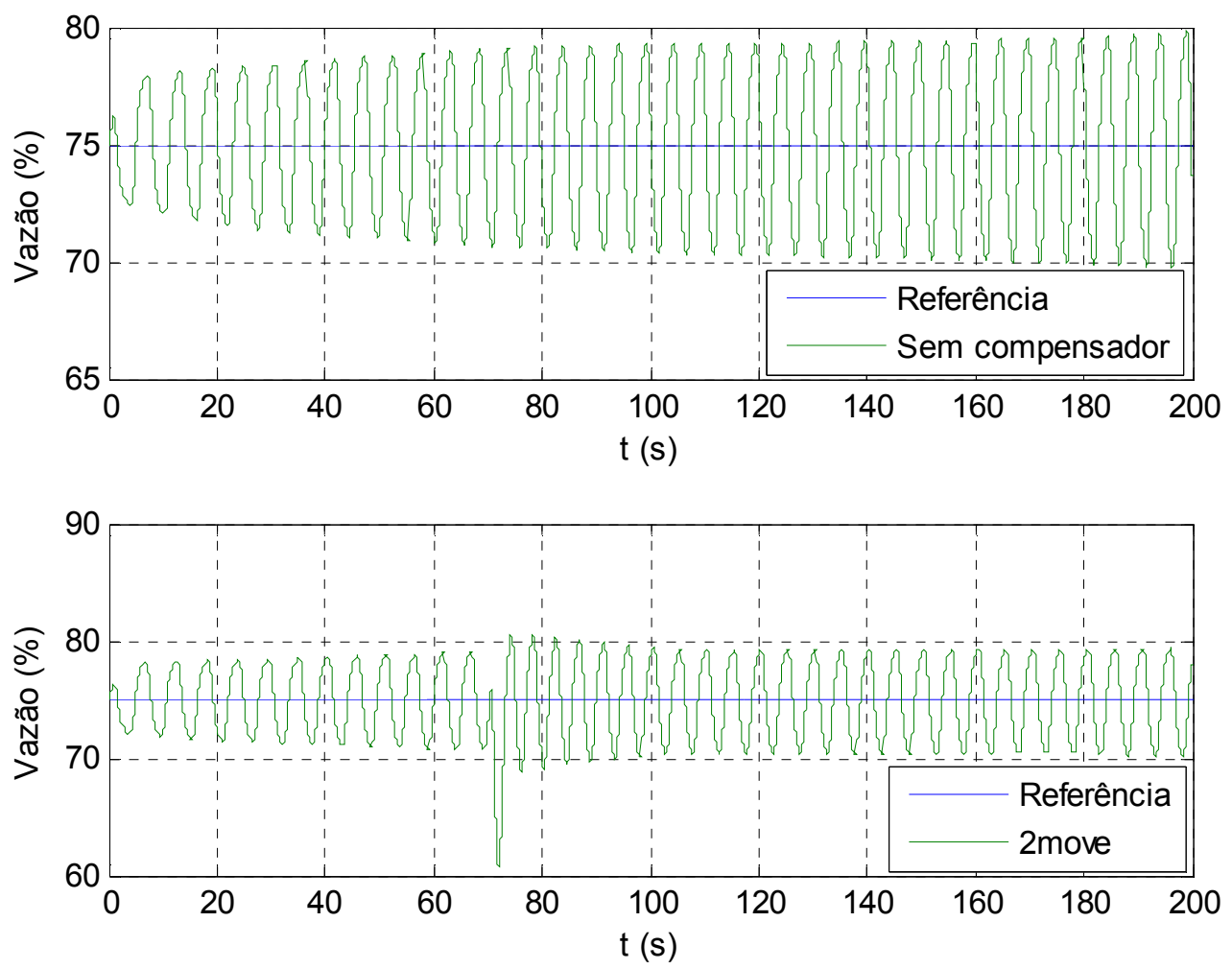

Figura 61: Compensador 2move x sem compensador, atrito high, HIL, má-sintonia

Finalmente, no ensaio com nível de atrito high no ambiente $H I L$, não é possível observar se o uso do compensador 2 move, de alguma forma, melhorou a resposta do sistema.

O compensador 2 move não apresentou melhora significativa no desempenho da malha de vazão, na presença de má-sintonia, exceto pela redução da amplitude da oscilação na maioria dos casos. Desta forma, dentre os três compensadores, aquele que apresentou melhores resultados nos ensaios de má-sintonia foi o IOL.

\subsubsection{Análise comparativa do ISE entre os compensadores para o ensaio de má-sintonia}

Assim como foi feito no ensaio em degrau e no ensaio de perturbação, o ensaio de má-sintonia também tem seus resultados de ISE descritos no formato de uma tabela e de gráicos. Seguem, na Tabela 8 e nas Figuras 62, 63, 64 e 65, os resultados obtidos para cada um dos compensadores, com relação ao sistema sem nenhum compensador, para os dois ambientes de simulação e para os dois níveis de atrito. 
Tabela 8: ISE - Ensaio de má-sintonia

\begin{tabular}{|l|c|c|}
\hline Nível de atrito & Atrito Low & Atrito High \\
\hline Sem compensador - 100\% simulado & $1,11 \mathrm{E}+04$ & $2,92 \mathrm{E}+04$ \\
\hline IOL - 100\% simulado & $0,00 \mathrm{E}+00$ & $0,00 \mathrm{E}+00$ \\
\hline Knocker - 100\% simulado & $1,09 \mathrm{E}+04$ & $3,04 \mathrm{E}+04$ \\
\hline $2 m o v e-100 \%$ simulado & $5,60 \mathrm{E}+03$ & $4,95 \mathrm{E}+03$ \\
\hline Sem compensador $-H I L$ & $1,52 \mathrm{E}+03$ & $1,38 \mathrm{E}+03$ \\
\hline IOL - HIL & $1,58 \mathrm{E}+03$ & $3,65 \mathrm{E}+02$ \\
\hline Knocker - HIL & $1,32 \mathrm{E}+02$ & $1,35 \mathrm{E}+03$ \\
\hline
\end{tabular}




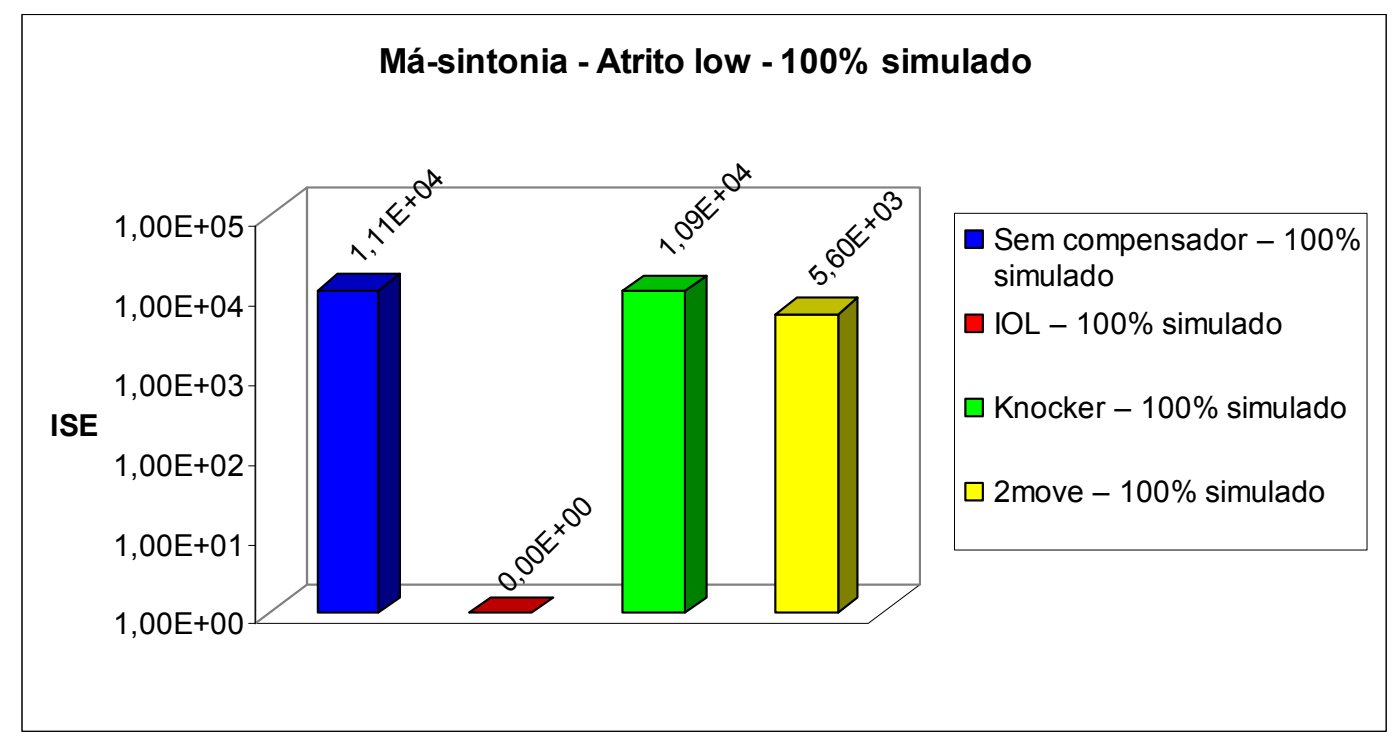

Figura 62: Gráfico de ISE, ensaio de má-sintonia, atrito low, ambiente $100 \%$ simulado

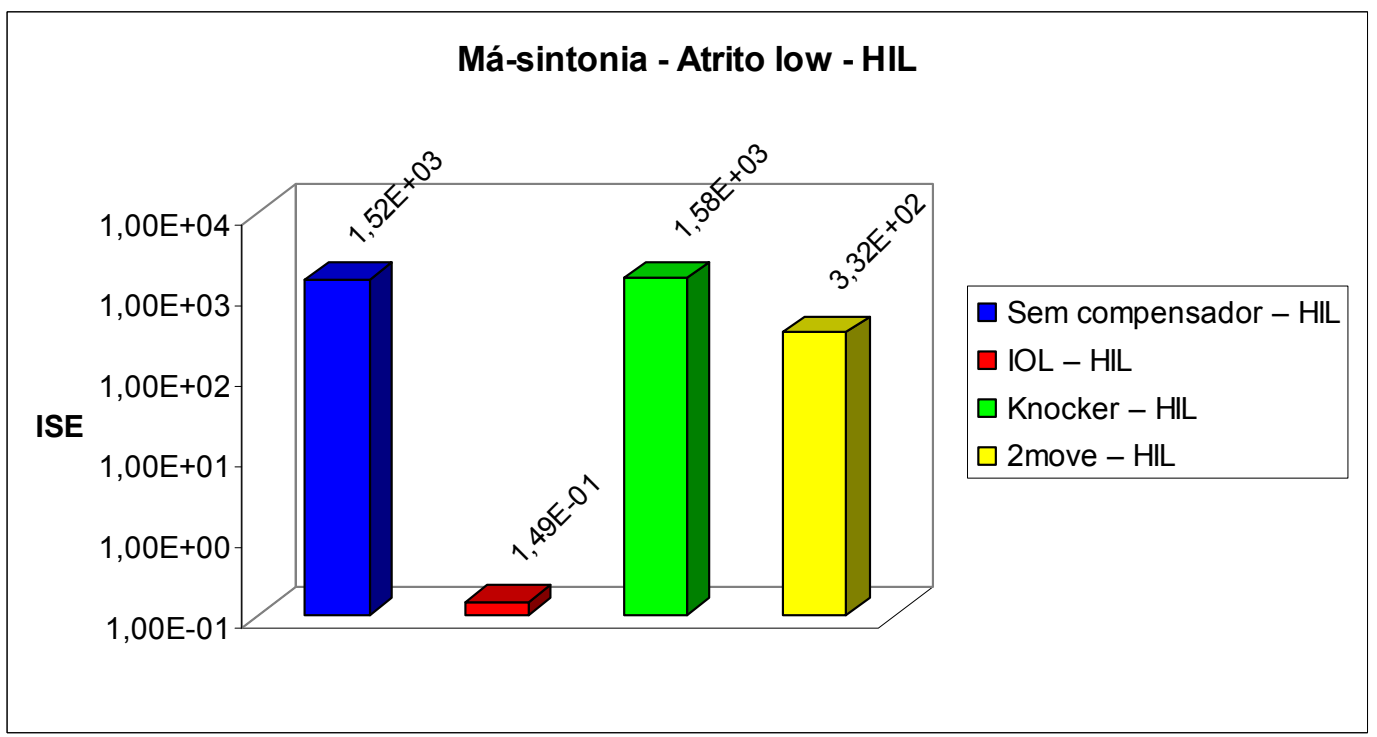

Figura 63: Gráfico de ISE, ensaio de má-sintonia, atrito low, ambiente HIL 


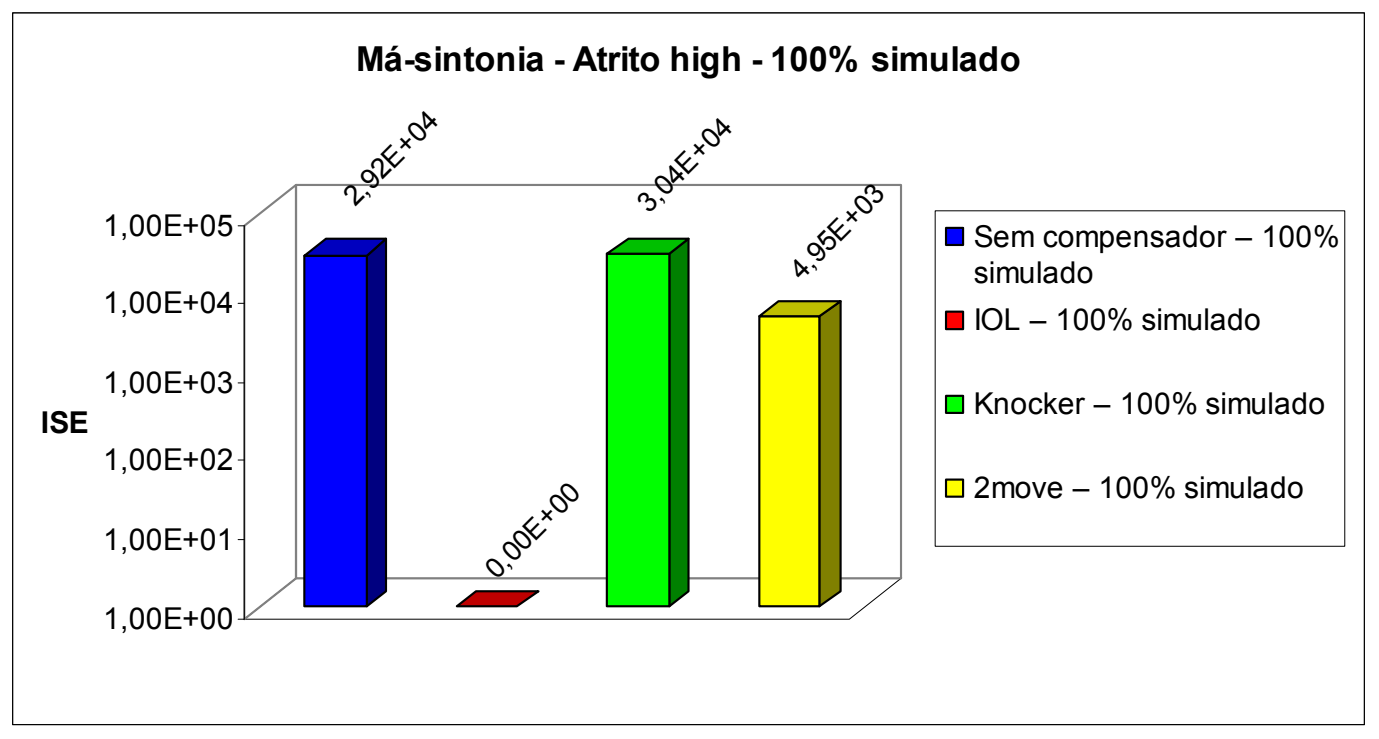

Figura 64: Gráfico de ISE, ensaio de má-sintonia, atrito high, ambiente $100 \%$ simulado

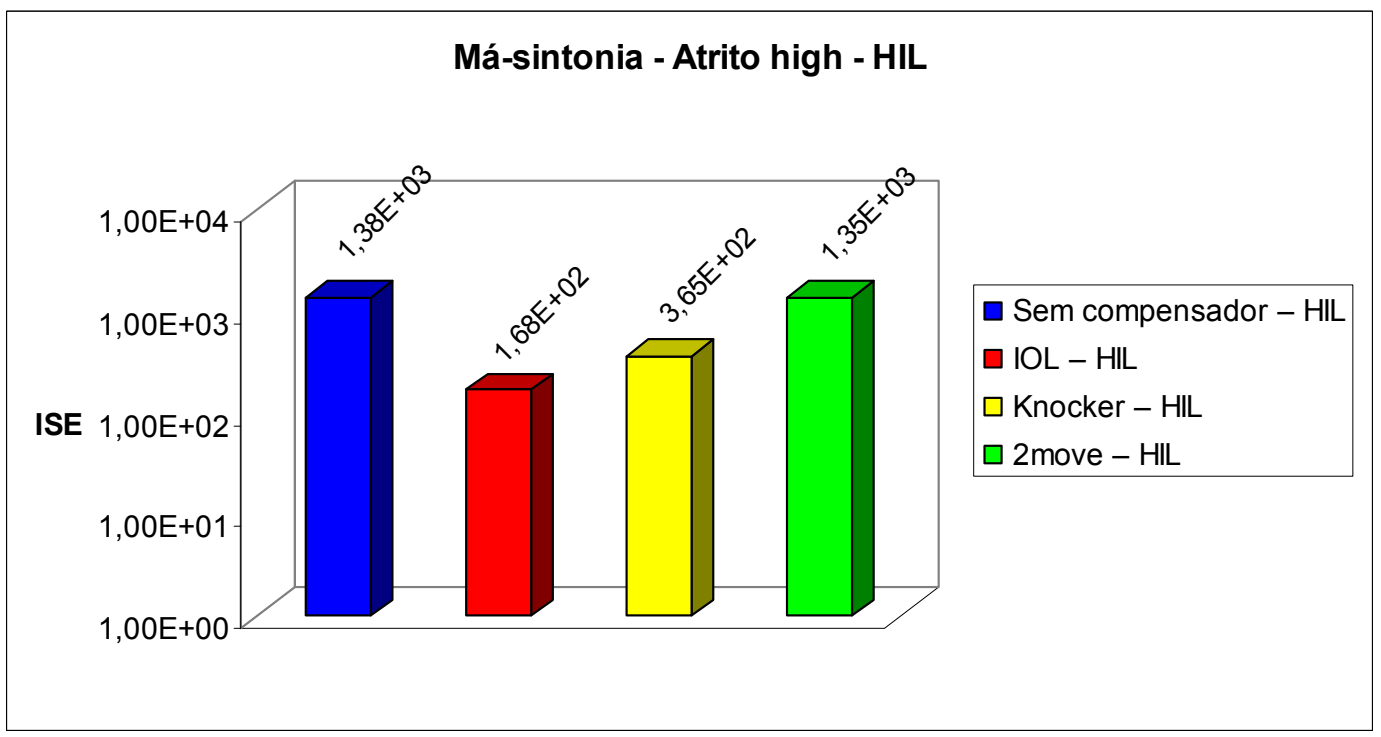

Figura 65: Gráfico de ISE, ensaio de má-sintonia, atrito high, ambiente HIL

O primeiro comentário com relação à Tabela 8 e às Figuras 62, 63, 64 e 65 é semelhante ao comentário que foi feito com relação à Tabela 6: no ensaio de perturbação, visualmente é muito difícil, em alguns casos, determinar o nível de melhora obtido ou não com os compensadores.

Os resultados mostrados na Tabela 8 e nas Figuras 62, 63, 64 e 65 indicam que, para o nível de atrito low, tanto no ambiente $100 \%$ simulado quanto no ambiente $H I L$, exceto para o compensador para o compensador Knocker no ambiente HIL, a utilização dos compensadores melhora o desempenho da malha de controle. A melhora é sutil e, na maioria dos casos, não é possível percebê-la nos gráficos. 
Já para o nível de atrito high, apenas os compensador IOL e 2move, no ambiente $100 \%$ simulado, apresentaram melhora no desempenho da malha. No ambiente HIL, os três compensadores apresentaram melhora no desempenho da malha.

Apesar de apresentar um bom desempenho para compensar as oscilações geradas na malha pela má-sintonia do controlador da planta, principalmente quando o compensador IOL foi utilizado, os resultados obtidos nos ensaios de má-sintonia são muito particulares. Na verdade, a idéia destes ensaios foi observar se, além das oscilações geradas pelo atrito estático, os compensadores seriam capazes de compensar outros tipos de oscilações presentes na malha que apresentassem um comportamento parecido às oscilações geradas pelo atrito estático. É importante ressaltar que, a rigor, os compensadores de atrito deveriam compensar somente o atrito, mas, no caso dos ensaios de má-sintonia em particular, os compensadores foram capazes de compensar oscilações cuja origem não era o atrito estático. 


\subsection{Breve análise das oscilações geradas na haste da válvula com o uso dos compensadores}

Foi dito anteriormente neste trabalho que os compensadores $\mathrm{IOL}$ e Knocker fazem com que a haste da válvula oscile demais, o que pode gerar desgaste prematuro da válvula.

Para analisar este comportamento, foi escolhido um dos diversos ensaios realizados até agora: ambiente 100\% simulado e ambiente HIL, nível de atrito high, ensaio em degrau. A seguir, na Figura 54, é mostrado o comportamento da haste da válvula, no ambiente $100 \%$ simulado, quando nenhum dos compensadores é utilizado.

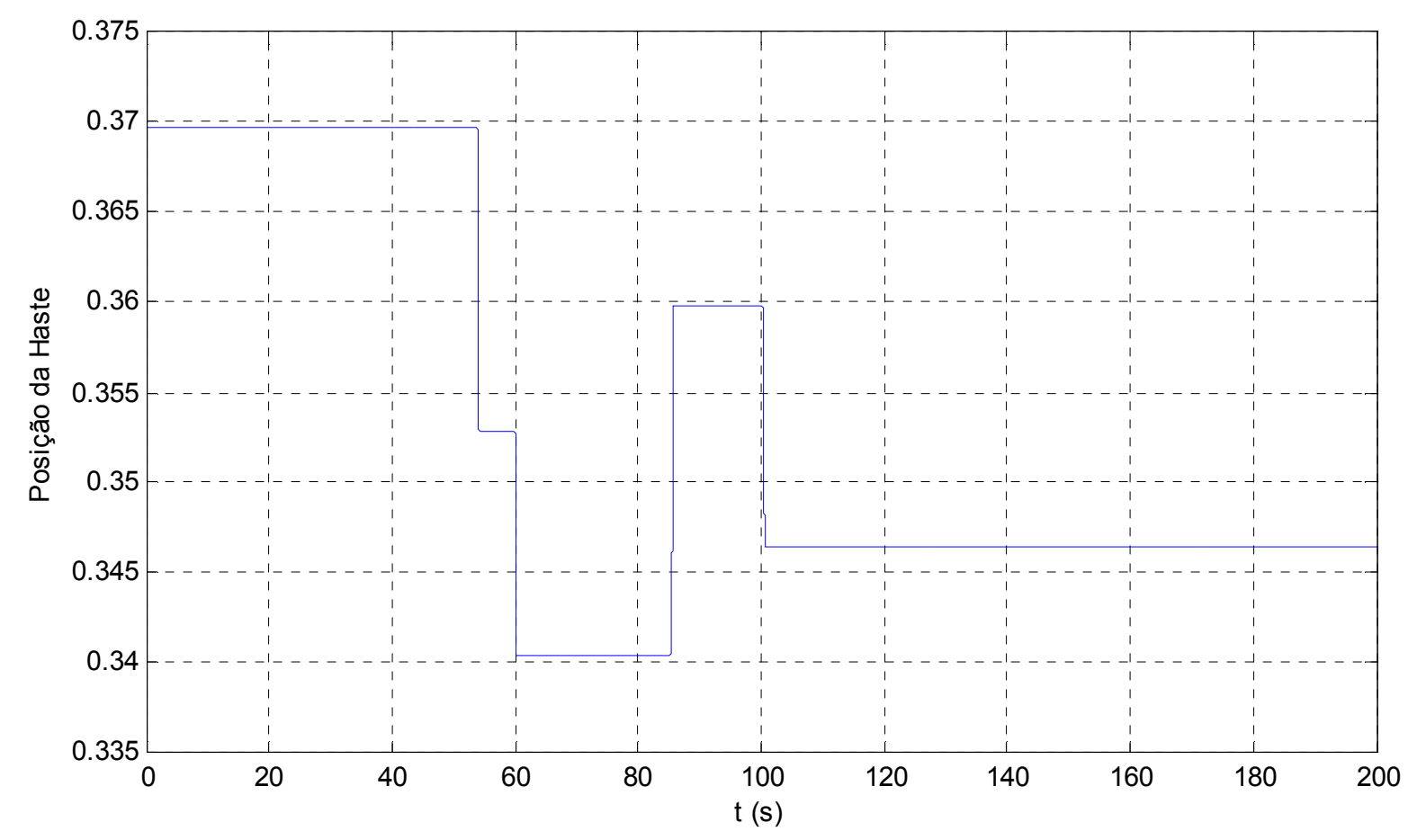

Figura 66: Sem compensador, $100 \%$ simulado, posição da haste da válvula

A análise da Figura 66 indica que a haste da válvula ficou oscilando em torno de um ponto de equilíbrio após o degrau. A seguir, na Figura 67, é mostrado o comportamento da haste da válvula, no ambiente $100 \%$ simulado, quando o compensador IOL é utilizado. 


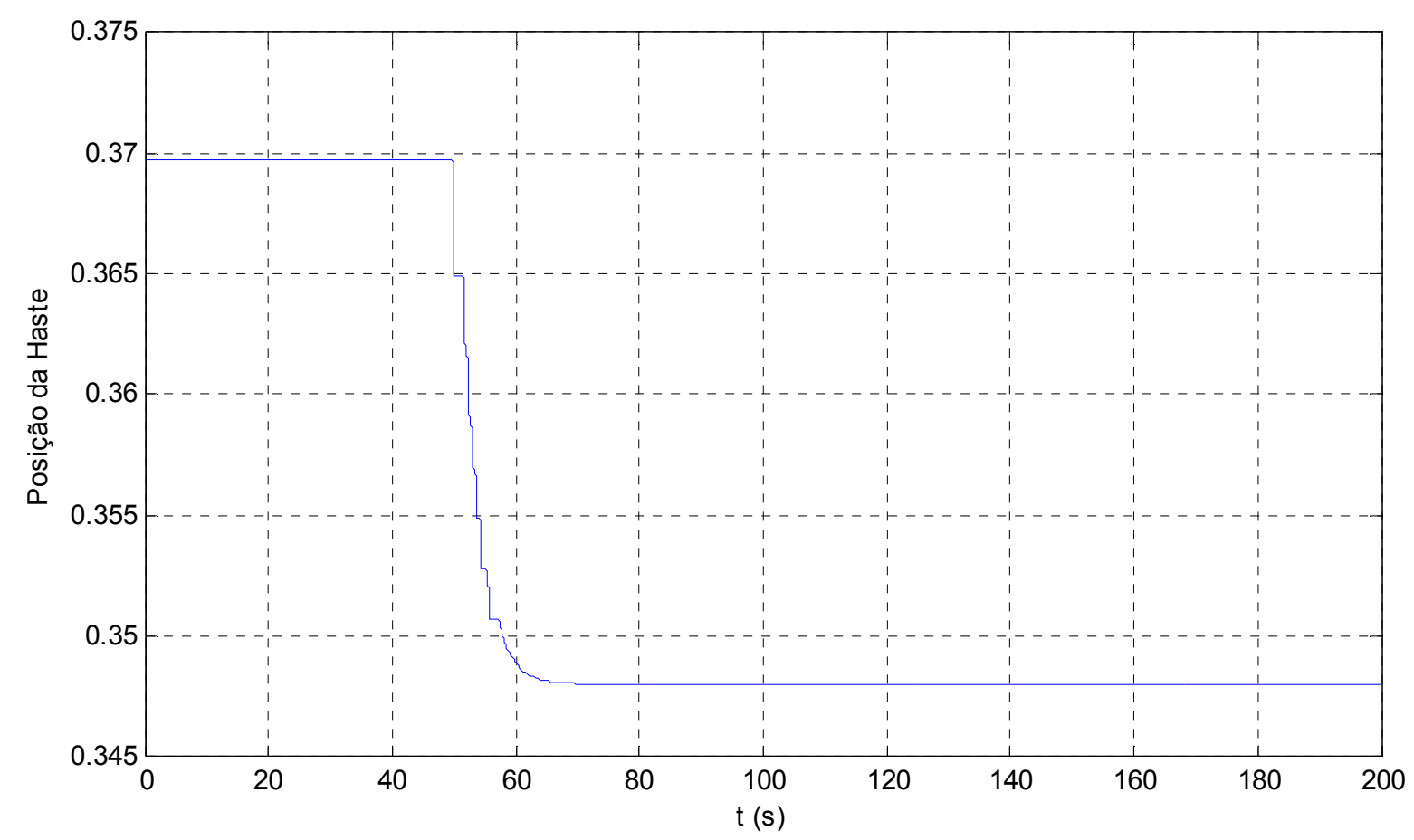

Figura 67: Compensador $1 O L, 100 \%$ simulado, posição da haste da válvula

A análise da Figura 67 indica que a haste da válvula ficou estabilizada em um ponto de equilíbrio após o degrau. Também fica claro que o compensador $I O L$ faz com que a posição de equilíbrio seja alcançada mais rápido do que na ausência do compensador. A seguir, na Figura 68, é mostrado o comportamento da haste da válvula, no ambiente $100 \%$ simulado, quando o compensador Knocker é utilizado.

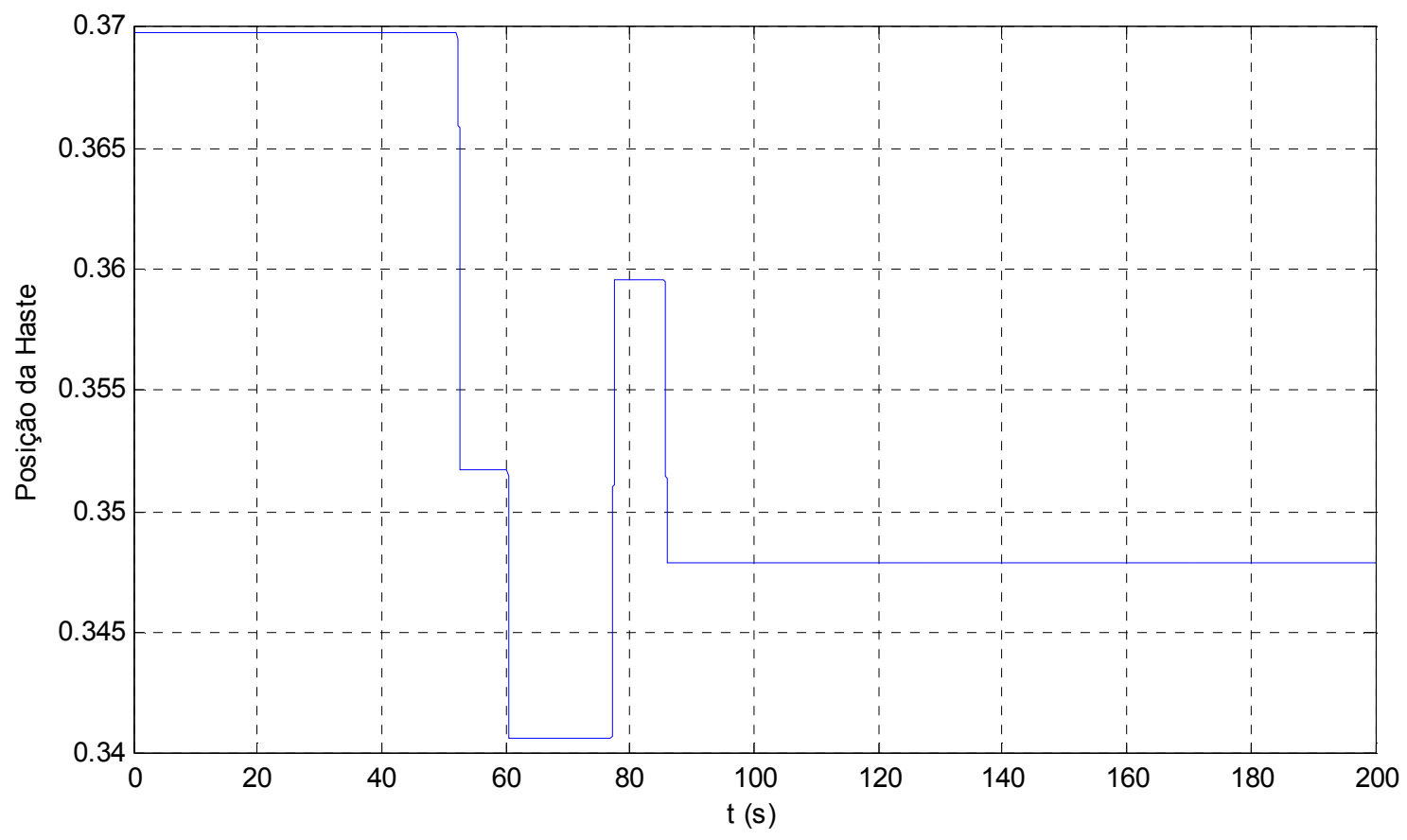

Figura 68: Compensador Knocker, 100\% simulado, posição da haste da válvula 
A Figura 68 indica que a haste da válvula ficou oscilando em torno de um ponto de equilíbrio após o degrau. A seguir, na Figura 69, é mostrado o comportamento da haste da válvula, no ambiente $100 \%$ simulado, quando o compensador 2 move é utilizado.

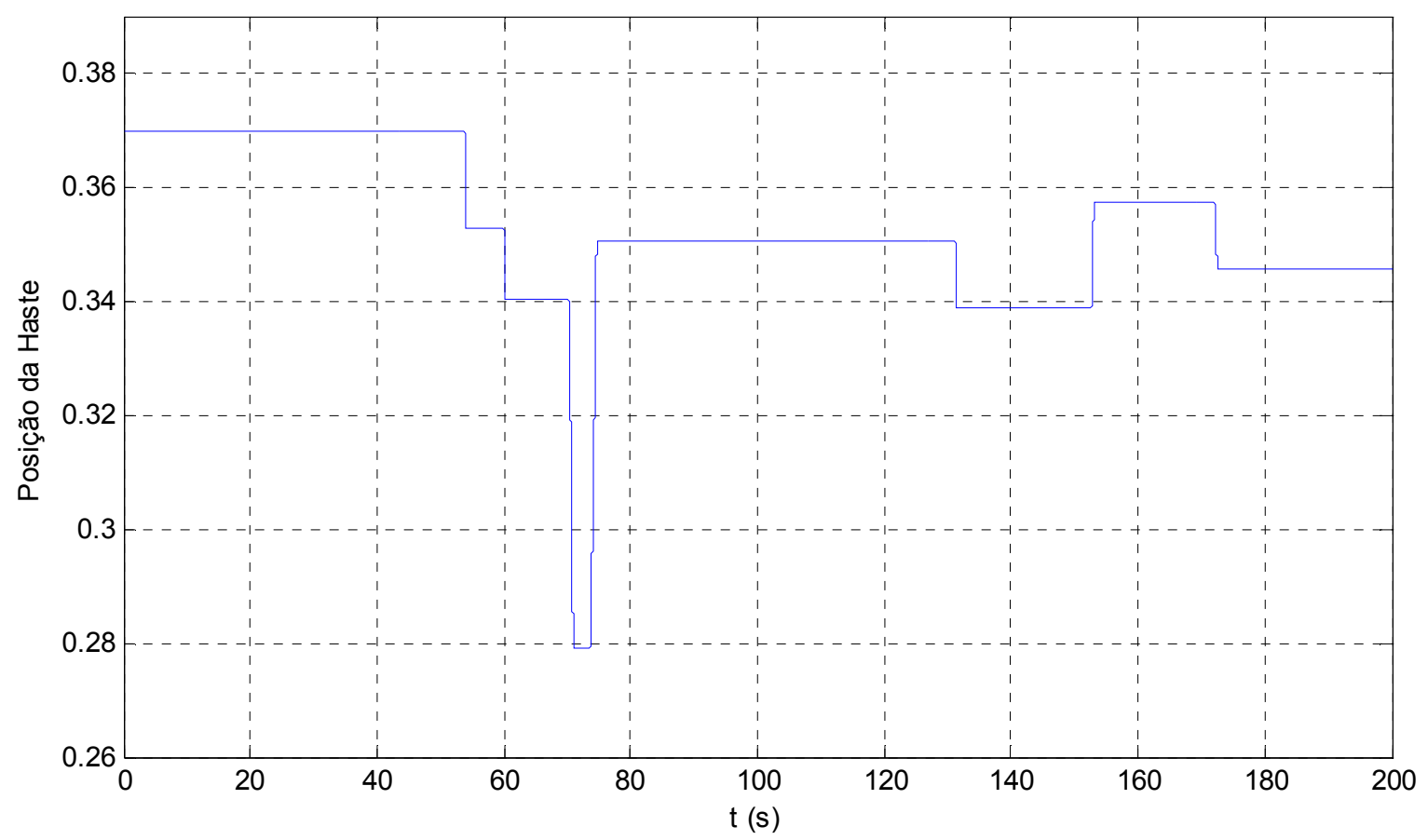

Figura 69: Compensador 2 move, $100 \%$ simulado, posição da haste da válvula

A Figura 69 também indica que a haste da válvula ficou oscilando em torno de um ponto de equilíbrio após o degrau. Desta forma, conclui-se que, no ambiente $100 \%$ simulado, apenas o uso do compensador IOL não gerou oscilações na haste da válvula.

A seguir, na Figura 70, é mostrado o comportamento da haste da válvula, no ambiente HIL, quando nenhum compensador é utilizado. 


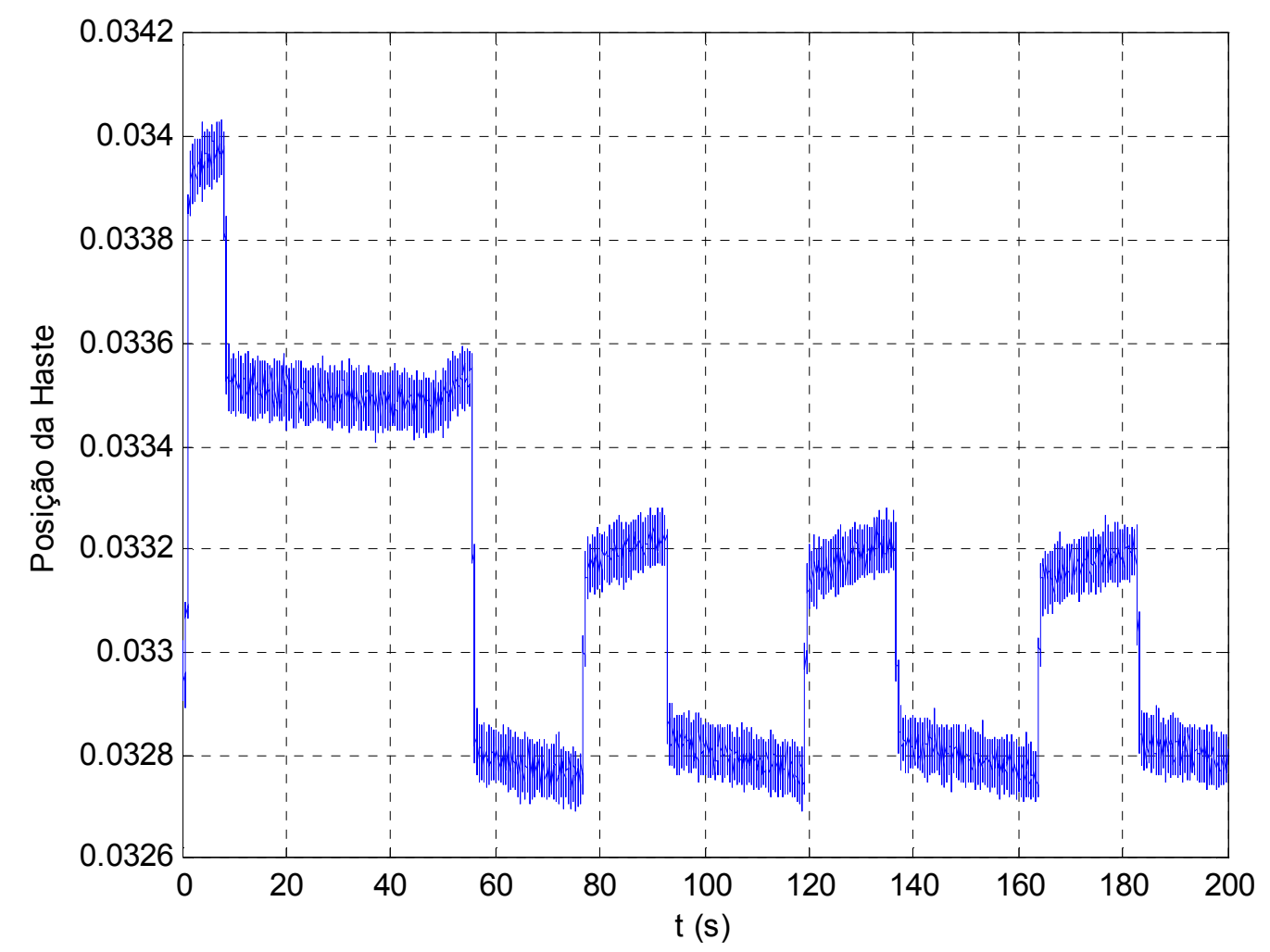

Figura 70: Sem compensador, HIL, posição da haste da válvula

A Figura 70 indica que, na ausência de compensador, a haste de válvula fica oscilando em torno do ponto de equilíbrio. A presença de ciclo limite é um indício, segundo a literatura, da presença de não linearidades na válvula. Uma possível nãolinearidade, neste caso, é o atrito estático. A seguir, na Figura 71, é mostrado o comportamento da haste da válvula, no ambiente HIL, quando o compensador IOL é utilizado. 


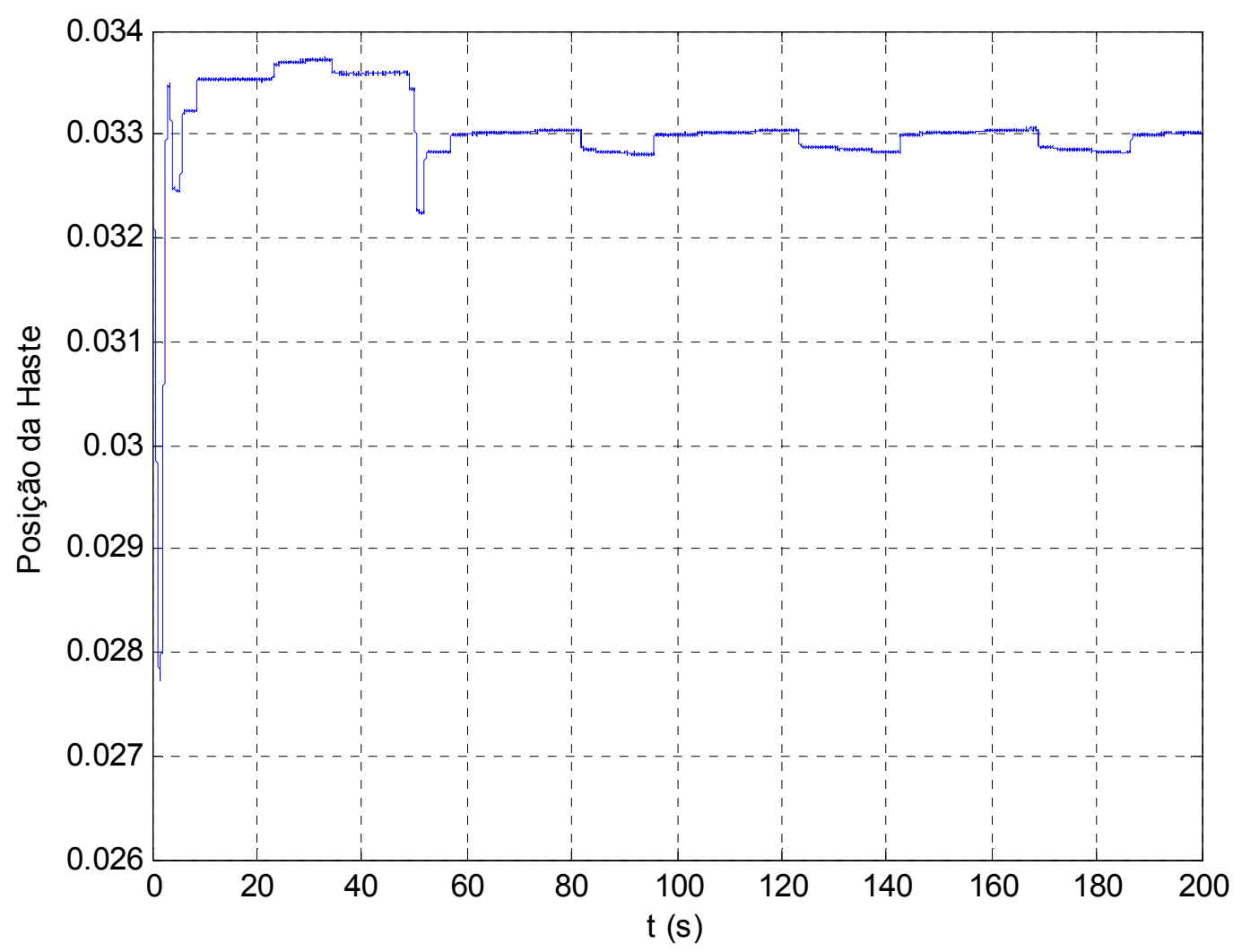

Figura 71: Compensador IOL, HIL, posição da haste da válvula

A Figura 71 indica que utilização do compensador $I O L$ neste ensaio basicamente manteve as oscilações causadas pelo atrito estático, ou seja, aparentemente, a quantidade de movimento da haste da válvula não aumentou com a utilização do compensador IOL. A seguir, na Figura 72, é mostrado o comportamento da haste da válvula, no ambiente HIL, quando o compensador Knocker é utilizado. 


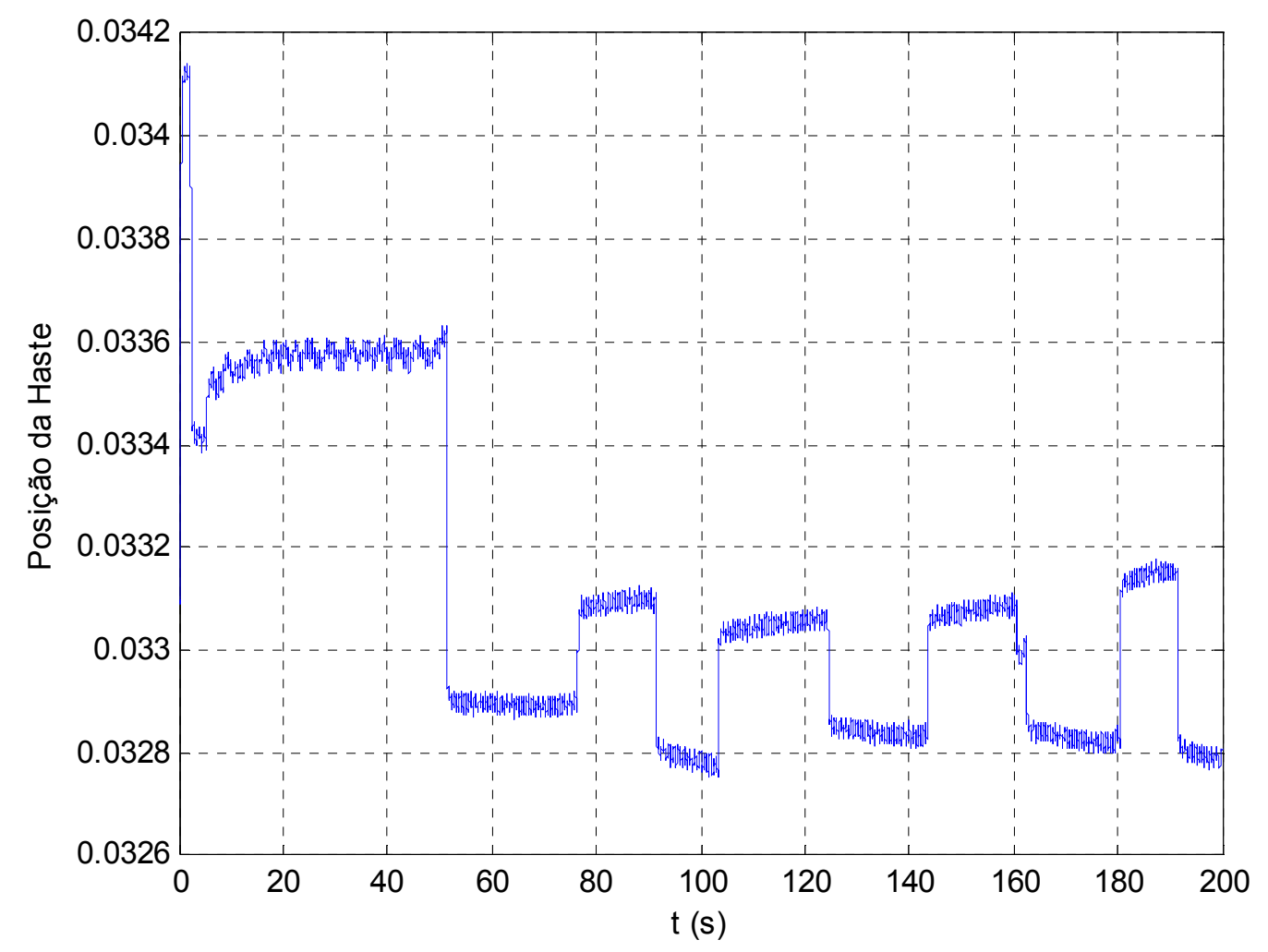

Figura 72: Compensador Knocker, HIL, posição da haste da válvula

A análise da Figura 72 indica que as oscilações presentes anteriormente na válvula sem compensador Knocker permanecem com a sua, ou seja, ele não aumenta a quantidade de movimento da haste, pelo menos numa amplitude que seja perceptível nos gráficos. Finalmente, na Figura 73 , é mostrado 0 comportamento da haste da válvula, no ambiente HIL, quando o compensador 2 move é utilizado. 


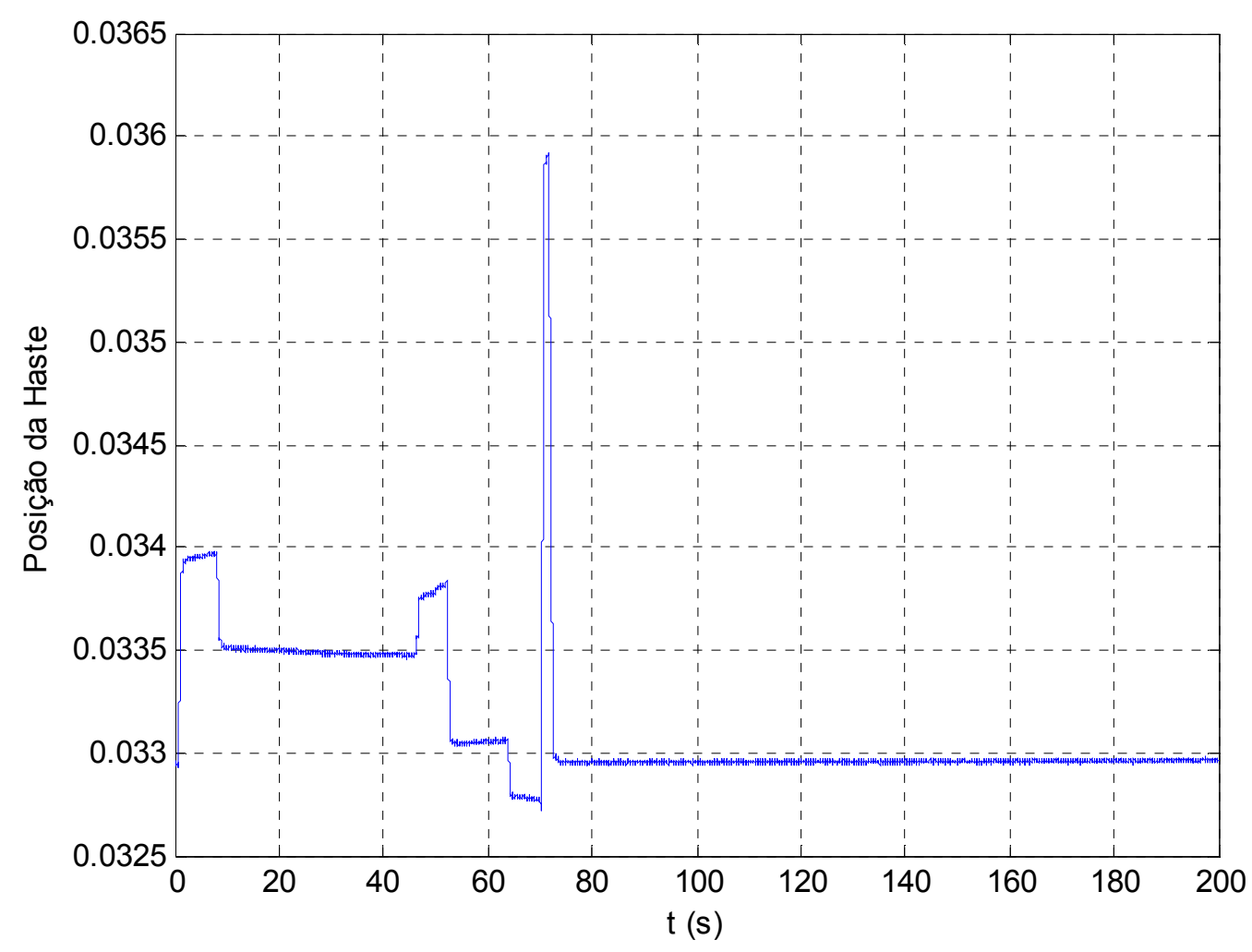

Figura 73: Compensador 2move, HIL, posição da haste da válvula

O resultado obtido com o compensador 2 move confirmou o que foi proposto na literatura: o compensador mantém a haste em uma determinada posição, sem ficar oscilando em torno de um ponto de equilíbrio, o que é muito bom do ponto de vista do desgaste da válvula.

Os diversos ensaios realizados anteriormente em diversas situações mostraram que, mesmo sendo o 2 move o compensador que supostamente não gera oscilações na haste, seus resultados não são tão bons em todos os ensaios, ao contrário principalmente do $I O L$, que apresentou um bom comportamento com relação ao valor de referência na maioria dos ensaios e que aparentemente não aumenta a quantidade de oscilações da válvula. 


\section{CAPÍTULO 5. CONCLUSÕES E SUGESTÕES PARA}

\section{TRABALHOS FUTUROS}

\subsection{Conclusões}

Neste trabalho, três compensadores de atrito propostos na literatura foram ensaiados de diversas maneiras para avaliar qual o desempenho deles sob diferentes condições de operação. Para sintetizar as principais características de cada um dos compensadores, a partir dos resultados obtidos nos ensaios, segue a Tabela 9.

Tabela 9: Características dos compensadores - atrito high, ambiente HIL

\begin{tabular}{|l|c|c|c|}
\hline \multicolumn{1}{|c|}{ Característica } & IOL & Knocker & 2move \\
\hline Interno/Externo & interno & externo & externo \\
\hline $\begin{array}{l}\text { Depende de estimação/ } \\
\text { detecção de parâmetros da } \\
\text { válvula }\end{array}$ & sim & não & não \\
\hline Resposta ao degrau & boa & boa & boa \\
\hline Resposta à perturbação & boa & ruim & ruim \\
\hline Resposta à má-sintonia & boa & ruim & boa \\
\hline $\begin{array}{l}\text { Oscilação da haste da } \\
\text { válvula }\end{array}$ & boa & boa & boa \\
\hline $\begin{array}{l}\text { Pode ficar acionado } \\
\text { constantemente }\end{array}$ & sim & sim & não \\
\hline Fácil de implementar & não & sim & não \\
\hline Fácil de sintonizar & não & não & não \\
\hline
\end{tabular}

A opção em referenciar as características dos compensadores ao nível de atrito high, no ambiente HIL, tem o seguinte sentido: foi mostrado neste trabalho que, no nível de atrito low, o compensador muitas vezes acaba piorando o desempenho da 
malha. Além disso, o ambiente HIL é aquele mais próximo de uma planta real e por isso é interessante tomar como base os resultados encontrados nele.

Os três compensadores avaliados no trabalho apresentaram melhor desempenho quando ensaiados no ambiente sem perturbação e sem má-sintonia do controlador. Quando ensaiados sob estas duas condições adversas, o desempenho dos compensadores foi boa, principalmente para o compensador IOL. Vale lembrar que, nos casos em que os compensadores apresentaram melhora (ainda que pequena), esta melhora pode ser transformada diretamente em um retorno financeiro para a empresa, dependendo, por exemplo, do tipo de produto final que esta empresa produz ou do tipo de poluentes que a empresa passa a emitir em menor quantidade quando uma melhora, por menor que seja, é alcançada.

Outro aspecto que ficou claro, principalmente no ensaio a degrau, é que nem sempre é vantajoso manter os compensadores ligados. Desta forma, o ideal é acionar o compensador quando houver suspeita de problema na válvula. Por este motivo, a detecção do nível de atrito na válvula é muito importante.

Ao contrário do que foi proposto na literatura, com relação às oscilações geradas na haste da válvula pelos compensadores IOL e Knocker, pode-se notar que ambos os compensadores não causar impacto aparente na quantidade de movimento da haste. O compensador 2 move também não gera estas oscilações, porém, é muito difícil de ajustar, além de não poder permanecer ligado constantemente, devido ao seu princípio de funcionamento.

Cada um dos três compensadores tem seus prós e contras, mas, de uma maneira geral, pelo que foi observado durante os ensaios, pode-se dizer que o compensador IOL apresentou os melhores resultados nos diversos ensaios realizados. Vale destacar que o compensador $I O L$ implementado neste trabalho foi desenvolvido a partir de (SILVA, 2003), já que o desenvolvimento do compensador proposto por (KAYIHAN; DOYLE III, 2000) não estava claro. 


\subsection{Sugestões para trabalhos futuros}

Em termos de sugestões para trabalhos futuros, é importante que este trabalho seja integrado com um trabalho de detecção da presença de atrito na válvula de controle, principalmente o atrito estático, pois conforme visto nos ensaios com nível de atrito high, o atrito estático atrapalha demasiadamente o funcionamento da válvula. Caso não seja detectado atrito muito elevado, pôde-se constatar que o desempenho da malha não apresenta grande melhora quando os compensadores são utilizados, podendo até causar piora em alguns casos.

Outra sugestão de trabalho futuro é explorar de forma mais detalhada o compensador IOL proposto por (KAYIHAN; DOYLE III, 2000), pois a formulação matemática proposta é um pouco diferente da obtida a partir de (SILVA, 2003). Talvez a utilização do compensador proposto por (KAYIHAN; DOYLE III, 2000) apresente resultados diferentes do que foi obtido neste trabalho. Ainda pensando-se em $I O L$, seria importante procurar algum fabricante de posicionador inteligente que tivesse interesse de implementar este algoritmo em seu produto, para que testes como um equipamento real pudessem ser feitos no campo.

Dando continuidade às sugestões de trabalhos futuros, uma possível melhoria seria a tentativa de automatizar a sintonia dos três compensadores. Na literatura, o único compensador que possui um roteiro de sintonia é o Knocker. Ainda assim, não é nada muito científico. As sintonias obtidas neste trabalho para os compensadores foram obtidas basicamente por tentativa e erro, o que não é muito interessante.

Outra sugestão para trabalhos futuros é testar o comportamento dos compensadores em outras plantas, com dinâmicas mais lentas do que a planta simulada de vazão. Conforme dito anteriormente, a planta de vazão foi escolhida neste trabalho por possuir uma pequena constante de tempo dominante. Entretanto, seria interessante avaliar se os resultados obtidos nesta planta são os mesmos em outras plantas com dinâmicas mais lentas.

Uma sugestão final para trabalhos futuros é mesclar o uso de compensadores externos (Knocker e 2move) com o compensador interno (IOL), para verificar se, através desta técnica, melhores resultados podem ser obtidos. 


\section{REFERÊNCIAS}

CANUDAS, C.; LISCHINSKY, P. Adaptative friction compensation with partially know dynamic friction model. International Journal of Adaptative Control and Signal Processing, n.11, p. 65-80, 1997.

CHOUDHURY, M. A. A. S.; THORNHILL, N. F.; SHAH, S. L. Modelling valve stiction. Control Engineering Practice, n. 13, p. 641-658, 2005.

DE CARLI, A.; CONG, S. Strategies for dynamic friction compensation. $3^{\text {rd }}$ European Control Conference, v. 3, p. 2730-2735, 1995.

FEEMSTER, M.; VEDAGARBHA, D. M.; DAWSON, D. H. Adaptive control techniques for friction compensation. Mechatronics, n. 9, p.125-145, 1999.

GARCIA, C. Modelagem de atrito em válvulas de controle. Salvador: XVI Congresso Brasileiro de Automática, 2006.

GARCIA, C. Comparison of friction models applied to a control valve. Control Engineering Practice, artigo aguardando aprovação.

HÄGGLUND, T. A friction compensator for pneumatic control valves. Journal of Process Control, n.12, p.897-904, 2002.

ISIDORI, A. Nonlinear control systems - an introduction. New York: Springer, 1989.

KAYIHAN, A.; DOYLE III, J.D. Friction compensation for a process control valve. Control Engineering Practice, n. 8, p. 799-812, 2000.

KRAVARIS, C.; CHUNG, C. B. Nonlinear state feedback synthesisby global input/output linearization. A.I.Ch.E. Journal, n. 33(4), p.592-603, 1987.

ROMANO, R. A.; GARCIA, C. Karnopp friction model identification for a real control valve. Artigo aceito para publicação no 17th IFAC World Congress, Seoul, Korea, 2008. 
SILVA, G. V. M. Controlo Não Linear. Escola Superior Tecnologia Setúbal. Apostila disponível online, 2003.

SRINIVASAN, R.; RENGASWAMY, R. Stiction Compensation in Process Control Loops: A Framework for Integrating Stiction Measure and Compensation. Ind. Eng. Chem. Res.,n. 44, p. 9164-9174, 2005.

SRINIVASAN, R.; RENGASWAMY, R. Approaches for efficient stiction compensation in process control valves. Computers \& Chemical Engineering, artigo já aprovado, mas ainda não publicado, 2007 (disponível online).

UEHARA, D.; GARCIA, C. ROMANO, R. A.; Comparação e equivalência dos modelos de atrito de Kano e Karnopp aplicados a válvulas de controle. Artigo aguardando aprovação. 